\title{
Portrait of blood-derived extracellular vesicles in patients with Parkinson's disease
}

Jérôme Lamontagne-Proulx, MSc ${ }^{1}$, Isabelle St-Amour, $\mathrm{PhD}^{1}$, Richard Labib, $\mathrm{PhD}^{2}$, Jérémie Pilon, $\mathrm{BSc}^{2}$, Hélèna L. Denis, $\mathrm{MSc}^{1}$, Nathalie Cloutier, $\mathrm{PhD}^{1}$, Florence Roux-Dalvai, $\mathrm{MSc}^{1}$, Antony T. Vincent, $\mathrm{MSc}^{3}$, Sarah L. Mason, $\mathrm{PhD}^{4}$, Anne-Claire Duchez, $\mathrm{PhD}^{1}$, Arnaud Droit, $\mathrm{PhD}^{1,5}$, Steve Lacroix, $\mathrm{PhD}^{1,5}$, Nicolas Dupré, $M D^{1,6}$, Mélanie Langlois, $M D^{1,6}$, Sylvain Chouinard, MD $^{7}$, Michel Panisset, MD $^{7}$, Roger A. Barker, MBBS, PhD ${ }^{4}$, Eric Boilard, PhD ${ }^{1,8 *}$, Francesca Cicchetti, PhD ${ }^{1,9 *}$

${ }^{1}$ Centre de recherche du CHU de Québec, Québec, QC, Canada; ${ }^{2}$ Département de mathématiques et génie industriel, École Polytechnique de Montréal, Montréal, QC, Canada; ${ }^{3}$ Institut de Biologie Intégrative et des Systèmes, Université Laval, Québec, QC, Canada; ${ }^{4}$ Department of Clinical Neurosciences, John van Geest Centre for Brain Repair, University of Cambridge, Cambridge, United Kingdom; ${ }^{5}$ Département de médecine moléculaire, Université Laval, Québec, QC, Canada; ${ }^{6}$ Département de médecine, Université Laval, Québec, QC, Canada; Département de neurosciences, Hôpital de l'Enfant-Jésus, Québec, QC, Canada; ${ }^{7}$ Centre Hospitalier de l'Université de Montréal and Centre de recherche du Centre Hospitalier de l'Université de Montréal, Hôpital Notre-Dame, Département de médicine, Université de Montréal, Montréal, QC, Canada; ${ }^{8}$ Département de microbiologie-infectiologie et d'immunologie, Université Laval, Québec, QC, Canada; 'Département de psychiatrie \& neurosciences, Université Laval, Québec, QC, Canada

\section{Correspondence to either:}

Francesca Cicchetti, Ph.D.

Centre de Recherche du CHU de Québec

Axe Neurosciences, T2-07

2705, Boulevard Laurier

Québec, QC, G1V 4G2, Canada

Tel \#: (418) 656-4141 ext. 48853

Fax \#: (418) 654-2753

E-mail: Francesca.Cicchetti@crchul.ulaval.ca
Eric Boilard, Ph.D.

Centre de Recherche du CHU de Québec

Infectious and immune diseases, T1-49

2705, Boulevard Laurier

Québec, QC, G1V 4G2, Canada

Tel \#: (418) 656-4141 ext. 46175

Fax \#: (418) 654-2765

E-mail: Eric.Boilard@crchudequebec.ulaval.ca

Financial disclosure: F.C., E.B., S.L. and I.S.-A. have filed a patent on the use of EEV as a biomarker in PD. J.L.P., R.L., J.P., H.L.D., N.C., F.R.-D., A.T.V., S.L.M., A-C.D., A.D., S.L., N.D., M.L., S.C. and R.A.B. declare no conflicts of interest.

Funding sources: The study was funded by The Michael J. Fox foundation and the Parkinson Society Canada to F.C. as main PI who is also a recipient of a Researcher Chair from the Fonds de Recherche du Québec en santé (FRQS) providing salary support and operating funds. I.S.-A. was supported by a CIHRHuntington Society of Canada postdoctoral fellowship. R.B. and J.P. are supported by the Natural Science and Engineering Research Council of Canada (NSERC). R.A.B. and S.L.M. are supported by a National Institute for Health Research (NIHR) award of a Biomedical Research Center to the University of Cambridge and Addenbrooke's Hospital. RAB is an NIHR Senior Investigator. HLD hold a Desjardins scholarship from the Fondation du CHU de Québec. A.-C.D. is supported by the Fonds de Recherche des maladies Rhumatismales de I'Université Laval and the Canadian Arthritis Network. E.B. is supported by the Canadian Institutes of Health Research. N.D. MD-MSc are also funded by CIHR and by Canadian Consortium on Neurodegeneration in Aging (CCNA). 


\section{ABSTRACT}

The production of extracellular vesicles (EV) is a ubiquitous feature of eukaryotic cells but pathological events can affect their formation and constituents. We sought to characterize the nature, profile and protein signature of EV in the plasma of Parkinson's disease (PD) patients and how they correlate to clinical measures of the disease. EVs were initially collected from cohorts of PD ( $n=60$; Controls, $n=37$ ) and Huntington's disease (HD) patients (Pre-manifest, $n=11$; manifest, $n=52$; Controls, $n=55$ ) - for comparative purposes in patients with another chronic neurodegenerative condition - and exhaustively analyzed using flow cytometry, electron microscopy and proteomics. We then collected 42 samples from an additional independent cohort of PD patients to confirm our initial results. Through a series of iterative steps, we optimized an approach for defining the EV signature in PD. We found that the number of EV derived specifically from erythrocytes segregated with UPDRS scores corresponding to different disease stages. Proteomic analysis further revealed that there is a specific signature of proteins that could reliably differentiate control subjects from mild and moderate PD patients. Taken together, we have developed an EV blood-based assay that has the potential to be used as a biomarker for PD.

Key words: Blood cells; Erythrocytes; Extracellular vesicles; Alpha-synuclein

\section{HIGHLIGHTS:}

- Optimization of methodology to identify extracellular vesicles (EV) using FACS

- Demonstration of minimal test-retest variability intra-patient using FACS

- Development of a new approach to uncover the entire proteome of EV

- Segregation of Parkinson's disease patients with EV from erythrocytes (EEV) count

- EEV protein signature differentiates control from Parkinson's disease patients

\section{ABREVATIONS}

EV: Extracellular vesicles,

EEV: Extracellular vesicles derived from erythrocytes

LEDD: levodopa equivalent daily dose

UPDRS: Unified Parkinson Disease Rating Scale 


\section{INTRODUCTION}

The last few years of research has seen our understanding of Parkinson's disease (PD) change dramatically. One of the major breakthroughs has been the realization that PD is a heterogeneous disorder, which brings with it challenges for the development and identification of useful biomarkers for diagnosis and disease progression, as well as the ability to track the successful translation of novel treatments to the clinic. This new understanding of the different clinical profiles seen in populations of PD patients has begun to translate into a redefinition of PD, as is evidenced by new diagnostic criteria released by the International PD and Movement Disorder Society (MDS) (Berg et al., 2014). This task force has also pointed out the importance of identifying reliable biomarkers for clinico-pathological diagnoses. Indeed, the development of a biomarker that could serve as a diagnostic tool, and/or a dependable predictor of disease course and evolution (and thus stratify populations of patients) as well as to assess treatment efficacy is of critical importance and urgently needed.

The search for such biomarkers has recently included the investigation of extracellular vesicles (EV); small entities that carry critical intracellular molecules and which mediate cell-to-cell communication in both physiological and disease conditions (Quek and Hill, 2017). EV are composed of membrane proteins and lipids, as well as cytoplasmic components of the cell from which they originate, such as mRNA and miRNA, organelles or infectious particles (e.g. prions, virus) (Porro et al., 2015). Their protein cargo, cell signature and availability in bodily fluids make EV very attractive candidate biomarkers and have already been studied in the blood, cerebrospinal fluid (CSF), urine and brains of patients with PD (see Figure S1) (Abd-Elhadi et al., 2015; Alvarez-Erviti et al., 2011; Araki et al., 2016; Barbour et al., 2008; Bartels et al., 2011; Danzer et al., 2012; El-Agnaf et al., 2006; Emmanouilidou et al., 2010; Fauvet et al., 2012; Fraser et al., 2013; Grey et al., 2015; Helferich et al., 2015; Ho et al., 2014; Kong et al., 2014; Kunadt et al., 2015; Melachroinou et al., 2013; Nakai et al., 2007; Nikam et al., 2009; Pretorius et al., 2014; Renella et al., 2014; Shi et al., 2014; Stuendl et al., 2016; Sudha et al., 2003; Tomlinson et al., 2015; Tsunemi et al., 2014; Wang et al., 2015). For example, EVs derived from the CSF contain a-synuclein (a-syn), its associated pathogenic species as well as the LRRK2 protein (Fraser et al., 2013). However, routinely collecting CSF presents a challenge given the invasive nature needed to collect it while plasma is a very accessible fluid that further allows real time monitoring, and which has consequently been more extensively studied from a biomarker perspective.

One of the reasons that EVs have become attractive for biomarker development relates to advances in 
their isolation involving ultracentrifugation, centrifugation by density gradient, size exclusion using membranes and columns, polymeric precipitation, capture by immune-affinity and microfluidic approaches (Shevchenko et al., 1996). However, the bulk of the already published work on EV in biofluids relies on using a series of differential centrifugations with or without size filtration, for example gradient techniques that concentrate and purify EV (Konoshenko et al., 2018; Willis et al., 2017). Techniques utilizing solely the ultracentrifugation to perform EV counts are biased because they favor aggregations of vesicles while co-isolating a number of contaminants, such as proteins (Linares et al., 2015). Techniques to isolate EV have therefore recently been developed with the goal of maintaining the integrity and purity of the isolated entities (Konoshenko et al., 2018). We sought to use these advances to develop new approaches that would allow for the optimal analysis of EV in blood, and therefore shed light on a more accurate picture of these elements in PD with the hope that this could be used for biomarker development. This work initially involved optimizing the FACS analysis by stringent controls to unequivocally identify EVs and their cell origin, performing test-retest experiments to validate consistency of results over time in the same patient and finally, using hemoglobin removal to uncover the entire proteome of EV analyzed. This having been done, we then sought to characterize the nature and profile of EV in the plasma of patients, and how they correlate to clinical measures of disease state as well as defining the protein content in the subpopulations of EV. Finally we sought to validate this whole approach using a second independent cohort of patients with PD.

\section{MATERIALS AND METHODS}

\section{Ethics statement and participant recruitment}

Institutional review boards approved this study (CHU de Québec, \#A13-2-1096; CHUM, \#14.228; Cambridge Central Regional Ethics Committee, REC \#03/303 \& \#08/H0306/26; and Cambridge University Hospitals Foundation Trust Research and Development department, R\&D \#A085170 \& \#A091246) in accordance with the Declaration of Helsinki, and written informed consents were obtained from all participants.

Blood samples were initially collected from 2 cohorts of patients with a total of 60 PD [one in Cambridge UK; one in Quebec Canada] as well as 37 age- and sex-matched healthy Controls (Table 1). For comparison, blood samples were also collected from a cohort of 52 Huntington's disease (HD) individuals [collected in Montreal, Canada] along with 55 age- and sex-matched healthy Controls (Table S1). Subsequently, an additional and independent cohort of 42 PD patients was collected to corroborate the 
results related to EEV counts obtained from these first cohorts of patients (Table S2). In the case of PD patients, the UK Parkinson's Disease Society Brain diagnostic criteria were used, which gives a diagnostic accuracy of $98.6 \%$ when applied by movement disorder specialists (Hughes et al., 2002; Massano and Bhatia, 2012). The patients, at the time of bleeding, also underwent clinical evaluation which included the Unified Parkinson Disease Rating Scale (UPDRS), Hoehn and Yahr (H\&Y) scale, the Mini Mental State Examination (MMSE), the Addenbrooke's Cognitive Examination (ACE) and the Beck Depression Inventory (BDI). UPDRS was obtained from the UK and Montreal cohorts but not the Quebec cohort for logistical reasons. In the case of the HD patients, their Unified Huntington Disease Rating Scale (UHDRS), Total Functional capacity (TFC) and calculated values for burden of disease (BDS) were all collected at the time of venepuncture and their diagnosis was confirmed by genetic testing. Participants were further asked to fill out a questionnaire related to health issues and medication and a full blood count was performed in all patients on the day of blood sampling. Comorbidities were determined from medical information reported by the participant or caregiver. Cancer refers to a participant having suffered from any cancer in the past. Medications were converted into levodopa equivalent daily dose (LEDD) using common calculator tools. It should be noted that blood sampling was conducted by the exact same team of investigators, following identical procedures in both UK and Canada.

For the test-retest experiments, collection of blood samples was performed on 25 healthy individuals with 2 samples per subject, taken after a 2-hour interval. This cohort included 11 men and 14 women with a mean age of $29 \pm 5$ years with no clinical reports of co-morbidities or medication intake. Note that fasting was not required prior to blood samplings in any of the cohorts that were recruited for this study. Calculation of \% CVs of concentration measurements of EEVs was performed using GraphPad PRISM ${ }^{\circledast}$ Version 6.0 (GraphPad Software, LaJolla, CA).

\section{Preparation of platelet-free plasma and EV labeling}

Citrated blood was centrifuged twice for 15 minutes at $2500 \mathrm{~g}$ at room temperature. Platelet-free plasma (PFP) was harvested and stored at $-80^{\circ} \mathrm{C}$ within 2 hours of sampling following previously published guidelines (Lacroix et al., 2012). For specific details on EV labeling, please refer to the supplementary material.

In all cases, the control samples came from healthy participants and the blood was collected at exactly the same time of day as for the PD and HD patients in the UK and Canadian clinics. Every blood sample 
was processed immediately to avoid release of non-physiological EV. For analyses relating to EV in plasma, all blood samples were centrifuged twice at $2500 \mathrm{~g}$ to enable PFP recovery. The plasma was fractionated into 3 aliquots per individual and frozen immediately following processing (maximum of 2 hours following blood collection). Blood samples from Controls and PD were collected in parallel and laboratory analyses were blinded to participant status.

\section{Flow cytometry quantification}

For EV quantification, we used a FACS Canto II Special Order Research Product equipped with a forward scatter (FSC) coupled to a photomultiplier tube (FSC-PMT) and a small particle option. Flow cytometer performance tracking was carried out daily using the BD cytometer setup and tracking beads (BD Biosciences, San Jose, CA, USA). The size of the EV was determined using fluorescent silica beads of 100, 500 and 1000nm (Figure S2). The settings for the EV detection were determined as previously described using a threshold of 200 for SSC (also see Figure S2) (Rousseau et al., 2015). For specific details on plasma-related EV quantification, please refer to the supplementary material.

\section{Production and purification of EEV}

Blood was collected in heparin tubes and centrifuged for 10 minutes at $282 \mathrm{~g}$ at room temperature. Blood cells were washed first in PBS-2\%FBS, then with $0.9 \%$ sodium chloride solution and centrifuged for 10 minutes at 750g. To avoid leukocyte and/or platelet contamination, the buffy coat and upper fraction of erythrocytes were removed. To preserve erythrocytes, two volumes of glycerolyte 57 solution (57\% glycerol, $142 \mathrm{mM}$ sodium lactate, $1 \mathrm{mM} \mathrm{KCl}, 25 \mathrm{mM}$ sodium phosphate $\mathrm{pH} 6.8$ ) were added to the pellet and stored at $-80^{\circ} \mathrm{C}$. For the in vitro generation of EEV, red blood cells were thawed and EV production was induced as previously described (Minetti et al., 2004). For specific details on EEV purification, please refer to supplementary material.

\section{C-reactive protein, free hemoglobin and $\alpha$-synuclein quantification}

The concentrations of C-reactive protein (CRP) and free hemoglobin were determined in the PFP of all donors using the RayBio Human CRP ELISA Kit (RayBiotech, Norcross, GA, USA) and the Hemoglobin Human ELISA kit (Abcam, Toronto, ON, Canada). To quantify $\alpha$-syn within erythrocytes and EEV, we used the human $\alpha$-Syn ELISA kit (ThermoFisher Scientific, Waltham, MA, USA). Absorbance values were measured at 450nm using a multi-detection microplate reader (Synergy HT; BioTek; Winooski, VT, USA). All ELISA tests were performed according to the manufacturer's instructions. 


\section{Scanning electron microscopy}

For the visualization by scanning electron microscopy, EEV were prepared as previously described (Duchez et al., 2015). For specific details on EEV preparation, please refer to supplementary material.

\section{Transmission electron microscopy}

For transmission electron microscopy, EEV were prepared and observed as previously described (Duchez et al., 2015). For specific details on EEV preparation and labelling, please refer to supplementary material.

\section{Mass spectrometry analysis and label free protein quantification}

The initial proteomic analyses were performed on 3 pools of 3 blood samples of each group. Following this, we undertook a completely new set of analyses to develop a method allowing us to isolate hemoglobin and better investigate the EEV proteome. For this, EVs from an additional 4 individuals per group (Control, mild PD and moderate PD) were prepared as described above. For each individual, $25 \mu \mathrm{g}$ of the protein sample, according to Bradford protein assay, was migrated onto an electrophoresis gel 4$12 \%$ Bis-Tris to separate hemoglobin from higher proteins. Following gel staining using Sypro Ruby (Thermo Fischer Scientific), the 12kDa band corresponding to the hemoglobin size was cut out and the remaining part of the gel further fractioned into 7 slices, exposed to trypsin digestion and peptide extraction on a MassPrep liquid handling robot (Waters, Milford, USA) according to the manufacturer's specifications and the protocol of Shevchenko et al. with the modifications suggested by Havlis et al. (Havlis et al., 2003; Shevchenko et al., 1996). For specific details on protein analysis purification, please refer to supplementary material. Spectra of peptides were searched against a human protein database (Uniprot Complete Proteome, taxonomy Homo sapiens - 83512 sequences) using the Andromeda search engine included in MaxQuant software version 1.5.5.1. (Cox and Mann, 2008). MaxQuant was also used to validate proteins and peptides at a 1\% False Discovery Rate using a target/decoy database search as well as to undertake a Label Free Quantification of the identified proteins using the 'match between runs' option.

\section{Statistical analyses}

All statistical analyses were performed by a qualified statistician and details pertaining to these analyses for each experiment are provided in the supplementary material. 


\section{RESULTS}

\section{Optimizing EV detection and the demonstration of reproducibility}

While we performed EV analyses in plasma, we ensured that reproducibility of EV identification and labeling was robust. For this, we undertook a series of control experiments to properly set the EV gate and fluorescent silica beads of 100nm (Red), 500nm (Blue) and 1000nm (Yellow) were acquired on a flow cytometer Canto II modified with a FSC-PMT small particle option (Figure S2A-C). The acquisition was performed at low speed at an approximated rate of $10 \mu \mathrm{l} / \mathrm{ml}$. The established EV gate was used for all experiments. Serial dilutions of EEV (1, 2, 4 and 10) were also undertaken to confirm the linearity of the quantification. FSC-PMT/SSC gates of PFP stained with annexin $V$ fluorescent conjugate (a ligand of phosphatidylserine) and respective fluorochrome-conjugated antibodies directed against erythrocyte (CD235a+), endothelial (CD31+/CD41-), platelet (CD41+) and leukocyte (CD14+CD45+, monocytes; CD15+CD45+, granulocytes)-derived EVs were carefully established.

We further completed numerous controls to ensure specific EV labeling. We first determined that treatment with the ion chelator EDTA inhibited the binding of annexin $\mathrm{V}$ to phosphatidylserine. We observed minimal background using antibodies in the absence of PFP. Subsequently, EV sensitivity to $0.5 \%$ triton was assessed. Under these conditions, the membrane of the EVs is dissolved while protein aggregates are left intact (György et al., 2011). Results show that vast majority of EVs positive for their own fluorochrome-conjugated antibodies were eliminated by detergent (Figure S2D-F). Finally, we conducted a test-retest assay where two PFP samples per subject were collected approximately 2 hours apart in 25 healthy individuals. All samples were tested in duplicate and minimal inter-sample variability was observed (16\% $\pm 7 \%)$ (Figure S2G).

In addition to full blood count, and as a precautionary measure, hematocrit, mean corpuscular hemoglobin and mean corpuscular volumes were evaluated and showed similar values between groups (Figure S3A). C-reactive protein quantifications were also obtained for all participants and revealed no differences between groups (Figure S3B). We did, however, observe a significant increase in EEV concentration in the PFP of individuals with diabetes and those suffering, or having suffered, from cancer (data not shown) and thus these participants were excluded from our analyses. PFP samples with elevated free hemoglobin (>45 000ng/ml), potentially due to hemolysis during blood sampling, were also excluded from further EEV-related analyses (Figure S3C), which account for the small discrepancies 
between the total number of participants initially recruited and those reported in each analysis.

\section{Increase in erythrocyte-derived EV in PD patients is not a diagnostic tool}

Once all the controls established and verified, we collected and carefully analyzed blood samples from patients with PD ( $n=60)$ along with age/sex-matched healthy Controls ( $n=37)$ (Table 1). Full blood counts were performed on each sample but did not reveal any differences in the number of platelets, leukocytes, monocytes, granulocytes except for erythrocytes, where a small significant difference $(p=0.049)$ was seen between PD patients and Controls (Figure 1A). We then labeled each cell type as well as each EV population present in plasma to generate accurate counts of EV by FACS. A series of specific labelings highlighted a notable increase in the mean number of EEV in PD patients with respect to their age- and sex-matched healthy Controls ( $p=0.04$; Figure $1 \mathrm{~B}-\mathrm{C}$ ). None of the EV derived from the other blood cell populations showed differences between PD and Controls.

Based on this observation, we evaluated the diagnostic value of EV for PD by taking a closer look at the data distribution. However, this uncovered that only 5 patients were responsible for this significant difference (Figure 1C, red inset). Further investigation, using a diagnostic accuracy test, revealed that the relevant proportion of the area under the Receiver Operating Characteristic (ROC) curve was 0.508 (data not shown), implying that the number of EEV could not be used as a discriminant between PD patients and healthy Controls. This was also confirmed by performing a Bayesian analysis of the data demonstrating that the proposed predictor of the onset of PD would be correct in less than $1 \%$ of the cases (data not shown). We obtained a similar result when we separated the patients into mild and moderate states according to their UPDRS scores or by cohort (data not shown).

\section{EV counts and clinical features}

Despite the absence of a diagnostic difference in EEV counts, we explored whether there could be a relationship between the number of EEV and clinical measures such as H\&Y stage, BDI, MMSE and ACE, but we found no significant correlations (data shown for H\&Y, Figure 2A). However, preliminary analyses revealed a correlation of $\mathrm{R}^{2}=0.37$ with a $p$ value of 0.0056 when plotting EEV counts/erythrocytes according to the UPDRS clinical rating scales (Figure 2B). In depth statistical analyses further revealed intriguing, but striking correlations between the number of vesicles derived from the red blood cells of PD patients and their total UPDRS (Figure 2C). Statistical linear regression analysis was performed for each group and the $\mathrm{R}^{2}$ values obtained demonstrated that in both cases, at least $87 \%$ of the variation in the total number of EEV/erythrocytes was due to the variation of the UPDRS (Figure 2C). Moreover, the 
results were significant with respect to the $p$ values obtained for each fit as they fell below the $5 \%$ confidence level. This could not be accounted for by medication, as there was no correlation with the patients LEDD (Figure 2D-E). Importantly, these results were then corroborated in an independent cohort of 42 PD patients where the correlations yielded an $\mathrm{R}^{2}=0.05$ and a $p$ value of 0.15 when plotting EEV counts/erythrocytes against scores obtained with the UPDRS clinical rating scale (Figure S4A).

In contrast to PD, correlation analyses failed to reveal an association between the number of EEV and HD stage using the UHDRS score (Figure S5).

\section{Proteomic signature of EEV in PD}

Given that these correlations are based on a small number of patients (cohort 1; n=19 and cohort 2; $n=42$ ), we sought to corroborate these results by examining the specific protein signature of EEV from mild and moderate PD patients (with respect to their UPDRS scores) and age-matched Controls. Given the significant amounts of hemoglobin within erythrocytes that could mask the true nature of the protein signature in EEV, we performed a label free quantitative proteomic analysis by nanoLC/MSMS (Wither et al., 2016) using two distinct approaches: with and without hemoglobin (Figure 3A-B). By removing hemoglobin, we identified a total of 818 proteins in comparison with 356 when we did not undertake this methodological step (refer to Table S3 for complete list of proteins) - a modification which is clearly needed to give a much more accurate evaluation of the protein content of EEV. Additionally, a Gene Ontology enrichment analysis on the 'Cellular Component' ontology on the two sets of identified proteins in comparison with the whole human proteome, revealed that our samples are enriched with elements associated with 'vesicles' and 'hemoglobin complex' (Figure S6).

Out of the 818 proteins identified in the proteome of EEV, 8 had expressions that were significantly different in patients with various stages of PD (Figure 3C). Hierarchical clustering, coupled to a heatmap, allowed us to group individuals according to stages of disease (Control, mild PD and moderate PD) and provided compelling evidence that the 8 proteins identified could also be grouped into three categories. Proteins of group I were highly and predominantly expressed in Controls, proteins of group II were highly and predominantly expressed in mild PD patients and proteins belonging to group III were highly and predominantly expressed in moderate PD patients (Figure 3D). This data set was further confirmed by volcano plots (Figure 3E). 
Finally, we assessed whether $\alpha$-Syn - which is not only the main component of Lewy bodies but is highly expressed in most blood cells - was differentially expressed in normal vs. diseased conditions. For this, we opted to use scanning electron microscopy, but this did not reveal any morphological changes between resting and activated erythrocytes in either condition (Figure 4A). We further used transmission electron microscopy to quantify the number of EEV containing $\alpha$-Syn and phosphorylated (serine 129) forms of the protein, but again there were no significant differences between PD patients and age- and sex-matched healthy Controls (Figure 4B-C). Quantified $\alpha$-Syn levels in EEV from PD patients and Controls using commercial ELISA kits corroborated these results (Figure 4D).

\section{DISCUSSION}

The primary goal of our study was to provide an accurate description of EV in PD patients. In order to do this, we took into account all relevant technical parameters and refined a number of approaches that may have been contentious in previous publications. These technical improvements included: 1) better methods to clearly identify EV when using FACS; 2) specific labeling to determine, with precision, the cell origin of the EV; 3) the demonstration of minimal test-retest variability intra-patient; 4) the deletion of hemoglobin from the samples for proteomic analyses which, as suspected, revealed numerous proteins which currently remain unidentified and finally, 5) the development of a user-friendly test which has the potential to be easily performed by western blots in any laboratory contexts using just a few microliters of blood. Once we had established the protocols for EV characterization, the second objective of this study was to explore the potential biomarker value of EVs in PD. We found that EEV counts did map to disease stage, a finding that was corroborated by a unique protein signature in control subjects, mild and moderate PD patients. Our observations were then confirmed in a second independent cohort of PD patients, showing that our findings are robust and thus could have widespread applicability for helping stage PD patients in the future.

Blood counts were systemically performed in all patients, EV identification was replicated using the most accepted and standardized methods of repetition, stringent controls (microbeads, antibodies negative control, EDTA and Triton) (Rousseau et al., 2015) and complex combinations of antibodies which allowed for the specific labeling of vesicles. Standard techniques used to analyse EVs (e.g. ultracentrifugation followed by immunoblotting) requires several days and a considerable amount of cells to isolate EVs. However, quantification by flow cytometry takes only 1 day and requires a relatively small quantity of plasma (Konoshenko et al., 2018). We further demonstrated minimal test-retest variability. Sequential 
analyses of EV during the same day from the same individual/sample (intra-assay variation) has been reported to vary between 1-12\% (Vestad et al., 2017). For example, circadian rhythm has been reported to influence the activation of platelets and therefore influence EV derived from these cells (Scheer et al., 2011). In recent studies, counts of microvesicles derived from platelets across different flow cytometry platforms showed an inter-laboratory variability ranging between $28 \%$ and $37 \%$ (Vogel et al., 2016). In our hands, variability measures ranged between $1-30 \%$, with an average at $16 \% \pm 7 \%$, indicative of strong reproducibility.

While proteomic studies of EEV have been previously reported, their description was limited to 270 proteins (Bosman et al., 2012, 2008). We herein report on an improved method to perform this type of analyses in blood samples by removing hemoglobin; a large protein that can easily mask others within a protein signature. Indeed, the high dynamic range of protein concentrations in erythrocytes and their $\mathrm{EEV}$, due to the abundance of hemoglobin, decreases the capacity of the mass spectrometer to detect signals corresponding to low abundance proteins. Analyzing the hemoglobin, separately from proteins of other molecular weights, allowed us to go deeper into the EEV proteome, identifying $129 \%$ more proteins than in the initial analysis. It is important to reiterate that our proteomic analyses were performed using very stringent parameters, which included a minimum of 2 peptides per protein and $\mathrm{p}$ values of less than 0.05 with an absolute $z$ score of 1.96 , corresponding to values outside of the $95 \%$ confidence range. Finally, our volcano plots and heatmap analyses revealed high specificity of the identified proteins for each group with nodes ranging between 80 and $90 \%$. With this, reproducibility of our proteomics data is high despite the smaller sample size (analyses performed on 3 pools of 3 samples per group and subsequently on 4 individual samples per group). Reports of the role of these proteins in PD are rare. However of interest, QDPR has been reported to be essential to the bisosynthesis of norepinephrin and serotonin (Kaufman et al., 1975). ABHD14B have been shown to be dysregulated in mice following a levo-dopa treatment (Charbonnier-Beaupel et al., 2015) and that mARNs for CNRIP1 are diminished in the striatum of a primate model of PD (Zeng et al., 1999). Finally, genetic variants of USP24 are associated to PD risk factors (Li et al., 2006) while another study of blood genetic profile revealed that ATP5A1 is down regulated in idiopathic PD patients (Shamir et al., 2017).

Although staging of PD is often done using the H\&Y clinical scale, we sought to use the UPDRS given its more comprehensive coverage of disease features - an approach that has recently been validated (Martínez-Martín et al., 2015). Using these scores in our initial study, we found that mild PD patients - 
with a UPDRS score lower than 37 - have an increased number of EV (correlations = 0.886); and that the exact same pattern then repeats itself with patients who had UPDRS scores between 37 and 75 (correlations $=0.873$ ) with a marked resetting of the number of EVs between these two stages. In this study, which was undertaken using patients in research clinics, patients with advanced disease (>75 UPDRS) were not recruited in large numbers because they have difficulty making it to the clinics. In order to further validate this finding, we undertook a second study in another 42 patients with PD, which also included patients with more advanced disease. In this additional independent cohort, we demonstrated that we can replicate, very closely, what we found in the first cohort. Namely, mild patients fell between the UPDRS scores of 0 - 39, moderate patients between 29 - 57 and severe patients (which we did not analyze in the first cohort), between 57 - 74 and that there EV changes paralleled that which we saw in our initial study. The overlapping zone is likely due to a number of factors including the fact that 1) this new cohort was scored by a different clinician than our first cohort. Indeed, despite the fact that neurologists are trained to score patients in a similar fashion, the UPDRS remains a subjective measure that can vary between clinicians, even when they are been validated as a rater using the MDS training videos. 2) The FACS sorting apparatus we use to quantify EEV does generate a small percentage of variability (around 8\%) between runs (data not shown). 3) We opted to test patients ON medication. It is therefore possible that the patient tested in the morning, who has just recently taken his medicine, scores slightly differently on the UPDRS than the patient who has taken in meds in the morning but were assessed late afternoon.

The bi-modal distribution revealed by the correlation analysis is intriguing but it would be very difficult to establish a definite cut-off between groups. The UPDRS is based on a questionnaire of more than 70 different questions which are all based on a subjective assessment of the patient. A patient falling at the border of mild and moderate stage PD may be very difficult to categorize. We have already ruled out medication (in particular LEED) and a number of co-morbidities (depression, cancer, diabetes, hypertension, hypercholesterolemia, asthma, allergies) as contributing to this. It is important to note that, while the $\mathrm{R}^{2}$ values are very impressive, the samples used for each group (cohort $1 ; n=19$ and cohort 2; n=42) are undersized with respect to the classical Pearson's chi-squared test. Further investigation with a larger cohort should therefore achieve more confident results which we are doing now. 
Overall, we have identified a novel biomarker in the blood of patients with PD that seems to correlate with disease stage and which is derived from 2 measures: the number of EEV/erythrocytes and the expression of 8 different proteins. The biological reasons as to why we find these correlations is still unresolved as is the pathological significance of the protein signature we identified. Nevertheless, our findings are robust and reproducible and further support recent findings that plasma EV derived from the CNS and containing a-syn correlate with the UPDRS scores in PD patients (Shi et al., 2014). Our results unveil a useful new biomarker, and while the EEV counts used a particular type of flow cytometer that is not necessarily accessible to all laboratories, the identification of specific proteins that match clinical stages of PD implies that these could be more easily tested/detected in samples using simple western blots. If replicated in other studies, we would then have a biomarker that could be easily tested in any laboratories or clinical context. 


\section{Acknowledgements}

The authors would like to thank all the students and staff who helped with the blood collections in Cambridge UK, Quebec City and Montreal, Mr. Richard Janvier for his very skilful electron microscopy preparation and analyses, Mr. Gilles Chabot for art work and the Bioimaging platform of the Infectious Disease Research Centre, funded by an equipment and infrastructure grant from the Canadian Foundation for Innovation, for the coordination of the project, we thank Mrs. Lynn Jean from the CHU de Montréal, and importantly, all patients and their families for being so generous with their time in participating in this study.

\section{Author Contributions}

J.L.P. participated in the design of the experiments and all aspects of the study including blood drive, experiments, data analysis and interpretation and preparations of figures. He also helped write some sections of the manuscript.

I.S.-A. participated in the design of the experiments and blood drives, took part in some data analysis and interpretation.

R.L. elaborated the statistical analysis strategy, performed statistical analyses related to Figure 2 and wrote part of the texts relating to the correlation results.

J.P. performed statistical analyses related to Figure 2 .

H.L.D. participated in the analysis of data, preparation of figures and experiments in Figure S2.G and Figure S4.

N.C. was involved in the original design of the flow cytometry experiments and participated in the blood drive in Cambridge.

F.R.-D. contributed to the design and analyses of the proteomic experiments, performed the nanoLCMS/MS and the Free Label quantification and helped with the figure design and writing of methodological aspects of the manuscript.

A.T.V. helped with the proteomic analyses, generated Figure 3 and wrote related methodological aspects of the manuscript.

S.L.M. helped with patient recruitment in Cambridge and participated in the preparation of blood drive in Cambridge.

A-C.D. was involved in the design of electron microscopy experiments and performed related analyses.

A.D. contributed to the proteomic analyses and data interpretation

S.L. had the initial idea to study EEV in HD, set up the collaboration and was involved in discussions pertaining to the study.

N.D. recruited patients - Quebec PD cohort.

M.L. recruited patients - Quebec PD cohort.

S.C. recruited patients - Montreal HD cohort.

R.A.B. helped in the recruiting of patients, participated in data interpretation and revised the manuscript.

E.B. initiated the study and was involved in the experimental design. He also revised the manuscript.

F.C. initiated the study and was involved in the experimental design. She supervised the project and wrote the manuscript. 


\section{References}

Abd-Elhadi, S., Honig, A., Simhi-Haham, D., Schechter, M., Linetsky, E., Ben-Hur, T., Sharon, R., 2015. Total and Proteinase K-Resistant a-Synuclein Levels in Erythrocytes, Determined by their Ability to Bind Phospholipids, Associate with Parkinson's Disease. Sci. Rep. 5, 11120. https://doi.org/10.1038/srep11120

Alvarez-Erviti, L., Seow, Y., Schapira, A.H., Gardiner, C., Sargent, I.L., Wood, M.J.A., Cooper, J.M., 2011. Lysosomal dysfunction increases exosome-mediated alpha-synuclein release and transmission. Neurobiol. Dis. 42, 360-367. https://doi.org/10.1016/j.nbd.2011.01.029

Araki, K., Yagi, N., Nakatani, R., Sekiguchi, H., So, M., Yagi, H., Ohta, N., Nagai, Y., Goto, Y., Mochizuki, H., 2016. A small-angle X-ray scattering study of alpha-synuclein from human red blood cells. Sci. Rep. 6, 30473. https://doi.org/10.1038/srep30473

Barbour, R., Kling, K., Anderson, J.P., Banducci, K., Cole, T., Diep, L., Fox, M., Goldstein, J.M., Soriano, F., Seubert, P., Chilcote, T.J., 2008. Red blood cells are the major source of alpha-synuclein in blood. Neurodegener. Dis. 5, 55-59. https://doi.org/10.1159/000112832

Bartels, T., Choi, J.G., Selkoe, D.J., 2011. a-Synuclein occurs physiologically as a helically folded tetramer that resists aggregation. Nature 477, 107-110. https://doi.org/10.1038/nature10324

Berg, D., Postuma, R.B., Bloem, B., Chan, P., Dubois, B., Gasser, T., Goetz, C.G., Halliday, G.M., Hardy, J., Lang, A.E., Litvan, I., Marek, K., Obeso, J., Oertel, W., Olanow, C.W., Poewe, W., Stern, M., Deuschl, G., 2014. Time to redefine PD? Introductory statement of the MDS Task Force on the definition of Parkinson's disease. Mov. Disord. Off. J. Mov. Disord. Soc. 29, 454-462. https://doi.org/10.1002/mds.25844

Bosman, G.J.C.G.M., Lasonder, E., Groenen-Döpp, Y.A.M., Willekens, F.L.A., Werre, J.M., 2012. The proteome of erythrocyte-derived microparticles from plasma: new clues for erythrocyte aging and vesiculation. J. Proteomics 76 Spec No., 203-210. https://doi.org/10.1016/j.jprot.2012.05.031

Bosman, G.J.C.G.M., Lasonder, E., Luten, M., Roerdinkholder-Stoelwinder, B., Novotný, V.M.J., Bos, H., De Grip, W.J., 2008. The proteome of red cell membranes and vesicles during storage in blood bank conditions. Transfusion (Paris) 48, 827-835. https://doi.org/10.1111/j.15372995.2007.01630.x

Charbonnier-Beaupel, F., Malerbi, M., Alcacer, C., Tahiri, K., Carpentier, W., Wang, C., During, M., Xu, D., Worley, P.F., Girault, J.-A., Hervé, D., Corvol, J.-C., 2015. Gene expression analyses identify Narp contribution in the development of L-DOPA-induced dyskinesia. J. Neurosci. Off. J. Soc. Neurosci. 35, 96-111. https://doi.org/10.1523/JNEUROSCI.5231-13.2015

Cox, J., Mann, M., 2008. MaxQuant enables high peptide identification rates, individualized p.p.b.-range mass accuracies and proteome-wide protein quantification. Nat. Biotechnol. 26, 1367-1372. https://doi.org/10.1038/nbt.1511

Danzer, K.M., Kranich, L.R., Ruf, W.P., Cagsal-Getkin, O., Winslow, A.R., Zhu, L., Vanderburg, C.R., McLean, P.J., 2012. Exosomal cell-to-cell transmission of alpha synuclein oligomers. Mol. Neurodegener. 7, 42. https://doi.org/10.1186/1750-1326-7-42

Duchez, A.-C., Boudreau, L.H., Naika, G.S., Bollinger, J., Belleannée, C., Cloutier, N., Laffont, B., MendozaVillarroel, R.E., Lévesque, T., Rollet-Labelle, E., Rousseau, M., Allaeys, I., Tremblay, J.J., Poubelle, P.E., Lambeau, G., Pouliot, M., Provost, P., Soulet, D., Gelb, M.H., Boilard, E., 2015. Platelet microparticles are internalized in neutrophils via the concerted activity of 12-lipoxygenase and 
secreted phospholipase A2-IIA. Proc. Natl. Acad. Sci. U. S. A. 112, E3564-3573. https://doi.org/10.1073/pnas.1507905112

El-Agnaf, O.M.A., Salem, S.A., Paleologou, K.E., Curran, M.D., Gibson, M.J., Court, J.A., Schlossmacher, M.G., Allsop, D., 2006. Detection of oligomeric forms of alpha-synuclein protein in human plasma as a potential biomarker for Parkinson's disease. FASEB J. Off. Publ. Fed. Am. Soc. Exp. Biol. 20, 419-425. https://doi.org/10.1096/fj.03-1449com

Emmanouilidou, E., Melachroinou, K., Roumeliotis, T., Garbis, S.D., Ntzouni, M., Margaritis, L.H., Stefanis, L., Vekrellis, K., 2010. Cell-produced alpha-synuclein is secreted in a calcium-dependent manner by exosomes and impacts neuronal survival. J. Neurosci. Off. J. Soc. Neurosci. 30, 6838-6851. https://doi.org/10.1523/JNEUROSCI.5699-09.2010

Fauvet, B., Mbefo, M.K., Fares, M.-B., Desobry, C., Michael, S., Ardah, M.T., Tsika, E., Coune, P., Prudent, M., Lion, N., Eliezer, D., Moore, D.J., Schneider, B., Aebischer, P., El-Agnaf, O.M., Masliah, E., Lashuel, H.A., 2012. a-Synuclein in central nervous system and from erythrocytes, mammalian cells, and Escherichia coli exists predominantly as disordered monomer. J. Biol. Chem. 287, 15345-15364. https://doi.org/10.1074/jbc.M111.318949

Fraser, K.B., Moehle, M.S., Daher, J.P.L., Webber, P.J., Williams, J.Y., Stewart, C.A., Yacoubian, T.A., Cowell, R.M., Dokland, T., Ye, T., Chen, D., Siegal, G.P., Galemmo, R.A., Tsika, E., Moore, D.J., Standaert, D.G., Kojima, K., Mobley, J.A., West, A.B., 2013. LRRK2 secretion in exosomes is regulated by 14-3-3. Hum. Mol. Genet. 22, 4988-5000. https://doi.org/10.1093/hmg/ddt346

Grey, M., Dunning, C.J., Gaspar, R., Grey, C., Brundin, P., Sparr, E., Linse, S., 2015. Acceleration of asynuclein aggregation by exosomes. J. Biol. Chem. 290, 2969-2982. https://doi.org/10.1074/jbc.M114.585703

György, B., Módos, K., Pállinger, E., Pálóczi, K., Pásztói, M., Misják, P., Deli, M.A., Sipos, A., Szalai, A., Voszka, I., Polgár, A., Tóth, K., Csete, M., Nagy, G., Gay, S., Falus, A., Kittel, A., Buzás, E.I., 2011. Detection and isolation of cell-derived microparticles are compromised by protein complexes resulting from shared biophysical parameters. Blood 117, e39-48. https://doi.org/10.1182/blood-2010-09-307595

Havlis, J., Thomas, H., Sebela, M., Shevchenko, A., 2003. Fast-response proteomics by accelerated in-gel digestion of proteins. Anal. Chem. 75, 1300-1306.

Helferich, A.M., Ruf, W.P., Grozdanov, V., Freischmidt, A., Feiler, M.S., Zondler, L., Ludolph, A.C., McLean, P.J., Weishaupt, J.H., Danzer, K.M., 2015. a-synuclein interacts with SOD1 and promotes its oligomerization. Mol. Neurodegener. 10, 66. https://doi.org/10.1186/s13024-015-0062-3

Ho, D.H., Yi, S., Seo, H., Son, I., Seol, W., 2014. Increased DJ-1 in urine exosome of Korean males with Parkinson's disease. BioMed Res. Int. 2014, 704678. https://doi.org/10.1155/2014/704678

Hughes, A.J., Daniel, S.E., Ben-Shlomo, Y., Lees, A.J., 2002. The accuracy of diagnosis of parkinsonian syndromes in a specialist movement disorder service. Brain J. Neurol. 125, 861-870.

Kaufman, S., Holtzman, N.A., Milstien, S., Butler, L.J., Krumholz, A., 1975. Phenylketonuria due to a deficiency of dihydropteridine reductase. N. Engl. J. Med. 293, 785-790. https://doi.org/10.1056/NEJM197510162931601

Kong, S.M.Y., Chan, B.K.K., Park, J.-S., Hill, K.J., Aitken, J.B., Cottle, L., Farghaian, H., Cole, A.R., Lay, P.A., Sue, C.M., Cooper, A.A., 2014. Parkinson's disease-linked human PARK9/ATP13A2 maintains zinc homeostasis and promotes a-Synuclein externalization via exosomes. Hum. Mol. Genet. 23, 2816-2833. https://doi.org/10.1093/hmg/ddu099 
Konoshenko, M.Y., Lekchnov, E.A., Vlassov, A.V., Laktionov, P.P., 2018. Isolation of Extracellular Vesicles: General Methodologies and Latest Trends. BioMed Res. Int. 2018, 8545347. https://doi.org/10.1155/2018/8545347

Kunadt, M., Eckermann, K., Stuendl, A., Gong, J., Russo, B., Strauss, K., Rai, S., Kügler, S., Falomir Lockhart, L., Schwalbe, M., Krumova, P., Oliveira, L.M.A., Bähr, M., Möbius, W., Levin, J., Giese, A., Kruse, N., Mollenhauer, B., Geiss-Friedlander, R., Ludolph, A.C., Freischmidt, A., Feiler, M.S., Danzer, K.M., Zweckstetter, M., Jovin, T.M., Simons, M., Weishaupt, J.H., Schneider, A., 2015. Extracellular vesicle sorting of a-Synuclein is regulated by sumoylation. Acta Neuropathol. (Berl.) 129, 695-713. https://doi.org/10.1007/s00401-015-1408-1

Lacroix, R., Judicone, C., Poncelet, P., Robert, S., Arnaud, L., Sampol, J., Dignat-George, F., 2012. Impact of pre-analytical parameters on the measurement of circulating microparticles: towards standardization of protocol. J. Thromb. Haemost. JTH 10, 437-446. https://doi.org/10.1111/j.1538-7836.2011.04610.x

Li, Y., Schrodi, S., Rowland, C., Tacey, K., Catanese, J., Grupe, A., 2006. Genetic evidence for ubiquitinspecific proteases USP24 and USP40 as candidate genes for late-onset Parkinson disease. Hum. Mutat. 27, 1017-1023. https://doi.org/10.1002/humu.20382

Linares, R., Tan, S., Gounou, C., Arraud, N., Brisson, A.R., 2015. High-speed centrifugation induces aggregation of extracellular vesicles. J. Extracell. Vesicles 4, 29509.

Maere, S., Heymans, K., Kuiper, M., 2005. BiNGO: a Cytoscape plugin to assess overrepresentation of gene ontology categories in biological networks. Bioinforma. Oxf. Engl. 21, 3448-3449. https://doi.org/10.1093/bioinformatics/bti551

Martínez-Martín, P., Rodríguez-Blázquez, C., Mario Alvarez, null, Arakaki, T., Arillo, V.C., Chaná, P., Fernández, W., Garretto, N., Martínez-Castrillo, J.C., Rodríguez-Violante, M., Serrano-Dueñas, M., Ballesteros, D., Rojo-Abuin, J.M., Chaudhuri, K.R., Merello, M., 2015. Parkinson's disease severity levels and MDS-Unified Parkinson's Disease Rating Scale. Parkinsonism Relat. Disord. 21, 50-54. https://doi.org/10.1016/j.parkreldis.2014.10.026

Massano, J., Bhatia, K.P., 2012. Clinical approach to Parkinson's disease: features, diagnosis, and principles of management. Cold Spring Harb. Perspect. Med. 2, a008870. https://doi.org/10.1101/cshperspect.a008870

Melachroinou, K., Xilouri, M., Emmanouilidou, E., Masgrau, R., Papazafiri, P., Stefanis, L., Vekrellis, K., 2013. Deregulation of calcium homeostasis mediates secreted a-synuclein-induced $\begin{array}{llll}\text { neurotoxicity. } & \text { Neurobiol. } & \text { Aging } & \text { 2853-2865. }\end{array}$ https://doi.org/10.1016/j.neurobiolaging.2013.06.006

Minetti, G., Ciana, A., Balduini, C., 2004. Differential sorting of tyrosine kinases and phosphotyrosine phosphatases acting on band 3 during vesiculation of human erythrocytes. Biochem. J. 377, 489497. https://doi.org/10.1042/BJ20031401

Nakai, M., Fujita, M., Waragai, M., Sugama, S., Wei, J., Akatsu, H., Ohtaka-Maruyama, C., Okado, H., Hashimoto, M., 2007. Expression of alpha-synuclein, a presynaptic protein implicated in Parkinson's disease, in erythropoietic lineage. Biochem. Biophys. Res. Commun. 358, 104-110. https://doi.org/10.1016/j.bbrc.2007.04.108

Nguyen, D.B., Ly, T.B.T., Wesseling, M.C., Hittinger, M., Torge, A., Devitt, A., Perrie, Y., Bernhardt, I., 2016. Characterization of Microvesicles Released from Human Red Blood Cells. Cell. Physiol. Biochem. Int. J. Exp. Cell. Physiol. Biochem. Pharmacol. 38, 1085-1099. 
https://doi.org/10.1159/000443059

Nikam, S., Nikam, P., Ahaley, S.K., Sontakke, A.V., 2009. Oxidative stress in Parkinson's disease. Indian J. Clin. Biochem. IJCB 24, 98-101. https://doi.org/10.1007/s12291-009-0017-y

Porro, C., Trotta, T., Panaro, M.A., 2015. Microvesicles in the brain: Biomarker, messenger or mediator? J. Neuroimmunol. 288, 70-78. https://doi.org/10.1016/j.jneuroim.2015.09.006

Pretorius, E., Swanepoel, A.C., Buys, A.V., Vermeulen, N., Duim, W., Kell, D.B., 2014. Eryptosis as a marker of Parkinson's disease. Aging 6, 788-819. https://doi.org/10.18632/aging.100695

Quek, C., Hill, A.F., 2017. The role of extracellular vesicles in neurodegenerative diseases. Biochem. Biophys. Res. Commun. 483, 1178-1186. https://doi.org/10.1016/j.bbrc.2016.09.090

R Core Team, 2016. R: A language and environment for statistical computing. R Found. Stat. Comput.

Renella, R., Schlehe, J.S., Selkoe, D.J., Williams, D.A., LaVoie, M.J., 2014. Genetic deletion of the GATA1regulated protein $a$-synuclein reduces oxidative stress and nitric oxide synthase levels in mature erythrocytes. Am. J. Hematol. 89, 974-977. https://doi.org/10.1002/ajh.23796

Rousseau, M., Belleannee, C., Duchez, A.-C., Cloutier, N., Levesque, T., Jacques, F., Perron, J., Nigrovic, P.A., Dieude, M., Hebert, M.-J., Gelb, M.H., Boilard, E., 2015. Detection and quantification of microparticles from different cellular lineages using flow cytometry. Evaluation of the impact of secreted phospholipase A2 on microparticle assessment. PloS One 10, e0116812. https://doi.org/10.1371/journal.pone.0116812

Scheer, F.A.J.L., Michelson, A.D., Frelinger, A.L., Evoniuk, H., Kelly, E.E., McCarthy, M., Doamekpor, L.A., Barnard, M.R., Shea, S.A., 2011. The human endogenous circadian system causes greatest platelet activation during the biological morning independent of behaviors. PloS One 6, e24549. https://doi.org/10.1371/journal.pone.0024549

Shamir, R., Klein, C., Amar, D., Vollstedt, E.-J., Bonin, M., Usenovic, M., Wong, Y.C., Maver, A., Poths, S., Safer, H., Corvol, J.-C., Lesage, S., Lavi, O., Deuschl, G., Kuhlenbaeumer, G., Pawlack, H., Ulitsky, I., Kasten, M., Riess, O., Brice, A., Peterlin, B., Krainc, D., 2017. Analysis of blood-based gene expression in idiopathic Parkinson disease. Neurology 89, 1676-1683. https://doi.org/10.1212/WNL.0000000000004516

Shevchenko, A., Wilm, M., Vorm, O., Mann, M., 1996. Mass spectrometric sequencing of proteins silverstained polyacrylamide gels. Anal. Chem. 68, 850-858.

Shi, M., Liu, C., Cook, T.J., Bullock, K.M., Zhao, Y., Ginghina, C., Li, Y., Aro, P., Dator, R., He, C., Hipp, M.J., Zabetian, C.P., Peskind, E.R., Hu, S.-C., Quinn, J.F., Galasko, D.R., Banks, W.A., Zhang, J., 2014. Plasma exosomal a-synuclein is likely CNS-derived and increased in Parkinson's disease. Acta Neuropathol. (Berl.) 128, 639-650. https://doi.org/10.1007/s00401-014-1314-y

Stuendl, A., Kunadt, M., Kruse, N., Bartels, C., Moebius, W., Danzer, K.M., Mollenhauer, B., Schneider, A., 2016. Induction of a-synuclein aggregate formation by CSF exosomes from patients with Parkinson's disease and dementia with Lewy bodies. Brain J. Neurol. 139, 481-494. https://doi.org/10.1093/brain/awv346

Sudha, K., Rao, A.V., Rao, S., Rao, A., 2003. Free radical toxicity and antioxidants in Parkinson's disease. Neurol. India 51, 60-62.

Suzuki, R., Shimodaira, H., 2006. Pvclust: an R package for assessing the uncertainty in hierarchical clustering. Bioinforma. Oxf. Engl. 22, 1540-1542. https://doi.org/10.1093/bioinformatics/btl117 
Tomlinson, P.R., Zheng, Y., Fischer, R., Heidasch, R., Gardiner, C., Evetts, S., Hu, M., Wade-Martins, R., Turner, M.R., Morris, J., Talbot, K., Kessler, B.M., Tofaris, G.K., 2015. Identification of distinct circulating exosomes in Parkinson's disease. Ann. Clin. Transl. Neurol. 2, 353-361. https://doi.org/10.1002/acn3.175

Tsunemi, T., Hamada, K., Krainc, D., 2014. ATP13A2/PARK9 regulates secretion of exosomes and asynuclein. J. Neurosci. Off. J. Soc. Neurosci. 34, 15281-15287. https://doi.org/10.1523/JNEUROSCI.1629-14.2014

Vestad, B., Llorente, A., Neurauter, A., Phuyal, S., Kierulf, B., Kierulf, P., Skotland, T., Sandvig, K., Haug, K.B.F., Øvstebø, R., 2017. Size and concentration analyses of extracellular vesicles by nanoparticle tracking analysis: a variation study. J. Extracell. Vesicles 6, 1344087. https://doi.org/10.1080/20013078.2017.1344087

Vogel, R., Coumans, F.A.W., Maltesen, R.G., Böing, A.N., Bonnington, K.E., Broekman, M.L., Broom, M.F., Buzás, E.I., Christiansen, G., Hajji, N., Kristensen, S.R., Kuehn, M.J., Lund, S.M., Maas, S.L.N., Nieuwland, R., Osteikoetxea, X., Schnoor, R., Scicluna, B.J., Shambrook, M., de Vrij, J., Mann, S.I., Hill, A.F., Pedersen, S., 2016. A standardized method to determine the concentration of extracellular vesicles using tunable resistive pulse sensing. J. Extracell. Vesicles 5, 31242.

Wang, X., Yu, S., Li, F., Feng, T., 2015. Detection of a-synuclein oligomers in red blood cells as a potential biomarker of Parkinson's disease. Neurosci. Lett. 599, 115-119. https://doi.org/10.1016/j.neulet.2015.05.030

Willis, G.R., Kourembanas, S., Mitsialis, S.A., 2017. Toward Exosome-Based Therapeutics: Isolation, Heterogeneity, and Fit-for-Purpose Potency. Front. Cardiovasc. Med. 4, 63. https://doi.org/10.3389/fcvm.2017.00063

Wither, M.J., Hansen, K.C., Reisz, J.A., 2016. Mass Spectrometry-Based Bottom-Up Proteomics: Sample Preparation, LC-MS/MS Analysis, and Database Query Strategies. Curr. Protoc. Protein Sci. 86, 16.4.1-16.4.20. https://doi.org/10.1002/cpps.18

Zeng, B.Y., Dass, B., Owen, A., Rose, S., Cannizzaro, C., Tel, B.C., Jenner, P., 1999. Chronic L-DOPA treatment increases striatal cannabinoid CB1 receptor mRNA expression in 6-hydroxydopaminelesioned rats. Neurosci. Lett. 276, 71-74. 


\section{Figures legends}

Table 1. Participant clinical information - PD cohort. Disease severity as measured using the H\&Y scale (score): Mild (1-1.5); Moderate (2-2.5); Severe (3-3.5). ${ }^{*} p<0.05$ vs. CTRL. Statistical analyses were performed using a Kruskal Wallis test followed by Dunn's multiple comparison test.

Figure 1. A. Blood cell quantification. Full blood counts performed in PD patients $(n=57)$ revealed no significant differences in the total number of any cell type between patients and their respective healthy sex- and age-matched CTRL ( $n=37$ ), except for erythrocytes. Statistical analyses were performed using unpaired t-tests when data followed normal distributions according to the Shapiro-Wilk test or MannWitney in cases of non-normality. B. Cell-derived EV quantification. The quantification of EV in plateletfree plasma of PD patients and controls was performed by high-sensitivity flow cytometry. Phosphatidylserine was evaluated with Annexin $\mathrm{V}$ binding. The complete blood count was obtained at the time of blood sampling for 35|37 Controls and 57|59 PD and was used to calculate the EV per cell ratio. Statistical analyses were performed using a Two-Way ANOVA. * For erythrocyte-derived EV quantification, 1 outlier (determined using Grubbs' method with alpha=0.0001) was removed. C. Diagnostic Value. Distribution plots of CD235a+ EV/total number of erythrocytes between PD and healthy sex- and age-matched CTRL (PD, $n=42$; CTRL, $n=24$ ). Abbreviation: CD235a-45-41-31-15-14, cluster of differentiation; CTRL, Control; EV, extracellular vesicle; EEV, erythrocyte-derived extracellular vesicle; PD, Parkinson's disease; PS, phosphatidylserine; UPDRS, Unified Parkinson's Disease Rating Scale.

Figure 2. Relationship between EEV and clinical measures of PD. A. Absence of correlations between EEV/Erythrocyte counts and H\&Y stage. B. Correlations between EEV/Erythrocyte counts with total UPDRS scores. C. Robust correlations between the number of EEV/total number of erythrocytes and UPDRS scores (PD, $n=20$, from the UK cohort exclusively since the Quebec cohort did not have recent UPDRS scores available). D. EV/erythrocytes ratios, UPDRS scores and LEDD values for all PD patients used in the correlation analyses. E. Absence of correlation between the number of EEV and LEDD. Correlations reported were determined using Pearson's goodness-of-fit test. Abbreviation: CD235a, glycophorin A; CTRL, Control; EEV, erythrocyte-derived extracellular vesicle; H\&Y, Hoehn and Yahr; LEDD, Levodopa equivalent daily dose; PD, Parkinson's disease; UPDRS, Unified Parkinson's Disease Rating Scale.

Figure 3. A-B. Proteomic analyses with and without hemoglobin. To ensure the specificity of the protein signature detected in EEV, we performed proteomic analyses using two distinct methodologies. A. The first set of analyses by nanoLC-MS/MS and Label Free Quantification was performed on the complete proteome of the EEV, yielding 356 proteins. B. The second set of analyses was also performed on the entire EEV proteome but this time, isolating hemoglobin and quantifying the proteins present in both fractions. This approach uncovered 708 proteins in the EEV proteome with an additional 110 proteins in the hemoglobin fraction for a total of 818 proteins, indicating that removing hemoglobin provides a much more accurate evaluation of the protein content of EEV. C-D. Specific protein signature of EEV in PD patients. B. NanoLC-MS/MS Label-free analysis of EEV in PD patients and healthy age-matched CTRL revealed a total of 818 proteins, of which 8 had an expression that was significantly different as a function of PD stage (C). The proteins/genes have been further separated into 3 groups in relation to their variations in comparison to CTRL (Group I), mild PD (Group II) or moderate PD (Group III). D. Heatmap establishing correlations between disease stages and the abundance of the variable proteins. Cold and hot colours represent low and high correlation levels, respectively. The AU $p$ value is indicated for each node. Protein level changes were determined by Welch's test $p$ value $<0.05$ and absolute value of z-score $>1.96,{ }^{*} p<0.05,{ }^{*} p<0.01$. Abbreviations: AU, Approximately Unbiased; CTRL Control; PD, 
Parkinson's disease. E. The protein ratios (log2(ratio)) of the three comparisons (mild PD/CTRL, moderate $\mathrm{PD} / \mathrm{CTRL}$ and moderate PD/mild PD) were plotted over the corresponding Welch's test $p$ value $(-\log 10$ ( $\mathrm{p}$ value)). The graphs display a $\vee$ shape, as expected, and only the proteins falling outside the limits of a $p$ value $<0.05$ and absolute value of $z$-score $>1.96$ (identified by black lines) were considered as variant proteins (red dots). Two variant proteins were excluded given that they were quantified using only one peptide. Abbreviations: ABHD14B, alpha/beta hydrolase domain-containing protein 14B; AIDA, axin interactor dorsalization-associated protein; AKR1A1, alcohol dehydrogenase NADP+; ATP5A1, ATP synthase subunit alpha mitochondrial; CNRIP1, cannabinoid receptor-interacting protein 1; CTRL: Control; NADSYN1, glutamine-dependent NAD(+) synthetase; USP24, ubiquitin carboxyl-terminal hydrolase 24; PD, Parkinson's disease; QDPR, Quinoid Dihydropteridine Reductase.

Figure 4. Detection of normal and phosphorylated a-Syn in EEV. A. Representative scanning electron micrographs of resting and activated erythrocytes in both PD patients and healthy sex- and age-matched CTRL. Scale bar: $2 \mu \mathrm{m}$. B. Representative transmission electron microscopy images of immunogold labeling for $\alpha$-Syn and $\alpha$-Syn pS129 in activated erythrocytes and EEV (some examples delineated by dotted lines). Arrowheads point to positive immunolabeling for either $\alpha$-Syn or $\alpha$-Syn pS129. Scale bar: 100nm. C. Quantification of a-Syn in EEV as detected by transmission electron microscopy and expressed as the percentage of EEVs positive for a-Syn/total number of EEV in healthy sex- and age-matched CTRL and PD patients ( $n=100$ erythrocytes sampled in $n=3$ CTRL and $n=3$ PD). D. Quantification of $a-S y n$ in EEV by ELISA assays in healthy sex- and age-matched CTRL, mild and moderate stage patients $(n=4$ erythrocytes per group; $n=13$ EEV per group) showed no measurable changes in a-Syn levels between PD and healthy sex- and age-matched CTRL. Statistical analyses were performed using a Mann-Whitney $U$ test (C) or a Kruskal-Wallis test (D). Abbreviations: $\alpha$-Syn, $\alpha$-synuclein; $\alpha$-Syn pS129, $\alpha$-synuclein phosphorylated Serine 129; CTRL, Control; EEV, erythrocyte-derived extracellular vesicle; PD, Parkinson's disease. 


\section{Supplementary figures}

Figure S1. Erythrocyte and EV implication in PD: summary of the literature. The search for a reliable biomarker in PD has included investigations on neuronal cells in specific in vitro systems, on cellular elements within the circulatory system, the CSF and urine with a targeted interest on the expression of a-Syn. However, none of these studies have convincingly identified a robust marker of PD. Abbreviations: aSyn, a-synuclein; CAT, Catalase; GPx, glutathione peroxidase; L1CAM, L1 cell adhesion molecule; LRRK2, Leucine-rich repeat kinase 2; RBC, red blood cells; SOD, superoxide dismutase; $\checkmark$ presence; $\uparrow$ increase; $\downarrow$ decrease.

Figure S2. Optimization of EV detection: controls for flow cytometry. Controls for EV identification. A. To properly set the EV gate, fluorescent silica beads of $100 \mathrm{~nm}$ (Red), 500nm (Blue) and 1000nm (Yellow) were acquired on a flow cytometer Canto II modified with a FSC-PMT small particle option. B. Serial dilutions of $\operatorname{EEV}(1,2,4$ and 10) were used to confirm the linearity of the quantification. C. FSC-PMT/SSC gates of PFP stained with annexin $\mathrm{V}$ and respective fluorochrome-conjugated antibodies directed against erythrocyte (CD235a+), endothelial (CD31+/CD41-), platelet (CD41+) and leukocyte (CD14+CD45+, monocytes; CD15+CD45+, granulocytes)-derived EVs. Controls for EV labeling. D. Treatment with the ion chelator EDTA inhibited the binding of annexin $V$ to phosphatidylserine. E. Minimal background was observed using antibodies in the absence of PFP and was subtracted from all subsequent EV quantifications. F. EV sensitivity to $0.5 \%$ triton was further assessed G. Reproducibility of EEV counts over time. EEV/Erythrocytes counts and $\mathrm{CV} \%$ obtained for the 25 additional participants. Each subject provided 2 samples at two distinct time points (C\#-1: Patient\#-Time 1, C\#-2: Patient\#-Time 2) yielding 2 measurements per patient. Abbreviations: AnnV, annexinV; EV, extracellular vesicle; EEV, erythrocytederived extracellular vesicle; FSC PMT-H, forward scatter photomultiplier tube; PBS, phosphate buffered saline; PFP, platelet free plasma; SSC-H, side scatter.

Figure S3. Blood counts and exclusion criteria. A. Evaluated hematocrit, mean corpuscular hemoglobin and mean corpuscular volumes were similar between groups (PD, $n=43 ; C T R L, n=24$ ). B. CRP (indicative of an inflammatory response) and free hemoglobin (indicative of hemolysis) (C) were further quantified in the PFP (PD, n=59; CTRL, $n=37$ ). Individuals presenting with levels exceeding $45000 \mathrm{ng} / \mathrm{ml}$ were excluded from the study to remove the possibility that these factors contributed to increased EEV concentrations. Statistical analyses were performed using Kruskal-Wallis test (A-B) and Mann-Whitney $U$ tests (C-E). Abbreviations: CTRL, controls; CRP, C-reactive protein; PD, Parkinson's disease; PFP, plateletfree plasma.

Figure S4. Relation between EEV and clinical measures of PD in additional cohort. A. Correlations between EEV/Erythrocyte counts with total UPDRS scores for mild (B), moderate (C) and severe patients (D) E. EV/erythrocytes ratios, UPDRS scores and LEDD values for all PD patients used in the correlation analyses. F. Absence of correlation between the number of EEV and LEDD. Correlations reported were determined using Pearson's goodness-of-fit test.

Figure S5. A. Cell-derived EV quantification of - HD cohort. The quantification of EV in platelet-free plasma of $\mathrm{HD}$ patients and controls was performed by high-sensitivity flow cytometry. Phosphatidylserine was evaluated with Annexin $\mathrm{V}$ binding. The complete blood count was obtained at the time of blood sampling for 53|54 CTRL, 10 pre-manifest and 48|50|51 HD patients and was used to calculate the EV per cell ratio. Statistical analyses were performed using Two-Way ANOVA. B. Distribution plots of CD235a+/total number of erythrocytes revealed no differences between HD and healthy sex- and age-matched CTRL (HD, $n=50$; Pre-HD, $n=10 ;$ CTRL, $n=52$ ) and C. no statistically 
significant correlations were found between the number of EEV/total number of erythrocytes and UHDRS scores (HD, $n=42$ ). Correlations were determined using Pearson's goodness-of-fit test, ${ }^{*} p<0.05$. Abbreviations: ACE, Addenbrooke's Cognitive Examination; BDI, Beck Depression Inventory; BDS, Burden of Disease Score; CD235a, glycophorin A; CTRL, Controls; EEV, erythrocyte-derived extracellular vesicle; EV, extracellular vesicle; HD, Huntington's disease; H\&Y, Hoehn and Yahr; MMSE, Mini-Mental State Examination; Pre-HD, Pre-manifest; PS, phosphatidylserine; TFC, Total Functional Capacity; UHDRS, Unified Huntington's Disease Rating Scale.

Figure S6. A Gene Ontology enrichment analysis was performed on the Cellular Component ontology using BinGO software. The list of 356 identified proteins in the entire EEV (A) and the list of the 818 identified proteins when hemoglobin was analyzed separately (B) were compared to the whole human proteome (reference list). Circle size is proportional to the number of proteins matching the corresponding GO term and the color scale corresponds to the $p$ value of enrichment (darker orange corresponds to greater statistical enrichments).

Table S1. Participant clinical information - HD cohort. Disease severity levels in relation to the TFC scale: Stage 1 (11-13); Stage 2 (7-10); Stage 3 (3-6); Stage 4 (1-2); Stage 5 (0). Disease severity was evaluated within 6 months of blood sampling. Comorbidities were determined from medical information reported by the participant or caregiver. Blood cell quantification. Full blood counts performed in HD patients at different stages of the disease (Pre-HD, $n=10$; Stage 1, $n=15$; Stage 2, n=12; Stage 3, n=11; Stage $4, n=10$; Stage $5, n=2$ ) revealed no significant differences in the total number of any cell type between patients and their respective healthy sex- and age-matched CTRL ( $n=54)$, except for erythrocytes. Statistical analyses were performed using a Kruskal Wallis test followed by Dunn's multiple comparison test.

Table S2. Participant clinical information - PD cohort no.2. Disease severity as measured using the UPDRS scale (score): Mild (0,39); Moderate (29,73); Severe $(57,74) .{ }^{*} p<0.05$ vs. CTRL. Statistical analyses were performed using a Kruskal Wallis test followed by Dunn's multiple comparison test.

Table S3. Complete list of proteins identified in the EEV proteome. Lists of the protein groups identified by LC-MS/MS analysis using Andromeda/MaxQuant search engine in the Uniprot Complete Proteome Homo sapiens database for the non-depleted sample (356 proteins) (A) or when hemoglobin was analyzed separately (818 proteins) (B). The lists were filtered at $1 \%$ False Discovery Rate using a target/decoy database search. 


\section{Figure 1.}

A

Blood cell quantification

\begin{tabular}{|c|c|c|c|c|c|c|c|c|}
\hline \multirow{2}{*}{ Cell type } & \multirow{2}{*}{ Units } & \multicolumn{3}{|c|}{ CTRL } & \multicolumn{3}{|c|}{ PD } & \multirow[b]{2}{*}{$p$ value } \\
\hline & & $n$ & Mean & SD & $\mathrm{n}$ & Mean & SD & \\
\hline Erythrocytes & $10^{9} / \mathrm{ml}$ & 35 & 4.75 & 0.61 & 56 & 4.56 & 0.47 & 0.049 \\
\hline Platelets & $10^{6} / \mathrm{ml}$ & 35 & 235 & 44 & 56 & 217 & 50 & 0.083 \\
\hline Leukocytes & $10^{6} / \mathrm{ml}$ & 35 & 6.91 & 1.62 & 56 & 6.53 & 1.97 & 0.347 \\
\hline Monocytes & $10^{6} / \mathrm{ml}$ & 35 & 0.56 & 0.14 & 56 & 0.53 & 0.18 & 0.308 \\
\hline Granulocytes & $10^{6} / \mathrm{ml}$ & 35 & 4.34 & 1.38 & 56 & 4.32 & 1.62 & 0.979 \\
\hline
\end{tabular}

B

\section{Cell-derived EV quantification}

\begin{tabular}{|c|c|c|c|c|c|c|c|c|c|}
\hline \multirow{2}{*}{ Cell type } & \multirow{2}{*}{ Markers } & \multirow{2}{*}{ Units } & \multicolumn{3}{|c|}{ CTRL } & \multicolumn{3}{|c|}{ PD } & \multirow{2}{*}{$\begin{array}{c}p \\
\text { value }\end{array}$} \\
\hline & & & $n$ & Mean & SEM & $\mathrm{n}$ & Mean & SEM & \\
\hline \multirow{4}{*}{ Erythrocytes } & CD235a+PS- & $10^{3} / \mu l$ & 36 & 18.2 & 46.5 & 59 & 32.0 & 36.3 & 0.04 \\
\hline & CD235a+PS+ & $10^{3 / \mu l}$ & 36 & 0.22 & 0.07 & 59 & 0.29 & 0.05 & 0.70 \\
\hline & $\mathrm{CD} 235 \mathrm{a}+$ total & $10^{3} / \mu 1$ & 36 & 18.4 & 47.0 & 59 & 32.3 & 36.7 & 0.04 \\
\hline & EV CD235a+leryth rocyte & & 34 & 0.0039 & 0.011 & 57 & 0.0069 & 0.008 & 0.03 \\
\hline \multirow{4}{*}{ Platelets } & CD41+PS- & $10^{3} / \mu 1$ & 37 & 7.88 & 1.68 & 59 & 10.3 & 1.33 & 0.27 \\
\hline & CD41+PS+ & $10^{3 / \mu 1}$ & 37 & 15.2 & 3.20 & 59 & 17.9 & 2.53 & 0.51 \\
\hline & CD41+ total & $10^{3 / \mu l}$ & 37 & 23.1 & 4.62 & 59 & 28.2 & 3.66 & 0.38 \\
\hline & EV CD41+/platelet & & 35 & 0.106 & 0.021 & 57 & 0.125 & 0.016 & 0.49 \\
\hline \multirow{3}{*}{$\begin{array}{l}\text { Endothelial } \\
\text { cells }\end{array}$} & CD31+CD41-PS- & $10^{3} / \mu 1$ & 37 & 15.8 & 8.04 & 59 & 11.7 & 6.37 & 0.75 \\
\hline & CD31+CD41-PS+ & $10^{3 / \mu l}$ & 37 & 0.91 & 0.13 & 59 & 0.92 & 0.10 & 0.96 \\
\hline & CD31+CD41- total & $10^{3 / \mu l}$ & 37 & 16.7 & 8.03 & 59 & 12.6 & 6.36 & 0.75 \\
\hline Leukocytes & CD45+ total & $10^{3 / \mu l}$ & 37 & 10.4 & 2.21 & 59 & 13.8 & 1.75 & 0.26 \\
\hline \multirow{6}{*}{ Monocytes } & CD45-CD14+ PS- & $10^{3 / \mu l}$ & 37 & 1.70 & 0.30 & 59 & 1.62 & 0.24 & 0.85 \\
\hline & CD45-CD14+ PS+ & $10^{3 / \mu l}$ & 37 & 1.20 & 4.00 & 59 & 5.84 & 3.17 & 0.50 \\
\hline & CD45+CD14+ PS- & $10^{3} / \mu 1$ & 37 & 0.16 & 0.04 & 59 & 0.14 & 0.03 & 0.74 \\
\hline & CD45+CD14+PS+ & $10^{3 / \mu l}$ & 37 & 0.60 & 0.79 & 59 & 1.47 & 0.63 & 0.59 \\
\hline & CD14+ total & $10^{3 / \mu l}$ & 37 & 3.66 & 4.88 & 59 & 9.06 & 3.87 & 0.60 \\
\hline & EV CD14+/monocyte & & 35 & 7.08 & 1.99 & 57 & 9.16 & 1.56 & 0.41 \\
\hline \multirow{5}{*}{ Granulocytes } & CD45-CD15+ PS- & $10^{3 / \mu l}$ & 37 & 12.3 & 7.96 & 59 & 16.7 & 6.30 & 0.92 \\
\hline & CD45-CD15+ PS+ & $10^{3} / \mu 1$ & 37 & 2.21 & 0.77 & 59 & 1.39 & 0.61 & 0.47 \\
\hline & CD45+CD15+ PS- & $10^{3} / \mu 1$ & 37 & 0.55 & 0.36 & 59 & 1.15 & 0.29 & 0.20 \\
\hline & CD45+CD15+PS+ & $10^{3} / \mu 1$ & 37 & 1.01 & 0.30 & 59 & 1.25 & 0.24 & 0.56 \\
\hline & CD15+ total & $10^{3 / \mu l}$ & 37 & 16.0 & 8.83 & 59 & 20.6 & 6.99 & 0.91 \\
\hline
\end{tabular}

\section{Diagnostic value}

C

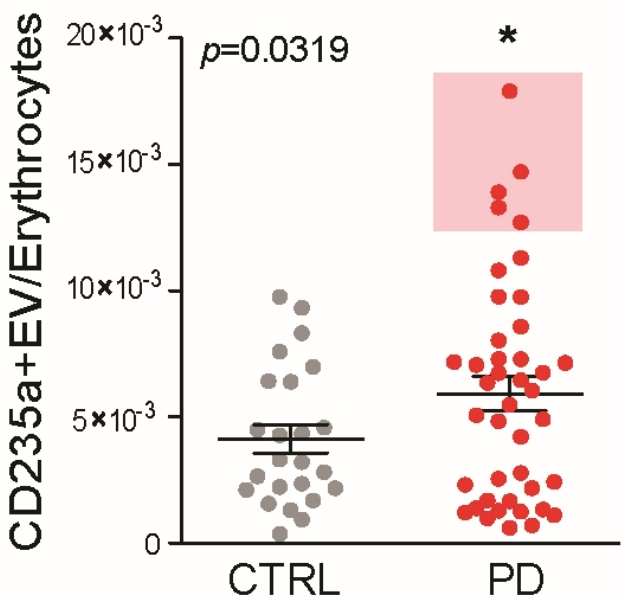




\section{Figure 2.}

\section{EEV in relation to clinical measures}

A

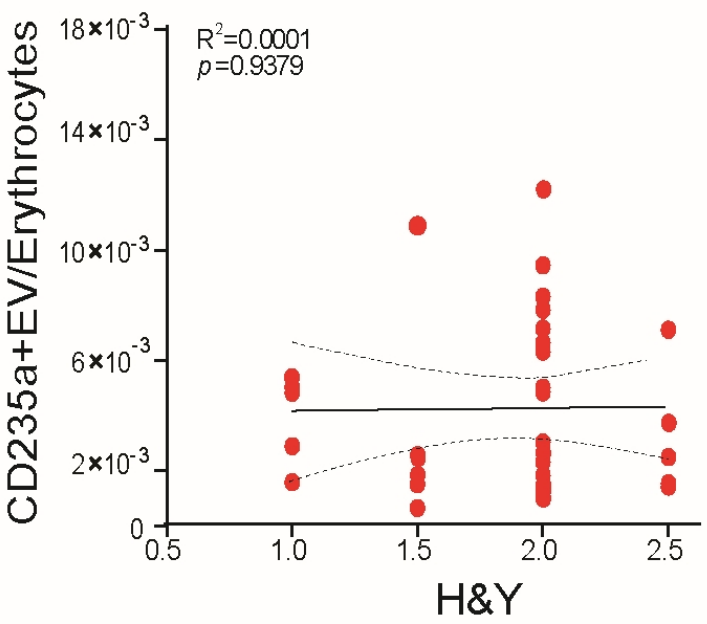

B

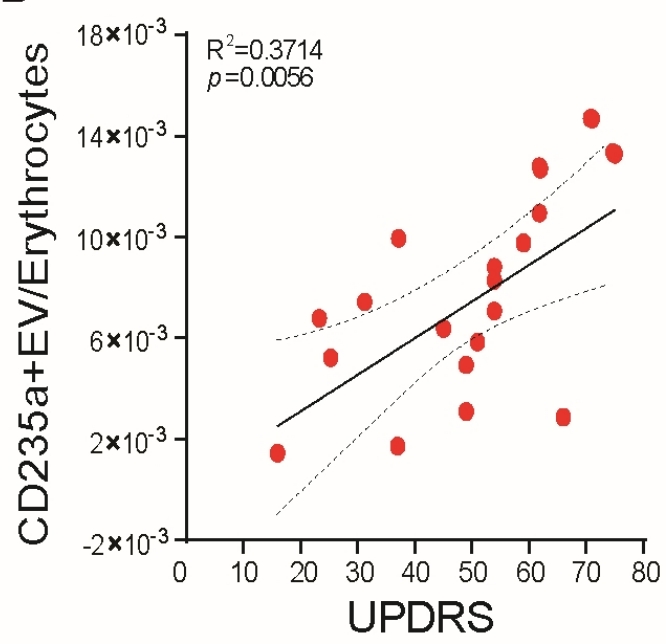

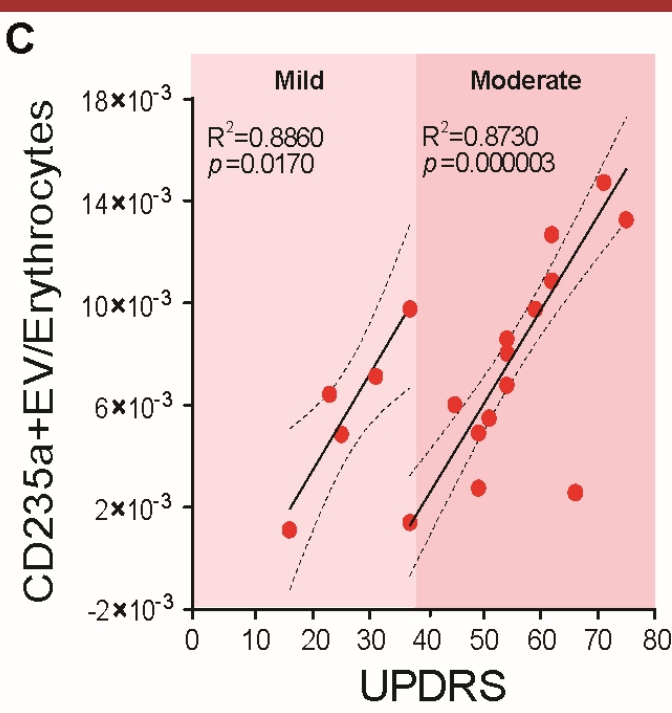

\section{LEDD and EV}

\begin{tabular}{|cccc|}
\hline Patients & EVlerythrocyte & UPDRS & LEDD \\
\hline PD1 & $1.10 \times 10^{-3}$ & 16 & $100 \mathrm{mg}$ \\
\hline PD2 & $6.45 \times 10^{-3}$ & 23 & $386 \mathrm{mg}$ \\
\hline PD3 & $4.83 \times 10^{-3}$ & 25 & $220 \mathrm{mg}$ \\
\hline PD4 & $7.14 \times 10^{-3}$ & 31 & $705 \mathrm{mg}$ \\
\hline PD5 & $9.75 \times 10^{-3}$ & 37 & $100 \mathrm{mg}$ \\
\hline PD6 & $1.38 \times 10^{-3}$ & 37 & $300 \mathrm{mg}$ \\
\hline PD7 & $6.04 \times 10^{-3}$ & 45 & $820 \mathrm{mg}$ \\
\hline PD8 & $2.78 \times 10^{-3}$ & 49 & $740 \mathrm{mg}$ \\
\hline PD9 & $4.91 \times 10^{-3}$ & 49 & $950 \mathrm{mg}$ \\
\hline PD10 & $5.47 \times 10^{-3}$ & 51 & $250 \mathrm{mg}$ \\
\hline PD11 & $6.75 \times 10^{-3}$ & 54 & $740 \mathrm{mg}$ \\
\hline PD12 & $8.57 \times 10^{-3}$ & 54 & $475 \mathrm{mg}$ \\
\hline PD13 & $8.03 \times 10^{-3}$ & 54 & $550 \mathrm{mg}$ \\
\hline PD14 & $9.77 \times 10^{-3}$ & 59 & $850 \mathrm{mg}$ \\
\hline PD15 & $10.8 \times 10^{-3}$ & 62 & $450 \mathrm{mg}$ \\
\hline PD16 & $12.7 \times 10^{-3}$ & 62 & $500 \mathrm{mg}$ \\
\hline PD17 & $25.5 \times 10^{-3}$ & 66 & nil \\
\hline PD18 & $14.7 \times 10^{-3}$ & 71 & $254 \mathrm{mg}$ \\
\hline PD19 & $13.3 \times 10^{-3}$ & 75 & $700 \mathrm{mg}$ \\
\hline
\end{tabular}

E

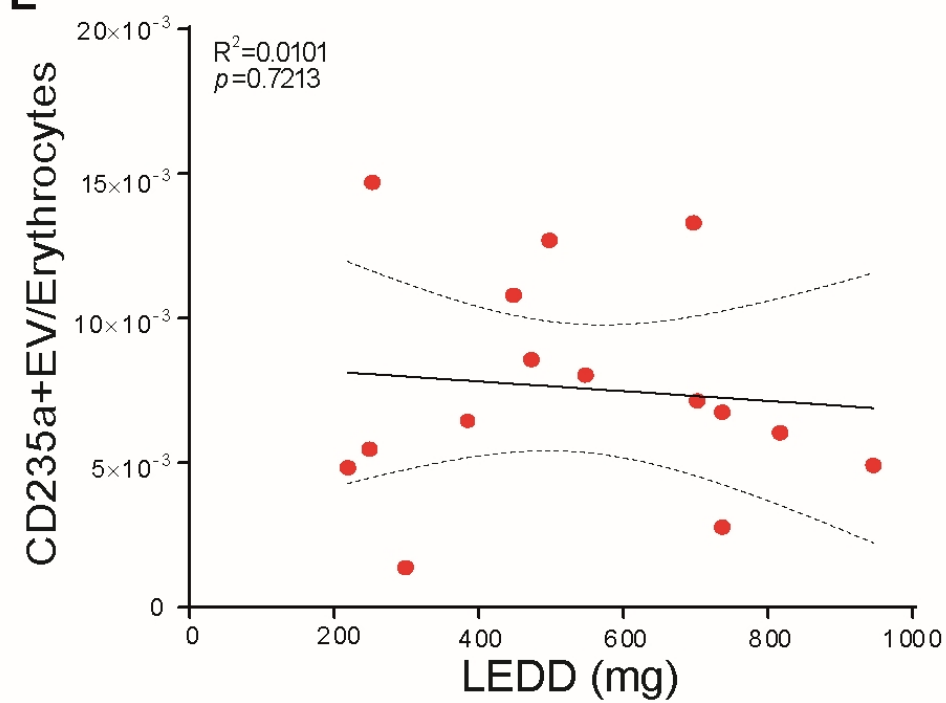




\section{Figure 3.}

A Approach no.1

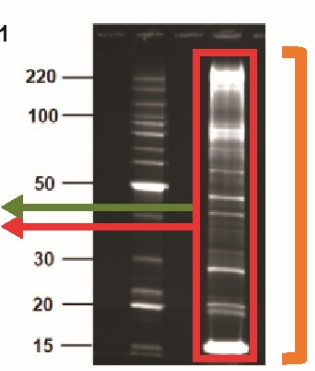

B

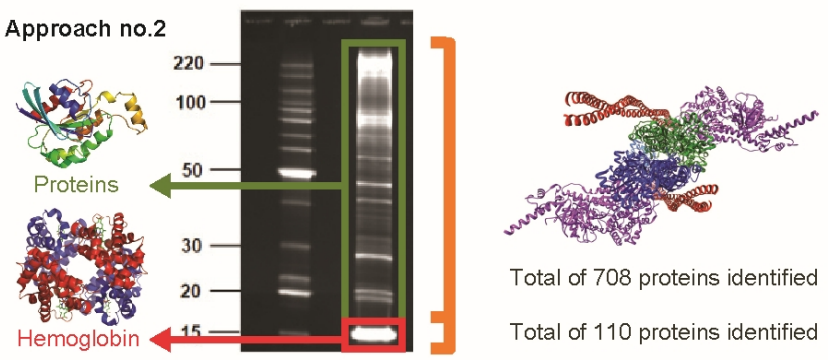

C

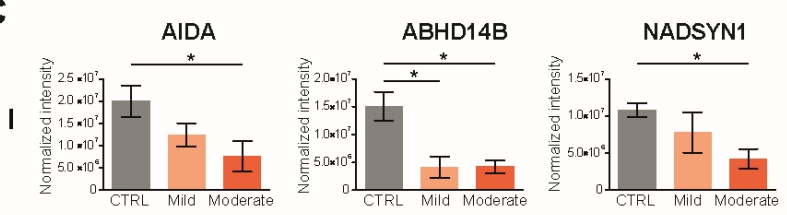

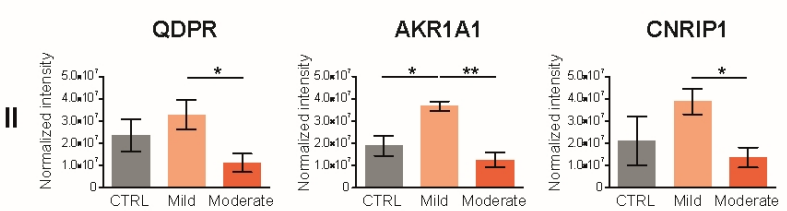

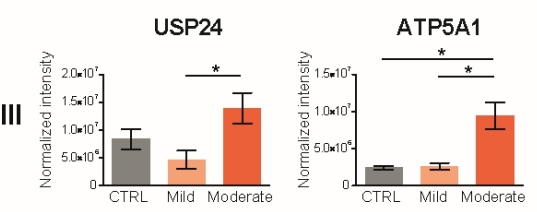

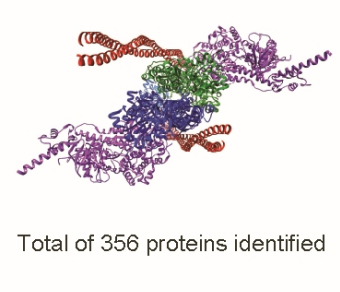

D

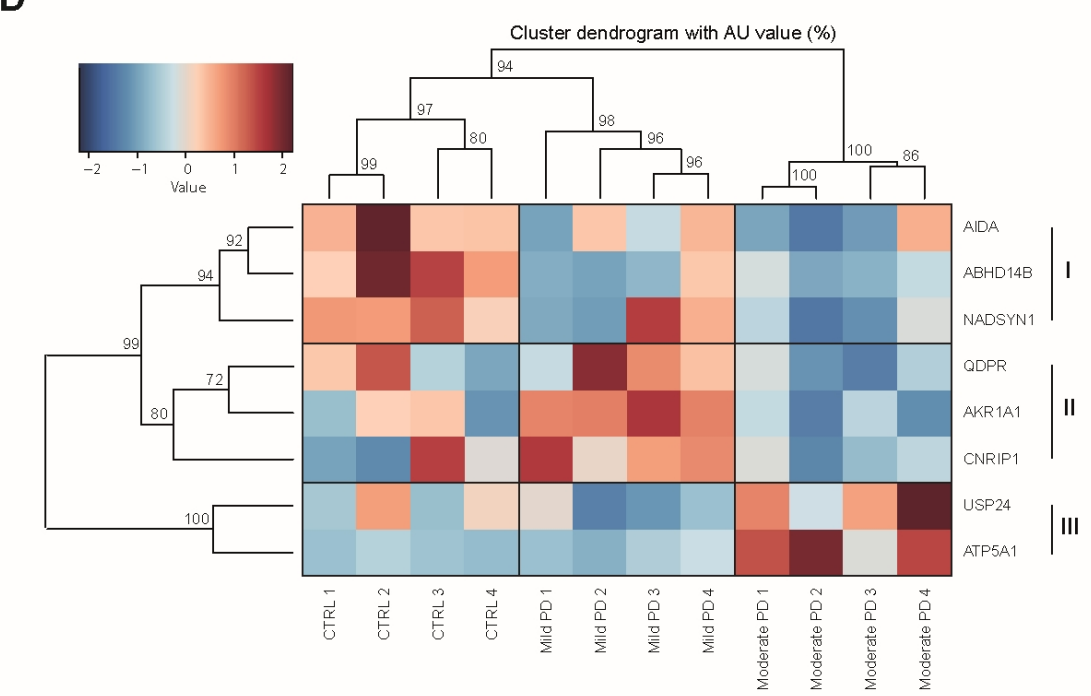

E
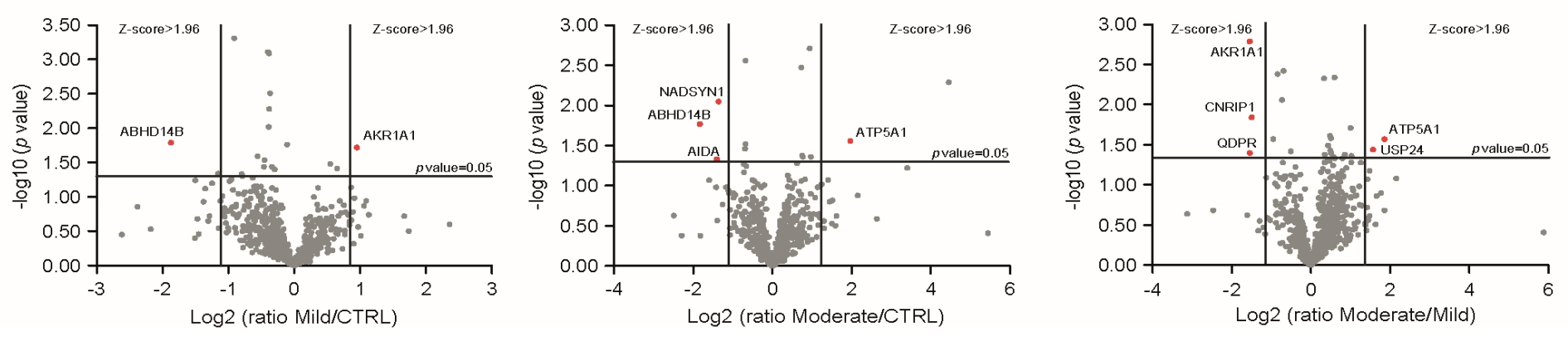
Figure 4.

A

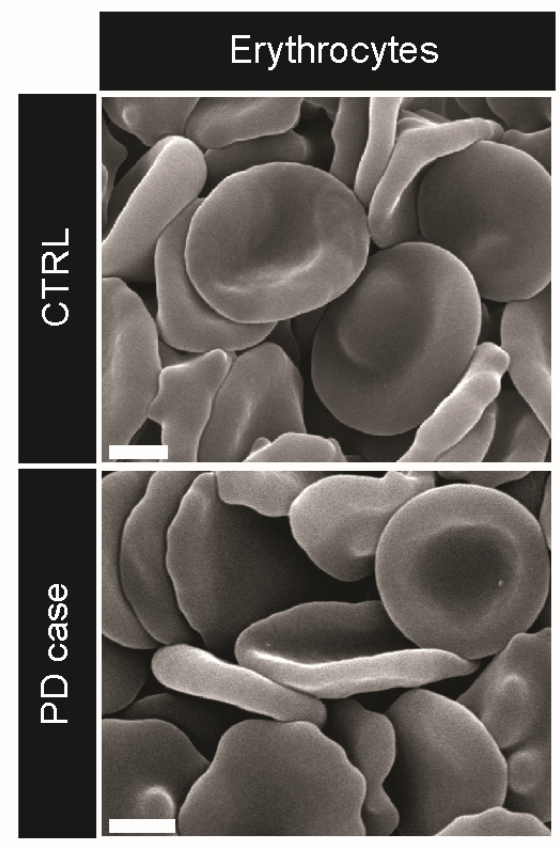

\section{Activated erythrocytes}
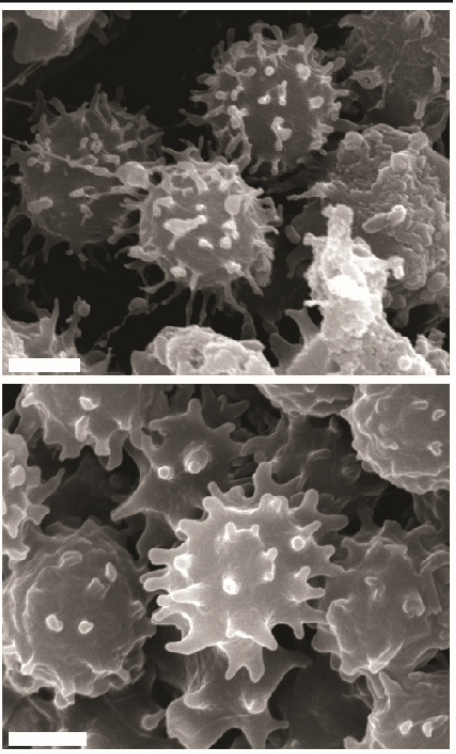

C
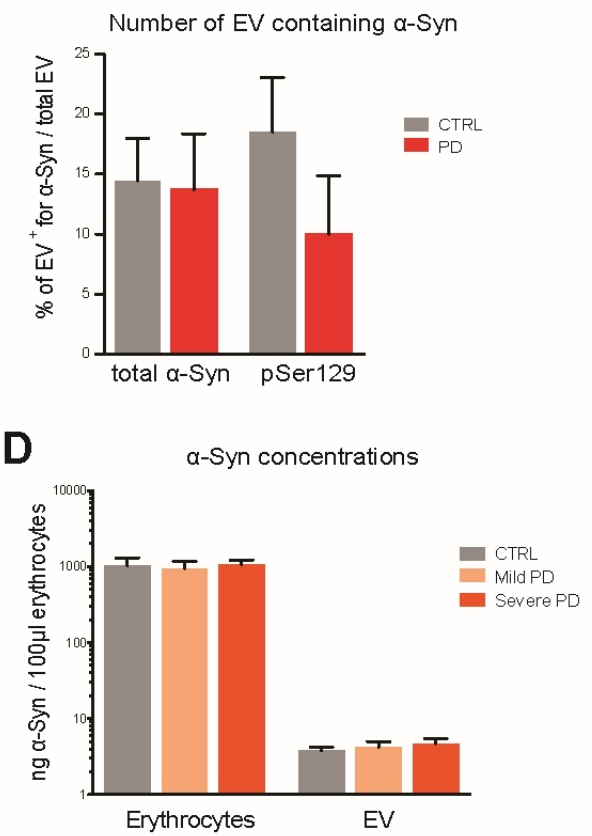

B

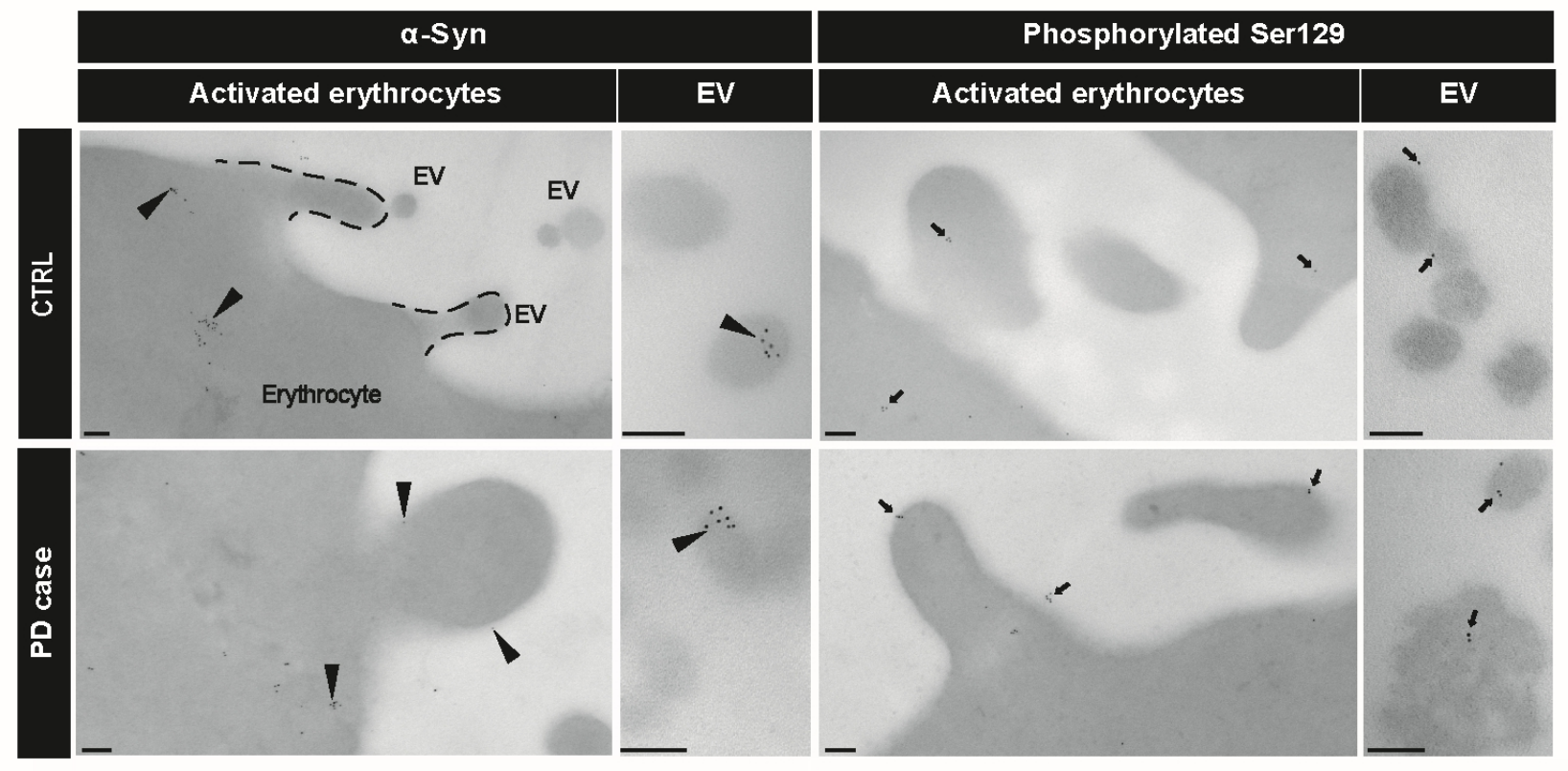




\section{SI Materials and methods}

\section{Preparation of platelet-free plasma and EV labeling}

For all experiments, diluted annexin-V buffer (BD Pharmingen, Mississauga, ON, Canada) and phosphate buffered saline (PBS) were filtered on $0.22 \mu \mathrm{m}$ pore size membranes (PALL, Mississauga, ON, Canada). To quantify EV according to their cell of origin, the following surface markers were used: CD235a+

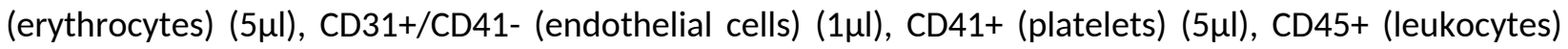
$(3 \mu l), C D 45+C D 14+$ (monocytes) $(10 \mu l)$, and CD45+CD15+ (granulocytes) $(2 \mu l)$, with or without annexin-V staining $(5 \mu \mathrm{l})$. PFP $(5 \mu \mathrm{l})$ was incubated with Phenylalanyl-prolyl-arginyl Chloromethyl Ketone (PPACK) 10mM (Calbiochem, Etobicoke, ON, Canada) for 5 minutes followed by a 30-minute incubation with antibodies and annexin- $\mathrm{V}$ in a final PBS volume of $100 \mu \mathrm{l}$, all at room temperature. Finally, samples were diluted to a final volume of $2 \mathrm{ml}$ prior to FACS analysis. The following antibodies were purchased from BD Pharmingen and used for all analyses: FITC-conjugated mouse anti-human CD235a (clone GA-R2 (HIR2), 1/20), PE-conjugated mouse anti-human CD31 (clone WM59, 1/100), V450-conjugated mouse antihuman CD41a (clone HIP8, 1/20), V450-conjugated mouse anti-human CD45 (clone HI30, 1/33), APC mouse anti-human CD14 (clone M5E2, 1/10), PE-conjugated mouse anti-human CD15 (clone HI98, 1/50), V450- and PerCP-Cy ${ }^{\mathrm{TM}}$ 5.5-conjugated annexin-V (1/20).

\section{Flow cytometry quantification}

The acquisition of EV was performed at low speed at an approximated rate of $10 \mu \mathrm{l} / \mathrm{min}$. To determine background noise levels, antibody mixes were incubated in the absence of PFP sample and unlabeled PFP was used as a negative control. Every sample was re-identified to ensure that the experimenter was blind to clinical status.

\section{Production and purification of EEV}

Briefly, the erythrocyte pellet was activated with 3 volumes of calcium ionophore solution $(150 \mathrm{mM} \mathrm{NaCl}$; 10mM Tris- $\mathrm{HCl}$; $1 \mathrm{mM} \mathrm{CaCl} 2 ; 5 \mu \mathrm{M}$ ionophore A23187 (Sigma, St Louis, MO)) for 30 minutes at $37^{\circ} \mathrm{C}$. Calcium ionophore is key to EV biogenesis. It participates in the activation and inhibition of proteins and phospholipids at the cell membrane. Calcium ionophore A23187 induces a change in the concentration of calcium which leads to vesicle formation. In contrast to water and freezing, which are frequently used to provoke the release of EEV, calcium ionophores avoid the destruction of the erythrocyte membranes (Nguyen et al., 2016). The activation was stopped by the addition of 5mM EDTA. Remaining erythrocytes 
were pelleted at $15000 \mathrm{~g}$ for 20 minutes. The EEV were centrifuged at $20000 \mathrm{~g}$ for 90 minutes and washed once in PBS. The EV pellet was re-suspended in PBS and frozen at $-80^{\circ} \mathrm{C}$ until further analyses.

\section{Scanning electron microscopy}

Preparations of erythrocytes $(5 \mu \mathrm{l})$ were fixed in $2 \%$ paraformaldehyde and $2.5 \%$ glutaraldehyde in PBS buffer at least 24 hours before standard dehydration. Samples were washed 3 times for 10 minutes with sodium cacodylate buffer (0.1M, pH 7.3) and fixed with $1 \%$ osmium tetroxide in sodium cacodylate buffer for 90 minutes. Subsequently, samples were washed and processed in 50\%, 70\%, 90\% and 100\% EtOH for dehydration (10 minutes/step). Finally, samples were soaked in two subsequent baths of $100 \%$ $\mathrm{EtOH}$, for 40 minutes and 10 minutes, air-dried overnight and coated with palladium. Observations were completed using a JEOL 6360LV scanning electron microscope (JEOL, Peabody, MA, USA).

\section{Transmission electron microscopy}

Preparations of EEV $(30 \mu \mathrm{l})$ and activated erythrocytes $(5 \mu \mathrm{l})$ were fixed in $2 \%$ paraformaldehyde at least 24 hours before being dehydrated and sealed in LR white. Slices of LR white were placed on a Formvar/carbon-coated grid and processed for immunolabeling. The tissues mounted on grids were blocked in 0.5\% BSA-c (Aurion, Wageningen, The Netherlands) in HBSS and incubated for 120 minutes with rabbit anti- $\alpha$-Syn antibody (Abcam, Toronto, ON, Canada) or rabbit anti- $\alpha$-Syn (phospho S129) antibody (Abcam, Toronto, ON, Canada), both diluted at 1:250 in HBSS and washed several times with distilled water. Finally, the grids were incubated for 60 minutes with an anti-rabbit IgG conjugated to 6nm gold particles (EMS, Hatfield, PA, USA) diluted at 1:200, washed several times with distilled water and then fixed in 2.5\% glutaraldehyde (EMS, Hatfield, PA, USA) in HBSS for 15 minutes. For this last step, the grids were treated with $3 \%$ uranyl acetate-0.075 M oxalate ( $\mathrm{pH} 7.0$ ) (EMS, Hatfield, PA, USA) for 1 minute, which was followed by several washes in distilled water. All staining experiments included negative controls where the primary antibody was omitted from the incubation media. Observations were completed with a TECNAI Spirit G2 transmission electron microscope at 80kV (FEI, Hillsboro, OR, USA).

\section{Mass spectrometry analysis and label free protein quantification}

The extracted peptides from the 7 slices of the same individual were pooled and analyzed by nanoLCMS/MS. The excised hemoglobin gel slices were also analyzed in the same conditions. One $\mu \mathrm{g}$ of each individual sample was injected on a Dionex UltiMate 3000 nanoRSLC system (Thermo Scientific) 


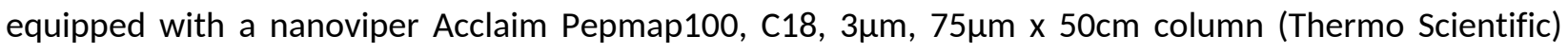
connected to the nanoelectrospray source of an Orbitrap Fusion mass spectrometer (Thermo Scientific). The peptides were eluted at $300 \mathrm{~nL} / \mathrm{min}$ using an acetonitrile gradient of 90 minutes with the mass spectrometer operating in the Data Dependent Acquisition mode. Peptide masses were measured in MS spectra detected in the orbitrap at $120 \mathrm{~K}$ resolution. MSMS fragmentation spectra of peptides were generated by Higher energy Collisional Dissociation (HCD) and detected in the ion trap.

\section{Statistical analyses}

Initial statistical analyses (unpaired t-tests when data followed normal distribution according to ShapiroWilk test or Mann-Witney in cases of non-normality) compared the number of each type of blood cells (erythrocytes, platelets, leukocytes, neutrophils, monocytes, lymphocytes) in control groups and patients of all stages of the UK to the Canadian cohorts. Comparison between each type of EV from every cells including erythrocytes, platelets, leukocytes, neutrophils, monocytes, lymphocytes and endothelial cells were performed using Two-Way ANOVA. This revealed no statistical differences between groups, allowing us to pool cohorts for subsequent analyses. Statistical analyses pertaining EEV quantification were performed using The Statistics and Machine Learning Toolbox provided by MathWorks ${ }^{\top M}$ under MATLAB ${ }^{\text {TM }}$ platform using the MATLAB $R$ R2015a version. Results obtained include the scatter plots, classical least-square linear regressions, R-squared and $p$ values, as well as Pearson's goodness-of-fit. Interval cut-off values were determined using a loop program developed in MATLAB ${ }^{T M}$. Model diagnostics, including residual behaviour and homoscedastivity, were obtained using the same Toolbox. Further details on the statistical tests chosen are described directly in the result section. For $\alpha$-Syn quantification, data were first tested for normality using the D'Agostino \& Pearson normality test. Comparisons between groups were obtained by Mann-Whitney $U$ test or Kruskal-Wallis ANOVA and performed using Prism 6.0 (GraphPad Software, LaJolla, CA). For proteomic analyses, the 'Intensity values' contained in the output 'proteingroup.txt' file of MaxQuant were used to quantify each identified protein in each individual sample. The values were normalized by the median of each column (all intensity values of proteins for one sample). The missing values were imputed with a noise value corresponding to the 1-percentile of each sample column. For each comparison between two groups (Control, mild PD or moderate PD), proteins with too many imputed values where considered not quantifiable (a minimum of three not-imputed values in one of the 2 groups are required). A protein ratio was calculated between the two groups using the average of intensity values in each group. Finally, a statistical Welch's test was performed between the two groups. The protein ratios were transformed 
into $\log 2$ (ratio) then centered by calculation of a z-score $(z$-score $=(x-\mu) / \sigma)$. A protein was considered as variant if it fulfilled the following criteria: minimum of 2 peptides quantified, Welch's test $p$ value $<0.05$ and absolute value of $z$-score $>1.96$ (corresponding to values outside of the $95 \%$ confidence interval). The Gene Ontology enrichment analysis on the identified proteins was performed on the Cytoscape platform (v. 3.4.0) using the BinGO software version 3.0.3 against all human genes with GO annotation (Uniprot-GOA generated 2015-06-22) (Maere et al., 2005). Enrichment was calculated by a hypergeometric test and Bonferroni Family-Wise Error Rate (FWER) was used to correct for multiple testing. The data for the resulting 8 proteins was standardized, hierarchically clustered and visualized as a heatmap by using the statistical framework R ( $R$ Core Team, 2016). The robustness of the nodes was evaluated by computing Approximately Unbiased (AU) $p$ values using the R package pvclust (10000 bootstraps, average method and correlation-based dissimilarity matrix) (Suzuki and Shimodaira, 2006). 
Figure S1.

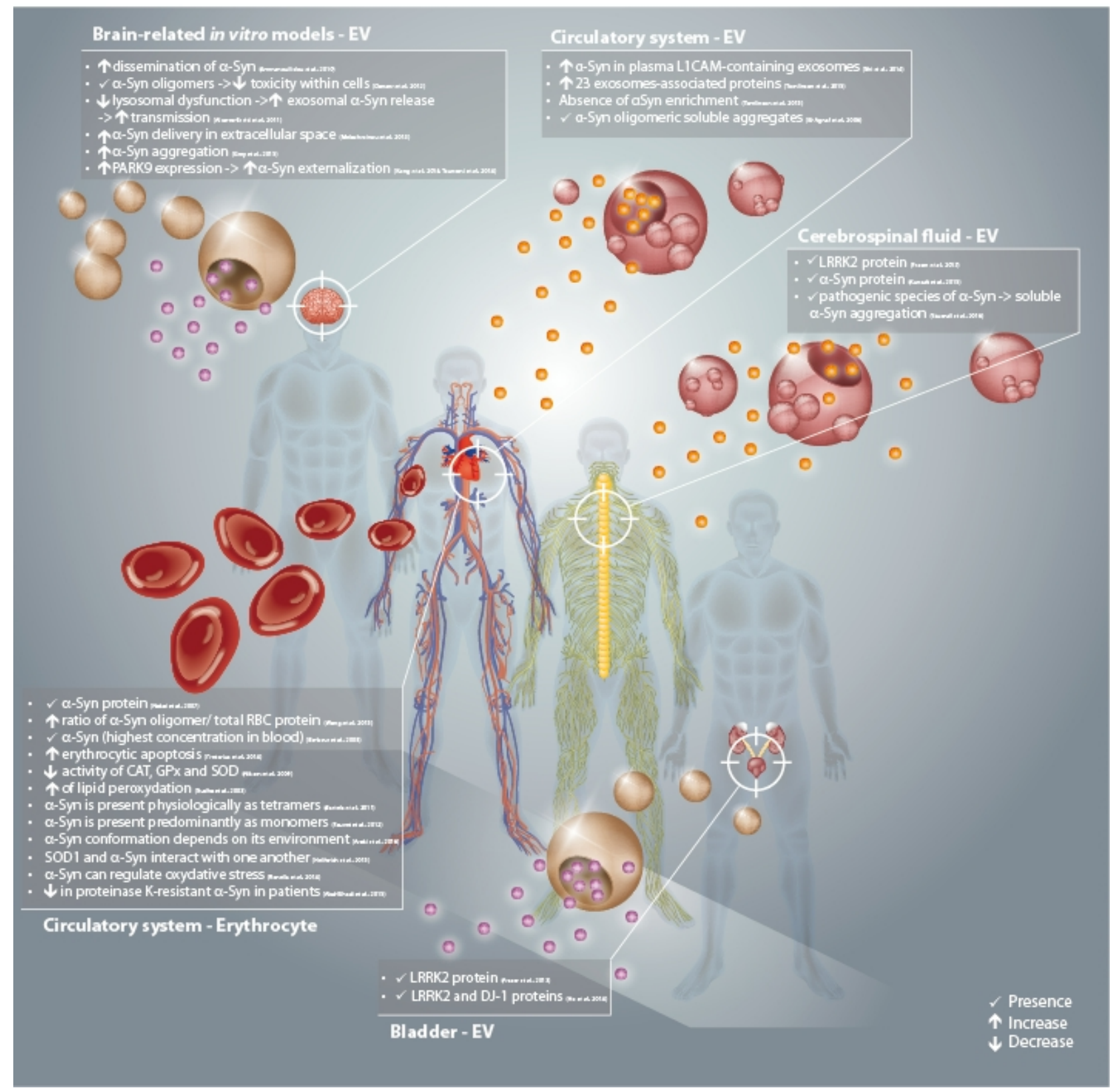


Figure S2.

\section{Controls for EV identification}

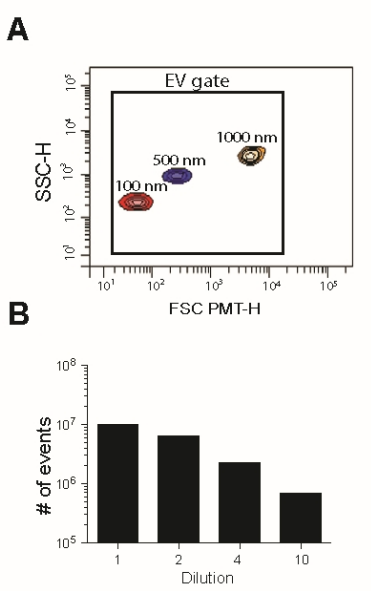

C
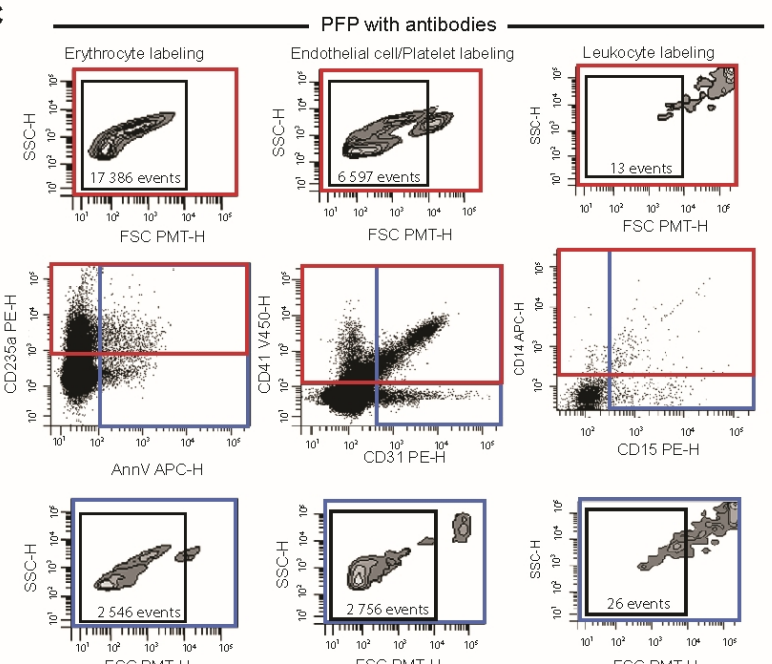

\section{Controls for EV labeling}
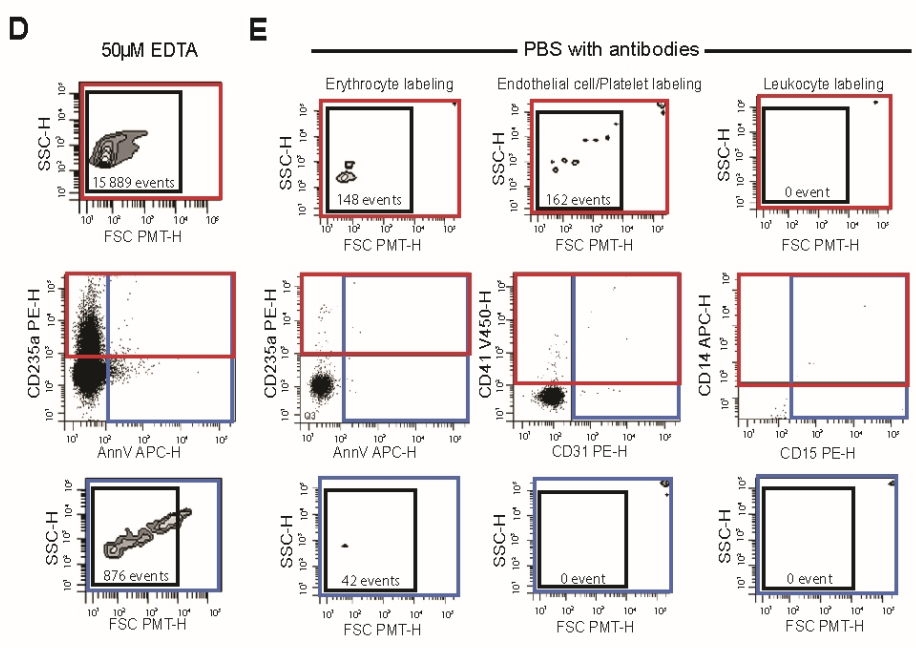

F
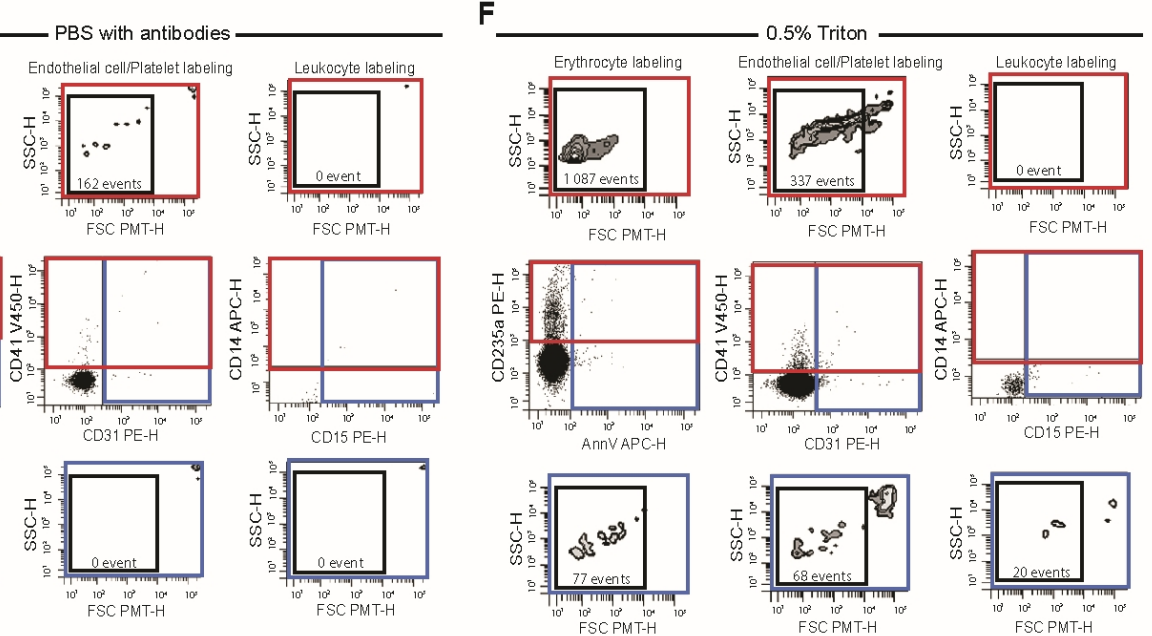

EEV/Erythrocytes intra-patient variability

G

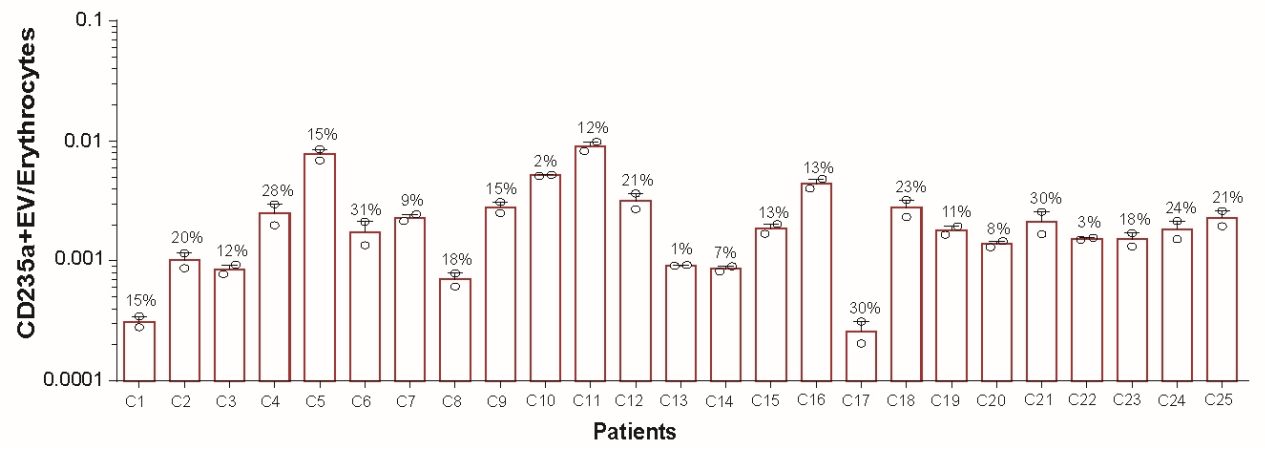




\section{Figure S3.}

A

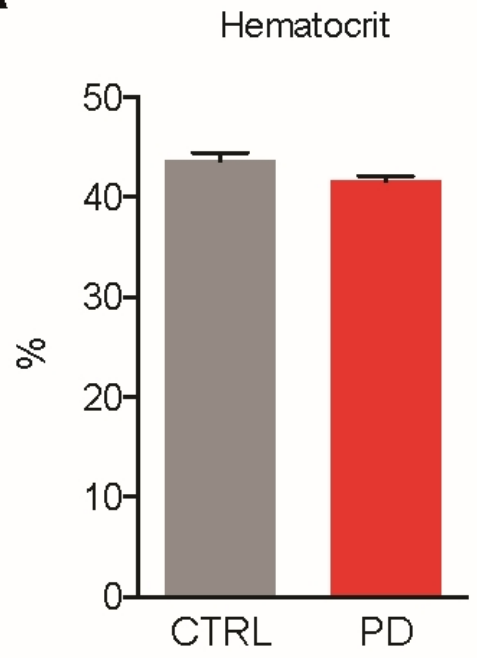

Mean Corpuscular Volume

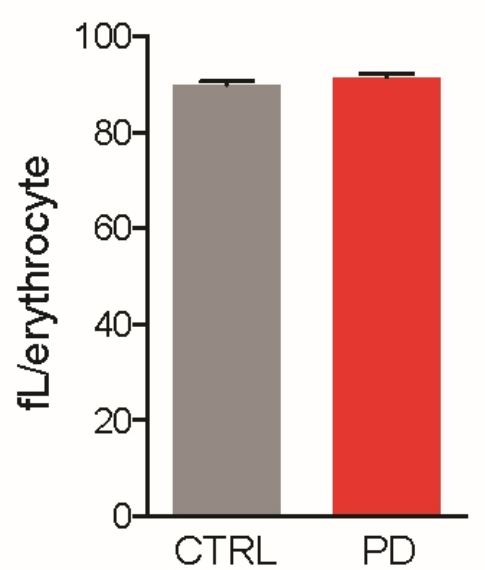

Mean Corpuscular Hemoglobin

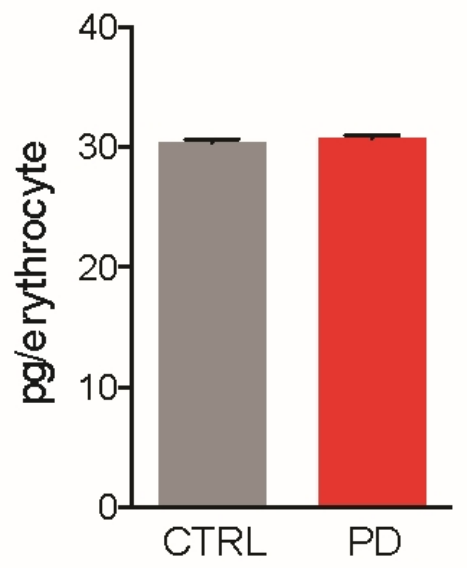

B

C-reactive protein

C
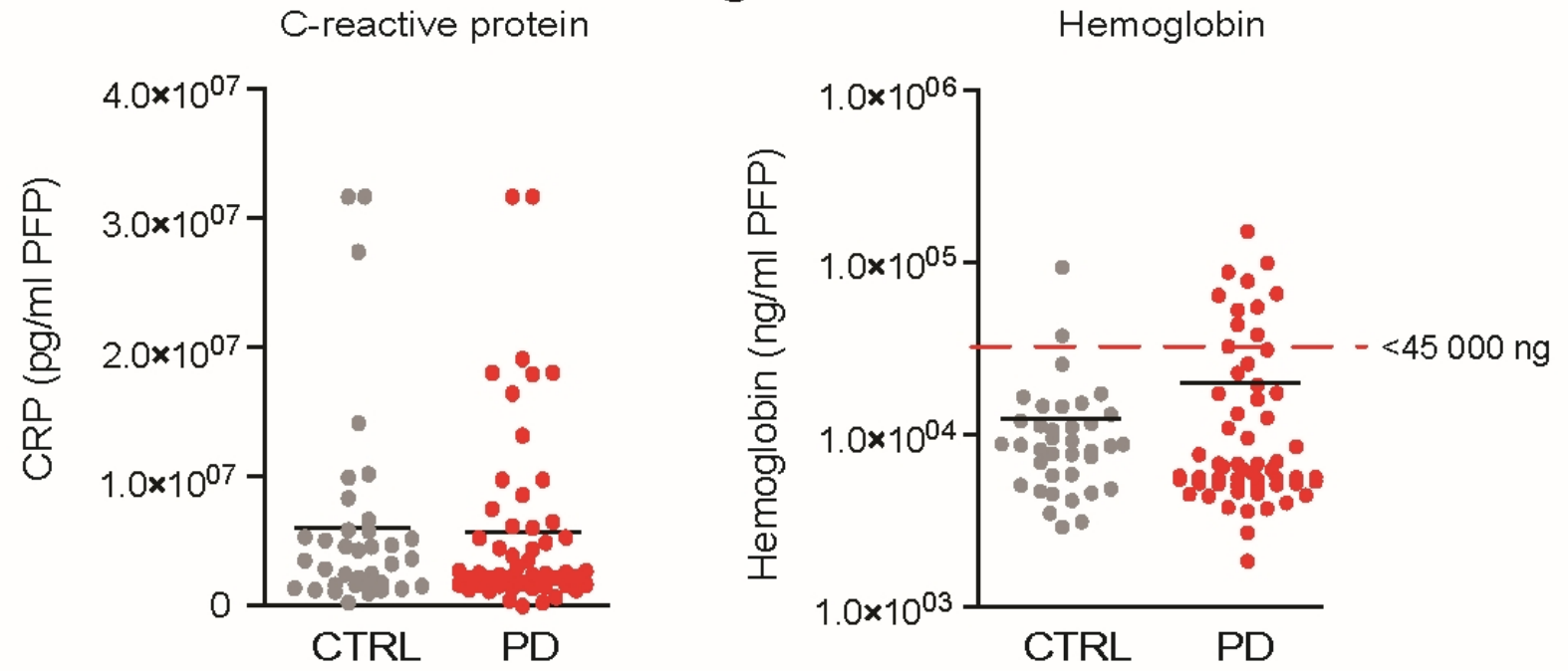


\section{Figure S4.}

\section{EEV in relation to UPDRS - cohort 2}
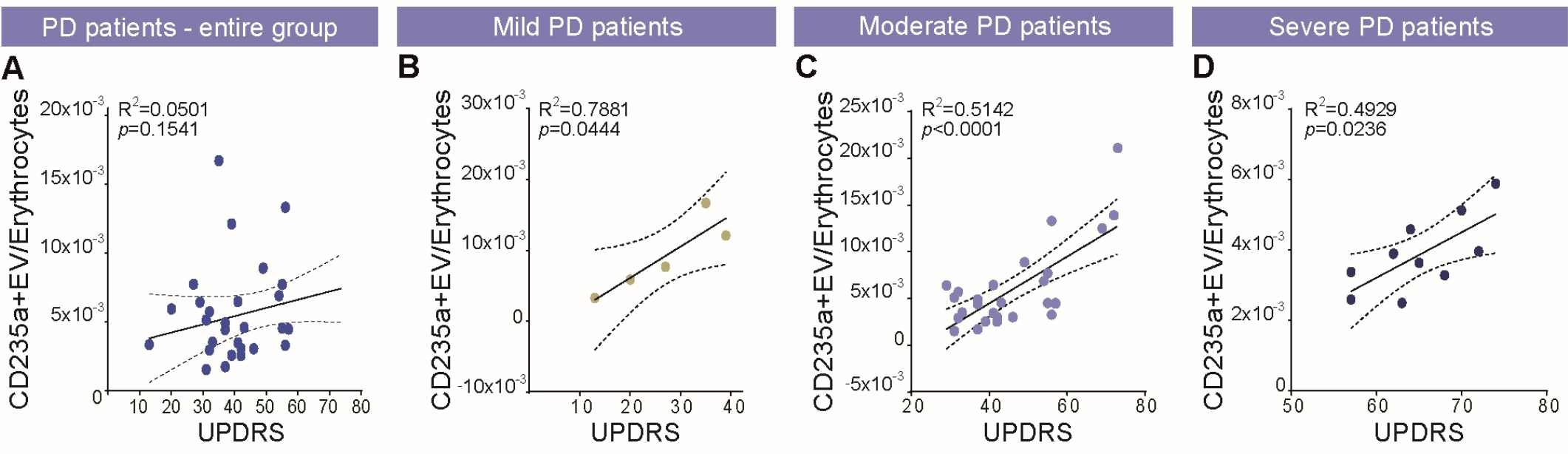

\begin{tabular}{|c|c|c|c|}
\hline Patient & EV/erythrocytes & UPDRS & LEDD \\
\hline P1 & $3,31 \mathrm{E}-03$ & 13 & $125 \mathrm{mg}$ \\
\hline P2 & $5,88 \mathrm{E}-03$ & 20 & $499 \mathrm{mg}$ \\
\hline P3 & $7,74 \mathrm{E}-03$ & 27 & $900 \mathrm{mg}$ \\
\hline P4 & $1,67 \mathrm{E}-02$ & 35 & $281 \mathrm{mg}$ \\
\hline P5 & $2,53 \mathrm{E}-03$ & 39 & $316 \mathrm{mg}$ \\
\hline P6 & $6,42 \mathrm{E}-03$ & 29 & $281 \mathrm{mg}$ \\
\hline P7 & $1,49 \mathrm{E}-03$ & 31 & $280 \mathrm{mg}$ \\
\hline P8 & $5,15 E-03$ & 31 & $375 \mathrm{mg}$ \\
\hline P9 & $5,74 \mathrm{E}-03$ & 32 & $441 \mathrm{mg}$ \\
\hline P10 & $2,94 \mathrm{E}-03$ & 32 & $188 \mathrm{mg}$ \\
\hline P11 & $3,47 \mathrm{E}-03$ & 33 & $3808 \mathrm{mg}$ \\
\hline P12 & $4,93 \mathrm{E}-03$ & 37 & $698,5 \mathrm{mg}$ \\
\hline P13 & $1,74 \mathrm{E}-03$ & 37 & $375 \mathrm{mg}$ \\
\hline P14 & $4,41 \mathrm{E}-03$ & 37 & $550 \mathrm{mg}$ \\
\hline P15 & $1,21 \mathrm{E}-02$ & 39 & $660 \mathrm{mg}$ \\
\hline P16 & $6,44 E-03$ & 41 & $300 \mathrm{mg}$ \\
\hline P17 & $3,43 E-03$ & 41 & $1364 \mathrm{mg}$ \\
\hline P18 & $3,03 E-03$ & 42 & $1000 \mathrm{mg}$ \\
\hline P19 & $2,51 \mathrm{E}-03$ & 42 & $3059 \mathrm{mg}$ \\
\hline P20 & $4,56 \mathrm{E}-03$ & 43 & $1238 \mathrm{mg}$ \\
\hline P21 & $3,00 E-03$ & 46 & $675 \mathrm{mg}$ \\
\hline
\end{tabular}

\begin{tabular}{|cccc|}
\hline Patient & EV/erythrocytes & UPDRS & LEDD \\
\hline P22 & $8,87 \mathrm{E}-03$ & 49 & nil \\
\hline P23 & $6,86 E-03$ & 54 & $500 \mathrm{mg}$ \\
\hline P24 & $7,68 E-03$ & 55 & $3126 \mathrm{mg}$ \\
\hline P25 & $4,51 \mathrm{E}-03$ & 55 & $769 \mathrm{mg}$ \\
\hline P26 & $1,33 \mathrm{E}-02$ & 56 & $450 \mathrm{mg}$ \\
\hline P27 & $3,26 \mathrm{E}-03$ & 56 & nil \\
\hline P28 & $4,50 \mathrm{E}-03$ & 57 & $757 \mathrm{mg}$ \\
\hline P29 & $3,38 \mathrm{E}-03$ & 57 & $5288 \mathrm{mg}$ \\
\hline P30 & $1,25 \mathrm{E}-02$ & 69 & $1100 \mathrm{mg}$ \\
\hline P31 & $3,97 \mathrm{E}-03$ & 72 & $540 \mathrm{mg}$ \\
\hline P32 & $2,11 \mathrm{E}-02$ & 73 & $2328 \mathrm{mg}$ \\
\hline P33 & $4,44 \mathrm{E}-03$ & 57 & $281 \mathrm{mg}$ \\
\hline P34 & $2,60 \mathrm{E}-03$ & 57 & $244 \mathrm{mg}$ \\
\hline P35 & $3,90 \mathrm{E}-03$ & 62 & $400 \mathrm{mg}$ \\
\hline P36 & $2,50 \mathrm{E}-03$ & 63 & $1019 \mathrm{mg}$ \\
\hline P37 & $4,59 \mathrm{E}-03$ & 64 & $600 \mathrm{mg}$ \\
\hline P38 & $3,64 \mathrm{E}-03$ & 65 & $1397 \mathrm{mg}$ \\
\hline P39 & $3,29 \mathrm{E}-03$ & 68 & $1550 \mathrm{mg}$ \\
\hline P40 & $5,13 \mathrm{E}-03$ & 70 & $1313 \mathrm{mg}$ \\
\hline P41 & $1,39 \mathrm{E}-02$ & 72 & $2694 \mathrm{mg}$ \\
\hline P42 & $5,89 \mathrm{E}-03$ & 74 & $600 \mathrm{mg}$ \\
\hline
\end{tabular}

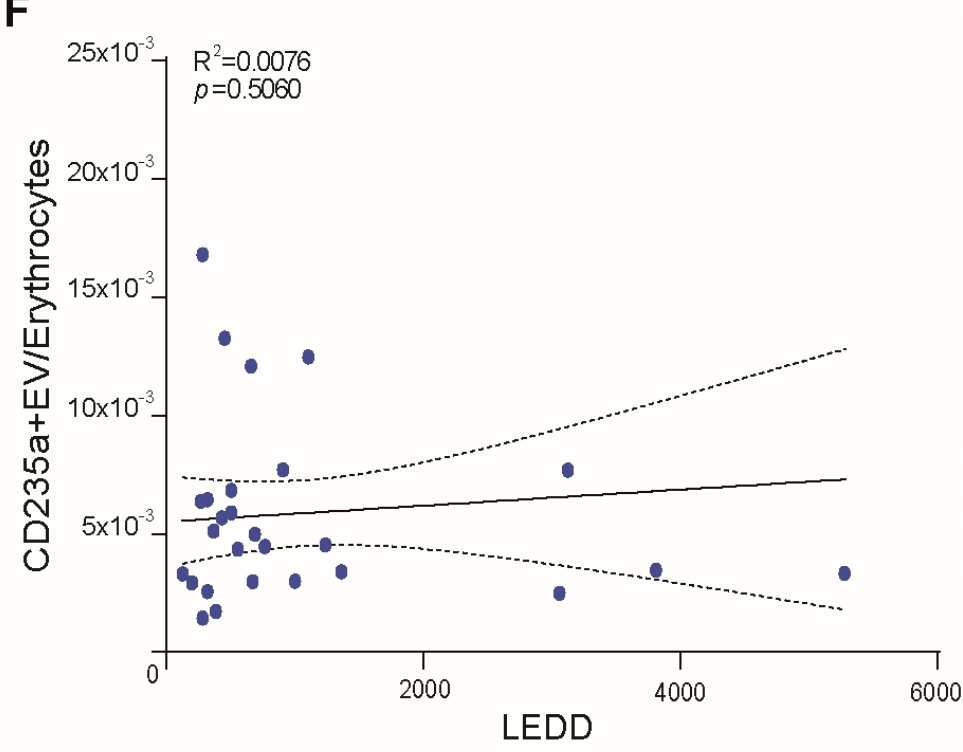


Figure S5.

A

Cell-derived EV quantification - HD cohort

\begin{tabular}{|c|c|c|c|c|c|c|c|c|c|c|c|c|}
\hline \multirow{2}{*}{ Cell types } & \multirow{2}{*}{ Markers } & \multirow{2}{*}{ Units } & \multicolumn{3}{|c|}{ CTRL } & \multicolumn{3}{|c|}{ HD pre-manifest } & \multicolumn{3}{|c|}{ HD } & \multirow{2}{*}{$p$ value } \\
\hline & & & $n$ & Mean & SEM & $n$ & Mean & SEM & $n$ & Mean & SEM & \\
\hline \multirow{4}{*}{ Erythrocytes } & CD235a+PS- & $10^{3} / \mu 1$ & 54 & 15.2 & 2.0 & 10 & 10.3 & 3.5 & 51 & 14.1 & 1.4 & 0.16 \\
\hline & CD235a+PS+ & $10^{3} / \mu l$ & 54 & 1.1 & 0.2 & 10 & 0.4 & 0.2 & 51 & 1.1 & 0.1 & 0.04 \\
\hline & CD235a+ total & $10^{3} / \mu l$ & 54 & 16.4 & 2.0 & 10 & 10.7 & 3.5 & 51 & 15.3 & 1.5 & 0.09 \\
\hline & EV CD235a+lerythrocyte & & 54 & 0.0035 & 0.0005 & 10 & 0.0023 & 0.0008 & 50 & 0.0033 & 0.0003 & 0.11 \\
\hline \multirow{3}{*}{ Platelets } & CD41+PS- & $10^{3} / \mu l$ & 54 & 9.2 & 2.2 & 10 & 4.3 & 1.3 & 50 & 6.1 & 1.0 & 0.78 \\
\hline & CD41+ total & $10^{3} / \mu l$ & 54 & 28.4 & 6.9 & 10 & 11.4 & 3.2 & 50 & 18.6 & 3.4 & 0.70 \\
\hline & EV CD41+/platelet & & 53 & 0.12 & 0.03 & 10 & 0.05 & 0.02 & 48 & 0.08 & 0.01 & 0.34 \\
\hline \multirow{3}{*}{$\begin{array}{l}\text { Endothelial } \\
\text { cells }\end{array}$} & CD31+CD41-PS- & $10^{3 / \mu l}$ & 54 & 1.4 & 0.3 & 10 & 0.6 & 0.2 & 50 & 1.2 & 0.2 & 0.31 \\
\hline & CD31+CD41-PS+ & $10^{3} / \mu l$ & 54 & 0.68 & 0.16 & 10 & 0.25 & 0.06 & 50 & 0.46 & 0.09 & 0.59 \\
\hline & CD31+CD41 - total & $10^{3 / \mu l}$ & 54 & 2.1 & 0.4 & 10 & 0.8 & 0.2 & 50 & 1.7 & 0.3 & 0.26 \\
\hline Leukocytes & CD45+ total & $10^{3 / \mu l}$ & 54 & 33.4 & 2.7 & 10 & 31.6 & 5.3 & 51 & 31.7 & 2.4 & 0.88 \\
\hline \multirow{5}{*}{ Monocytes } & CD45-CD14+ PS+ & $10^{3} / \mu l$ & 54 & 1.8 & 0.3 & 10 & 0.8 & 0.3 & 51 & 1.5 & 0.2 & 0.14 \\
\hline & CD45+CD14+ PS- & $10^{3 / \mu l}$ & 54 & 0.18 & 0.07 & 10 & 0.069 & 0.016 & 51 & 0.056 & 0.008 & 0.34 \\
\hline & CD45+CD14+PS+ & $10^{3} / \mu l$ & 54 & 0.62 & 0.12 & 10 & 0.24 & 0.06 & 51 & 0.55 & 0.14 & 0.12 \\
\hline & CD14+ total & $10^{3} / \mu l$ & 54 & 6.0 & 1.3 & 10 & 2.6 & 0.4 & 51 & 3.7 & 0.4 & 0.08 \\
\hline & EV CD14+/monocyte & & 53 & 12.3 & 2.5 & 10 & 5.7 & 0.6 & 48 & 8.0 & 1.0 & 0.13 \\
\hline \multirow{6}{*}{ Granulocytes } & CD45-CD15+ PS- & $10^{3} / \mu l$ & 54 & 1.2 & 0.1 & 10 & 1.2 & 0.3 & 51 & 1.5 & 0.2 & 0.33 \\
\hline & CD45-CD15+ PS+ & $10^{3} / \mu l$ & 54 & 0.12 & 0.04 & 10 & 0.18 & 0.08 & 51 & 0.22 & 0.11 & 0.33 \\
\hline & CD45+CD15+ PS- & $10^{3 / \mu l}$ & 54 & 0.20 & 0.05 & 10 & 0.07 & 0.02 & 51 & 0.15 & 0.04 & 0.64 \\
\hline & CD45+CD15+PS+ & $10^{3} / \mu l$ & 54 & 0.25 & 0.05 & 10 & 0.13 & 0.06 & 51 & 0.20 & 0.04 & 0.39 \\
\hline & CD15+ total & $10^{3} / \mu l$ & 54 & 1.7 & 0.2 & 10 & 1.6 & 0.4 & 51 & 0.20 & 0.3 & 0.67 \\
\hline & EV CD15+/granulocyte & & 53 & 0.41 & 0.04 & 10 & 0.42 & 0.13 & 48 & 0.50 & 0.08 & 0.75 \\
\hline
\end{tabular}

\section{Diagnostic value}

\section{B}

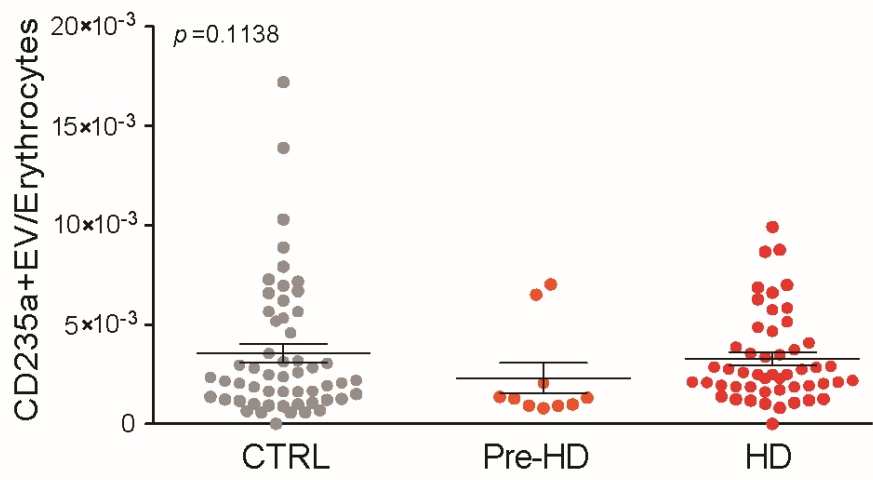

\section{EEV in relation to clinical measures}

C

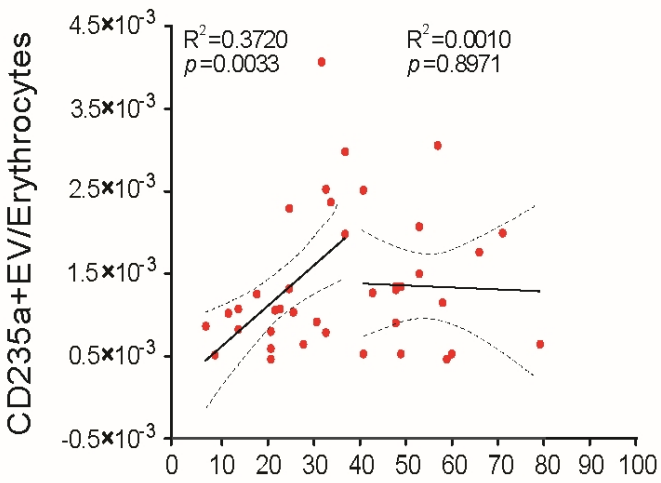

UHDRS 


\section{Figure S6.}

\section{A}

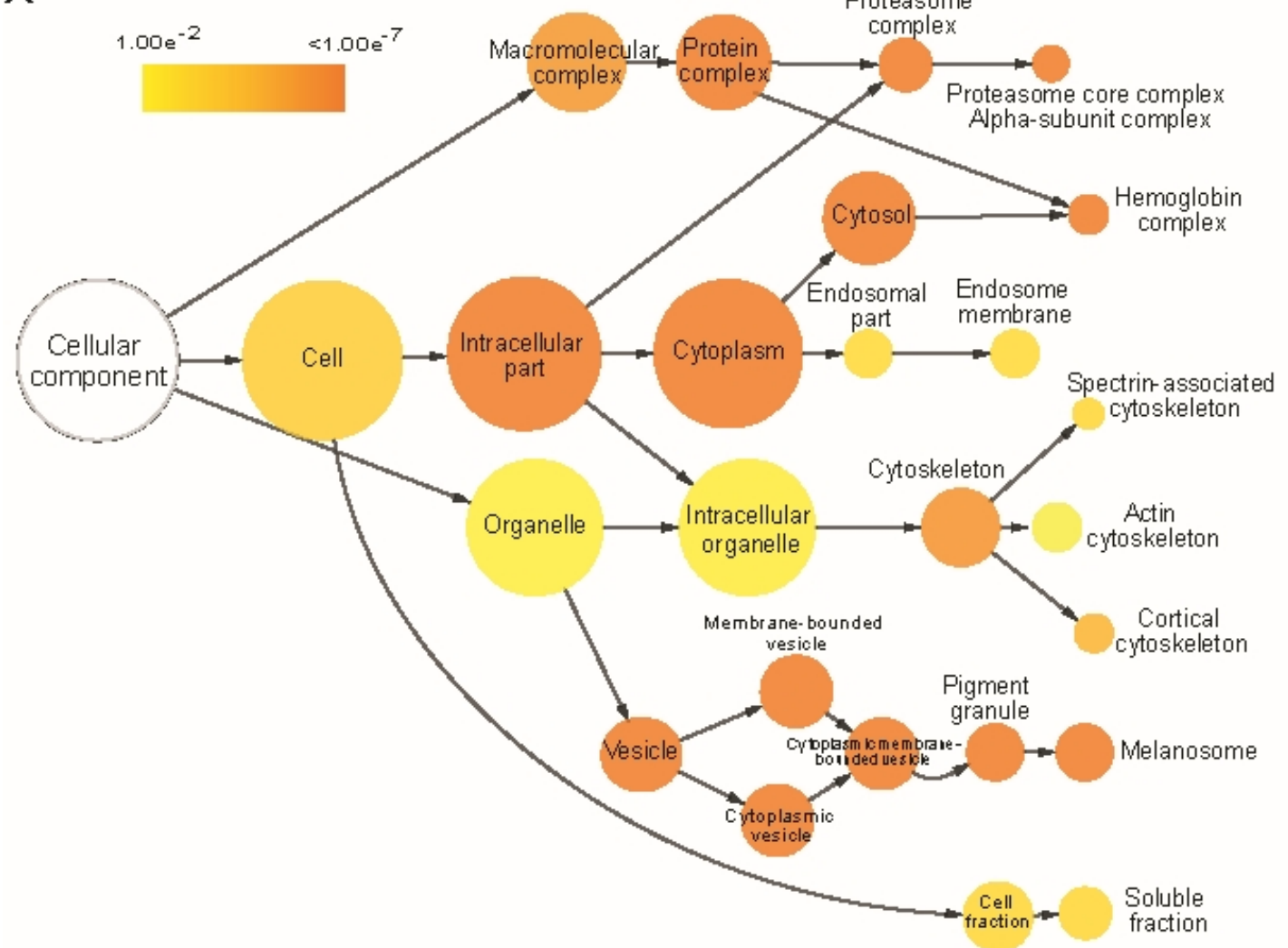

\section{B}

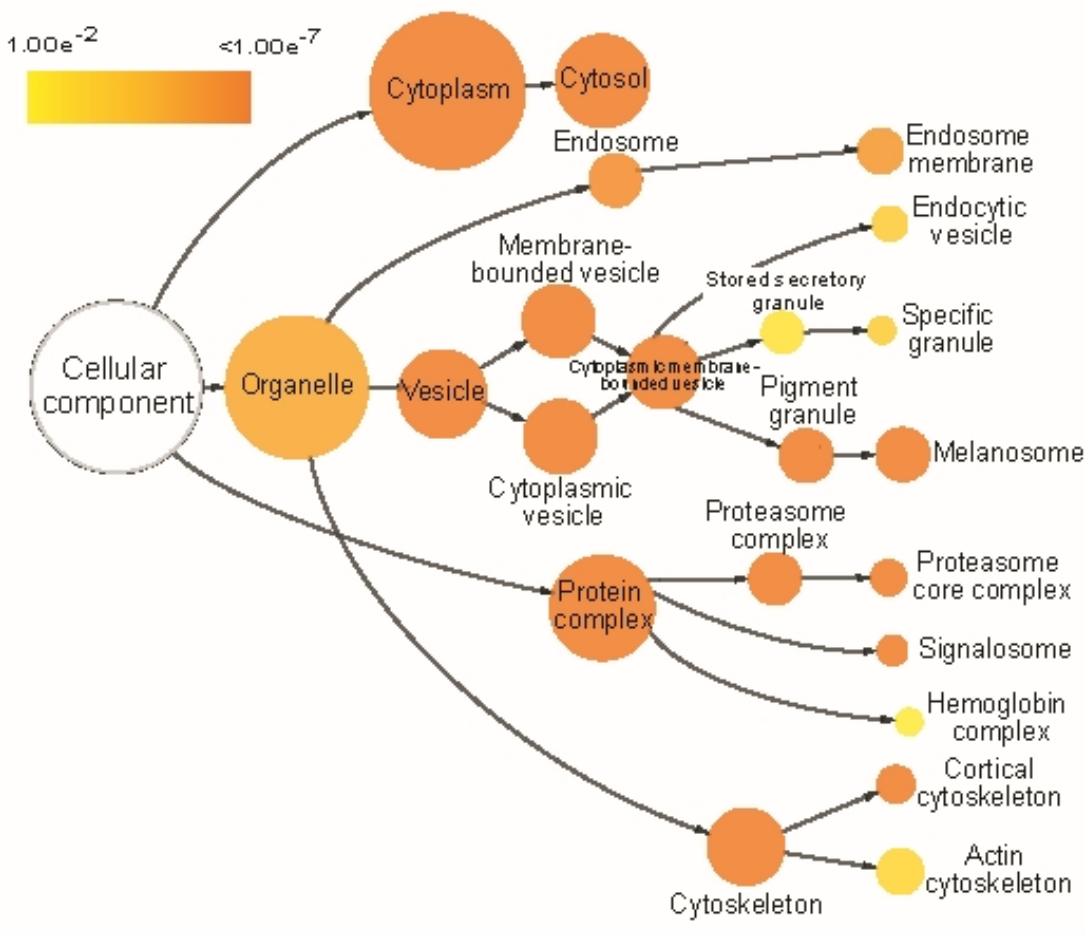


Table 1. Participant clinical information

\begin{tabular}{|c|c|c|c|c|c|c|}
\hline \multicolumn{7}{|c|}{ PD cohort } \\
\hline & \multirow{2}{*}{ CTRL } & \multicolumn{4}{|c|}{ PD Patients - Stages of disease } & \multirow[b]{2}{*}{$p$ value } \\
\hline & & Unknown & Mild & Moderate & Severe & \\
\hline$n$ & 37 & 7 & 12 & 33 & 8 & \\
\hline Age & 66.8 & 69.8 & 66.7 & 71.1 & $75.0^{*}$ & 0.04 \\
\hline Gender F (M) & $18(19)$ & $1(6)$ & $6(6)$ & $16(17)$ & $0(8)$ & 0.05 \\
\hline \multicolumn{7}{|l|}{ Disease severity } \\
\hline Hoehn \& Yahr (n) & & & $1 \pm 0.3(12)$ & $2 \pm 0.2(33)$ & $3 \pm 0.5(8)$ & $<0.0001$ \\
\hline UPDRS (n) & & & $38 \pm 11(6)$ & $52 \pm 19(17)$ & $73 \pm 20(6)$ & 0.02 \\
\hline MMSE (n) & & & $29 \pm 2(7)$ & $29 \pm 1(19)$ & $26 \pm 3(6)$ & 0.01 \\
\hline BDI $(n)$ & & & $3 \pm 2(6)$ & $4 \pm 2(17)$ & $13 \pm 7(4)$ & 0.03 \\
\hline $\operatorname{ACE}(n)$ & & & $96 \pm 4(6)$ & $92 \pm 7(17)$ & $84 \pm 14(6)$ & 0.13 \\
\hline \multicolumn{7}{|l|}{ Comorbidities } \\
\hline Depression & 3 & 1 & 2 & 1 & 2 & 0.29 \\
\hline Cancer & 5 & 0 & 3 & 4 & 1 & 0.64 \\
\hline Diabetes & 2 & 0 & 0 & 1 & 2 & 0.10 \\
\hline Hypertension & 10 & 1 & 2 & 10 & 3 & 0.76 \\
\hline Hypercholesterolemia & 5 & 0 & 1 & 6 & 1 & 0.73 \\
\hline Asthma & 3 & 1 & 1 & 5 & 0 & 0.71 \\
\hline Allergies & 2 & 0 & 2 & 6 & 2 & 0.28 \\
\hline
\end{tabular}

Table 1. Participant clinical information - PD cohort. Disease severity as measured using the H\&Y scale (score): Mild (1-1.5); Moderate (2-2.5); Severe (3-3.5). ${ }^{*} p<0.05$ vs. CTRL. Statistical analyses were performed using a Kruskal Wallis test followed by Dunn's multiple comparison test. 
Table S1. Participant clinical information

\section{HD cohort}

\begin{tabular}{|c|c|c|c|c|c|c|c|c|}
\hline & \multirow{2}{*}{ CTRL } & \multicolumn{7}{|c|}{ HD Patients - Stages of disease } \\
\hline & & Pre-HD & Stage 1 & Stage 2 & Stage 3 & Stage 4 & Stage 5 & $p$ value \\
\hline$n$ & 55 & 11 & 15 & 13 & 12 & 10 & 2 & \\
\hline Age & 55.0 & 37.5 & 53.1 & 54.2 & 58.3 & 58.1 & 55.5 & 0.02 \\
\hline Gender F (M) & $31(22)$ & $6(5)$ & $5(10)$ & $4(9)$ & $8(4)$ & $7(3)$ & $1(1)$ & 0.26 \\
\hline \multicolumn{9}{|l|}{ Disease severity } \\
\hline CAG $(n)$ & $28.3(3)$ & $41.1(10)$ & $42.3(13)$ & $42.6(12)$ & $43.7(7)$ & $44.3(7)$ & & $<0.001$ \\
\hline UHDRS (n) & & $2.7(11)$ & $15.7(14)$ & $34.5(11)$ & $42.9(12)$ & $55.9(10)$ & $67.5(2)$ & $<0.001$ \\
\hline $\operatorname{TFC}(n)$ & $13(16)$ & $13(11)$ & $12.5(15)$ & $7.8(13)$ & $4.3(12)$ & $1.6(10)$ & $0(2)$ & $<0.001$ \\
\hline $\operatorname{BDS}(n)$ & & $206(10)$ & 337 (13) & $356(12)$ & $442(7)$ & $465(7)$ & & $<0.001$ \\
\hline \multicolumn{9}{|l|}{ Comorbidities } \\
\hline Depression & 8 & 1 & 1 & 3 & 6 & 4 & 1 & 0.0497 \\
\hline Cancer & 0 & 0 & 0 & 0 & 0 & 0 & 0 & \\
\hline Diabetes & 3 & 1 & 1 & 1 & 1 & 1 & 0 & 0.99 \\
\hline Hypertension & 4 & 1 & 2 & 1 & 1 & 2 & 0 & 0.92 \\
\hline Hypercholesterolemia & 8 & 1 & 1 & 0 & 0 & 1 & 0 & 0.32 \\
\hline Asthma & 0 & 0 & 1 & 0 & 0 & 0 & 0 & 0.65 \\
\hline Allergies & 3 & 0 & 2 & 2 & 0 & 0 & 0 & 0.33 \\
\hline
\end{tabular}

\begin{tabular}{|c|c|c|c|c|c|c|c|c|c|c|c|c|c|c|c|c|c|c|c|c|c|c|c|}
\hline \multicolumn{24}{|c|}{ Blood cell quantification } \\
\hline \multirow{2}{*}{ Cell type } & \multirow{2}{*}{ Units } & \multicolumn{3}{|c|}{ CTRL } & \multicolumn{3}{|c|}{ Pre-HD } & \multicolumn{3}{|c|}{ Stage 1} & \multicolumn{3}{|c|}{ Stage 2} & \multicolumn{3}{|c|}{ Stage 3} & \multicolumn{3}{|c|}{ Stage 4} & \multicolumn{3}{|c|}{ Stage 5} & \multirow{2}{*}{$p$ value } \\
\hline & & $n$ & Mean & SD & $n$ & Mean & SD & $n$ & Mean & SD & $n$ & Mean & SD & $n$ & Mean & SD & $\mathrm{n}$ & Mean & SD & $\mathrm{n}$ & Mean & SD & \\
\hline Erythrocytes & $10 \% \mathrm{ml}$ & 54 & 4.58 & 0.36 & 10 & 4.59 & 0.36 & 15 & 4.75 & 0.37 & 12 & 4.56 & 0.29 & 11 & 4.69 & 0.44 & 10 & 4.76 & 0.39 & 2 & 4.35 & 0.26 & 0.44 \\
\hline Platelets & $10 \% \mathrm{ml}$ & 54 & 229 & 51 & 10 & 259 & 85 & 15 & 232 & 68 & 12 & 218 & 54 & 11 & 268 & 63 & 10 & 212 & 46 & 2 & 305 & 55 & 0.09 \\
\hline Leukocytes & $106 / \mathrm{ml}$ & 54 & 6.61 & 1.60 & 10 & 6.97 & 1.64 & 15 & 6.30 & 1.13 & 12 & 7.67 & 2.97 & 11 & 6.97 & 2.00 & 10 & 6.84 & 2.07 & 2 & 5.30 & 1.56 & 0.47 \\
\hline Monocytes & $10^{6 / \mathrm{ml}}$ & 54 & 0.51 & 0.16 & 10 & 0.48 & 0.57 & 15 & 0.49 & 0.50 & 12 & 0.55 & 0.18 & 11 & 0.58 & 0.24 & & 0.51 & 0.16 & 2 & 0.61 & 0.42 & 0.79 \\
\hline
\end{tabular}

Table S1. Participant clinical information - HD cohort. Disease severity levels in relation to the TFC scale: Stage 1 (11-13); Stage 2 (7-10); Stage 3 (3-6); Stage 4 (1-2); Stage 5 (0). Disease severity was evaluated within 6 months of blood sampling. Comorbidities were determined from medical information reported by the participant or caregiver. Blood cell quantification. Full blood counts performed in HD patients at different stages of the disease (Pre-HD, n=10; Stage 1, $n=15$; Stage 2, $n=12$; Stage 3, $n=11$; Stage 4, $n=10$; Stage 5, n=2) revealed no significant differences in the total number of any cell type between patients and their respective healthy sex- and age-matched CTRL ( $n=54)$, except for erythrocytes. Statistical analyses were performed using a Kruskal Wallis test followed by Dunn's multiple comparison test. 


\section{Table S2. Participant clinical information}

\begin{tabular}{|c|c|c|c|c|}
\hline \multicolumn{5}{|c|}{ PD cohort - cohort 2} \\
\hline & \multicolumn{4}{|c|}{ PD Patients - Stages of disease } \\
\hline & Mild & Moderate & Severe & p value \\
\hline$n$ & 5 & 27 & 10 & \\
\hline Age & 63.4 & 68.5 & 71.3 & 0.26 \\
\hline Gender F (M) & $2(3)$ & $11(16)$ & $4(6)$ & 0.99 \\
\hline \multicolumn{5}{|l|}{ Disease severity } \\
\hline UPDRS (n) & $27 \pm 8(5)$ & $46 \pm 11(27)$ & $71(10)$ & $<0.0001$ \\
\hline \multicolumn{5}{|l|}{ Comorbidities } \\
\hline Depression & 0 & 5 & 1 & 0.51 \\
\hline Cancer & 0 & 0 & 0 & NA \\
\hline Diabetes & 0 & 0 & 0 & NA \\
\hline Hypertension & 0 & 3 & 0 & 0.42 \\
\hline Hypercholesterolemia & 0 & 3 & 0 & 0.42 \\
\hline Asthma & 0 & 2 & 0 & 0.56 \\
\hline Allergies & 0 & 1 & 0 & 0.75 \\
\hline
\end{tabular}

Table S2. Participant clinical information - PD cohort no.2. Disease severity as measured using the UPDRS scale (score): Mild (0,39); Moderate $(29,73)$; Severe $(57,74) .{ }^{*} p<0.05$ vs. CTRL. Statistical analyses were performed using a Kruskal Wallis test followed by Dunn's multiple comparison test. 


\section{Table S3. Complete list of proteins identified in the EVV proteome}

\section{A. Uniprot Complete Proteome Homo sapiens database for the non-depleted sample}

\begin{tabular}{|c|c|c|c|}
\hline $\begin{array}{c}\text { Protein } \\
\text { ID }\end{array}$ & Protein names & $\begin{array}{c}\text { Gene } \\
\text { names }\end{array}$ & $\begin{array}{c}\text { Razor + } \\
\text { unique } \\
\text { peptides }\end{array}$ \\
\hline P02549 & Spectrin alpha chain, erythrocytic 1 & SPTA1 & 136 \\
\hline P11277 & Spectrin beta chain, erythrocytic & SPTB & 123 \\
\hline P16157 & Ankyrin-1 & ANK1 & 70 \\
\hline P02730 & Band 3 anion transport protein & SLC4A1 & 38 \\
\hline P55072 & Transitional endoplasmic reticulum ATPase & VCP & 33 \\
\hline P16452 & Erythrocyte membrane protein band 4.2 & EPB42 & 33 \\
\hline P11171 & Protein 4.1 & EPB41 & 33 \\
\hline P04040 & Catalase & CAT & 32 \\
\hline Q13228 & Selenium-binding protein 1 & SELENBP1 & 29 \\
\hline B4DT77 & Annexin;Annexin A7 & ANXA7 & 27 \\
\hline Q8WUM4 & Programmed cell death 6-interacting protein & PDCD6IP & 27 \\
\hline P35612 & Beta-adducin & ADD2 & 26 \\
\hline P68871 & Hemoglobin subunit beta;LVV-hemorphin-7;Spinorphin & HBB & 25 \\
\hline Q00610 & Clathrin heavy chain 1 & CLTC & 25 \\
\hline P69905 & Hemoglobin subunit alpha & HBA1 & 22 \\
\hline B4DVE7 & Annexin A11 & ANXA11 & 20 \\
\hline J3QLD9 & Flotillin-2 & FLOT2 & 20 \\
\hline P08758 & Annexin A5;Annexin & ANXA5 & 19 \\
\hline P09525 & Annexin A4;Annexin & ANXA4 & 18 \\
\hline O75955; & Flotillin-1 & FLOT1 & 18 \\
\hline $\mathrm{P} 11142$ & Heat shock cognate $71 \mathrm{kDa}$ protein & HSPA8 & 18 \\
\hline P32119 & Peroxiredoxin-2 & PRDX2 & 17 \\
\hline P00491 & Purine nucleoside phosphorylase & PNP & 17 \\
\hline P27105 & Erythrocyte band 7 integral membrane protein & STOM & 17 \\
\hline P00918 & Carbonic anhydrase 2 & CA2 & 17 \\
\hline P23634 & Plasma membrane calcium-transporting ATPase 4 & ATP2B4 & 17 \\
\hline C9JIF9 & Acylamino-acid-releasing enzyme & APEH & 17 \\
\hline P00915 & Carbonic anhydrase 1 & CA1 & 16 \\
\hline P63261 & Actin, cytoplasmic 2 & ACTG1 & 16 \\
\hline Q5VU58 & Tropomyosin alpha-3 chain & TPM3 & 16 \\
\hline P30041 & Peroxiredoxin-6 & PRDX6 & 16 \\
\hline E7EU23 & Rab GDP dissociation inhibitor beta & GDI2 & 16 \\
\hline Q00013 & $55 \mathrm{kDa}$ erythrocyte membrane protein & MPP1 & 16 \\
\hline E7EV01 & Calpain-5 & CAPN5 & 16 \\
\hline J3KPS3 & Fructose-bisphosphate aldolase A & ALDOA & 15 \\
\hline Q08495 & Dematin & DMTN & 15 \\
\hline P23276 & Kell blood group glycoprotein & KEL & 15 \\
\hline P69892 & Hemoglobin subunit gamma-2 & HBG2 & 14 \\
\hline
\end{tabular}




\begin{tabular}{|c|c|c|c|}
\hline P60174 & Triosephosphate isomerase & TPI1 & 14 \\
\hline P62258 & 14-3-3 protein epsilon & YWHAE & 14 \\
\hline 075326 & Semaphorin-7A & SEMA7A & 14 \\
\hline O75340 & Programmed cell death protein 6 & PDCD6 & 13 \\
\hline E7EV99 & Alpha-adducin & ADD1 & 13 \\
\hline Q5VZU9 & Tripeptidyl-peptidase 2 & TPP2 & 13 \\
\hline P53396 & ATP-citrate synthase & ACLY & 13 \\
\hline C9J0K6 & Sorcin & SRI & 12 \\
\hline P04406 & Glyceraldehyde-3-phosphate dehydrogenase & GAPDH & 12 \\
\hline P07738 & Bisphosphoglycerate mutase & BPGM & 12 \\
\hline B7Z3I9 & Delta-aminolevulinic acid dehydratase & ALAD & 12 \\
\hline Q86X55 & Histone-arginine methyltransferase CARM1 & CARM1 & 12 \\
\hline P07195 & L-lactate dehydrogenase B chain;L-lactate dehydrogenase & LDHB & 12 \\
\hline P23526 & Adenosylhomocysteinase & $\mathrm{AHCY}$ & 12 \\
\hline Q32Q12 & Nucleoside diphosphate kinase & NME1-NME2 & 12 \\
\hline B7Z7A9 & Phosphoglycerate kinase 1 & PGK1 & 11 \\
\hline P11166 & Solute carrier family 2 , facilitated glucose transporter member 1 & SLC2A1 & 11 \\
\hline P22303 & Acetylcholinesterase & $\mathrm{ACHE}$ & 11 \\
\hline Q9NP58 & ATP-binding cassette sub-family B member 6 , mitochondrial & ABCB6 & 11 \\
\hline P40925 & Malate dehydrogenase, cytoplasmic;Malate dehydrogenase & $\mathrm{MDH} 1$ & 11 \\
\hline P00352 & Retinal dehydrogenase 1 & ALDH1A1 & 11 \\
\hline F2Z2V0 & Copine-1 & CPNE1 & 11 \\
\hline K7EMC9 & WW domain-binding protein 2 & WBP2 & 10 \\
\hline F5H7S3 & Tropomyosin alpha-1 chain & TPM1 & 10 \\
\hline A6NN80 & Annexin A6;Annexin & ANXA6 & 10 \\
\hline P30043 & Flavin reductase (NADPH) & BLVRB & 9 \\
\hline H7BXD5 & Grancalcin & GCA & 9 \\
\hline P04083 & Annexin A1;Annexin & ANXA1 & 9 \\
\hline P62937 & Peptidyl-prolyl cis-trans isomerase & PPIA & 9 \\
\hline P37837 & Transaldolase & TALDO1 & 9 \\
\hline Q06830 & Peroxiredoxin-1 & PRDX1 & 9 \\
\hline O75131 & Copine-3 & CPNE3 & 9 \\
\hline P00390 & Glutathione reductase, mitochondrial & GSR & 9 \\
\hline E7EQB2 & Lactotransferrin & LTF & 9 \\
\hline P07384 & Calpain-1 catalytic subunit & CAPN1 & 9 \\
\hline P02042 & Hemoglobin subunit delta & HBD & 8 \\
\hline P30086 & $\begin{array}{c}\text { Phosphatidylethanolamine-binding protein 1;Hippocampal cholinergic neurostimulating } \\
\text { peptide }\end{array}$ & PEBP1 & 8 \\
\hline P35613 & Basigin & BSG & 8 \\
\hline Q9H0U4 & Ras-related protein Rab-1B;Putative Ras-related protein Rab-1C & $\begin{array}{l}\text { RAB1B;RAB1 } \\
\text { C }\end{array}$ & 8 \\
\hline P63092 & Guanine nucleotide-binding protein $\mathrm{G}(\mathrm{s})$ subunit alpha isoforms & GNAS & 8 \\
\hline P48506 & Glutamate--cysteine ligase catalytic subunit & GCLC & 8 \\
\hline P06702 & Protein S100-A9 & S100A9 & 7 \\
\hline Q9UBV8 & Peflin & PEF1 & 7 \\
\hline P17931 & Galectin-3;Galectin & LGALS3 & 7 \\
\hline
\end{tabular}




\begin{tabular}{|c|c|c|c|}
\hline P28066 & Proteasome subunit alpha type- 5 & PSMA5 & 7 \\
\hline P07451 & Carbonic anhydrase 3 & CA3 & 7 \\
\hline E7EQ12 & Calpastatin & CAST & 7 \\
\hline P50895 & Basal cell adhesion molecule & BCAM & 7 \\
\hline P28074 & Proteasome subunit beta type- 5 & PSMB5 & 7 \\
\hline G3V5Z7 & Proteasome subunit alpha type;Proteasome subunit alpha type- 6 & PSMA6 & 7 \\
\hline P25786 & Proteasome subunit alpha type-1 & PSMA1 & 7 \\
\hline G3V1D3 & Dipeptidyl peptidase 3 & DPP3 & 7 \\
\hline P49247 & Ribose-5-phosphate isomerase & RPIA & 7 \\
\hline Q5T9B7 & Adenylate kinase isoenzyme 1 & AK1 & 7 \\
\hline P25789 & Proteasome subunit alpha type- 4 ; Proteasome subunit beta type & PSMA4 & 7 \\
\hline B4E022 & Transketolase & TKT & 7 \\
\hline J3QS39 & $\begin{array}{l}\text { Ubiquitin-60S ribosomal protein L40;Ubiquitin;60S ribosomal protein L40;Ubiquitin-40S } \\
\text { ribosomal protein S27a;Ubiquitin;40S ribosomal protein S27a;Polyubiquitin- } \\
\text { B;Ubiquitin;Polyubiquitin-C;Ubiquitin }\end{array}$ & $\begin{array}{l}\text { UBB;RPS27A } \\
\text {;UBC;UBA52; } \\
\text { UBBP4 }\end{array}$ & 6 \\
\hline H0Y7A7 & Calmodulin & CALM2 & 6 \\
\hline P28070 & Proteasome subunit beta type- 4 & PSMB4 & 6 \\
\hline Q9H4G4 & Golgi-associated plant pathogenesis-related protein 1 & GLIPR2 & 6 \\
\hline Q9BY43 & Charged multivesicular body protein $4 a$ & CHMP4A & 6 \\
\hline P48426 & Phosphatidylinositol 5-phosphate 4-kinase type-2 alpha & PIP4K2A & 6 \\
\hline P28289 & Tropomodulin-1 & TMOD1 & 6 \\
\hline P07911 & Uromodulin;Uromodulin, secreted form & UMOD & 6 \\
\hline Q9GZP4 & PITH domain-containing protein 1 & PITHD1 & 6 \\
\hline P78417 & Glutathione S-transferase omega-1 & GSTO1 & 6 \\
\hline P25788 & Proteasome subunit alpha type-3 & PSMA3 & 6 \\
\hline O14818 & Proteasome subunit alpha type-7;Proteasome subunit alpha type-7-like & $\begin{array}{l}\text { PSMA7;PSM } \\
\text { A8 }\end{array}$ & 6 \\
\hline P08107 & Heat shock $70 \mathrm{kDa}$ protein $1 \mathrm{~A} / 1 \mathrm{~B}$ & HSPA1A & 6 \\
\hline H0YD13 & CD44 antigen & CD44 & 6 \\
\hline P61225 & Ras-related protein Rap-2b;Ras-related protein Rap-2c;Ras-related protein Rap-2a & $\begin{array}{l}\text { RAP2B;RAP2 } \\
\text { A;RAP2C }\end{array}$ & 6 \\
\hline P05109 & Protein S100-A8;Protein S100-A8, N-terminally processed & S100A8 & 6 \\
\hline P23528 & Cofilin-1 & CFL1 & 6 \\
\hline Q99808 & Equilibrative nucleoside transporter 1 & SLC29A1 & 6 \\
\hline P84077 & $\begin{array}{l}\text { ADP-ribosylation factor 1;ADP-ribosylation factor 3;ADP-ribosylation factor 5;ADP-ribosylation } \\
\text { factor } 4\end{array}$ & $\begin{array}{l}\text { ARF1;ARF3;A } \\
\text { RF5;ARF4 }\end{array}$ & 6 \\
\hline P31946 & 14-3-3 protein beta/alpha;14-3-3 protein beta/alpha, N-terminally processed & YWHAB & 6 \\
\hline C9JIS1 & $\begin{array}{l}\text { Guanine nucleotide-binding protein } \mathrm{G}(\mathrm{I}) / \mathrm{G}(\mathrm{S}) / \mathrm{G}(\mathrm{T}) \text { subunit beta-2;Guanine nucleotide-binding } \\
\text { protein subunit beta-4 }\end{array}$ & GNB2;GNB4 & 6 \\
\hline P53990 & IST1 homolog & IST1 & 6 \\
\hline Q99497 & Protein DJ-1 & PARK7 & 6 \\
\hline F5H7U0 & 6-phosphogluconate dehydrogenase, decarboxylating & PGD & 6 \\
\hline B7Z7E9 & Aspartate aminotransferase, cytoplasmic & GOT1 & 6 \\
\hline P62834 & $\begin{array}{l}\text { Ras-related protein Rap-1A;Ras-related protein Rap-1b;Ras-related protein Rap-1b-like } \\
\text { protein }\end{array}$ & $\begin{array}{l}\text { RAP1A;RAP1 } \\
\text { B }\end{array}$ & 6 \\
\hline P04899 & Guanine nucleotide-binding protein G(i) subunit alpha-2 & GNAI2 & 6 \\
\hline P25325 & 3-mercaptopyruvate sulfurtransferase;Sulfurtransferase & MPST & 6 \\
\hline Q9NP79 & Vacuolar protein sorting-associated protein VTA1 homolog & VTA1 & 6 \\
\hline P00492 & Hypoxanthine-guanine phosphoribosyltransferase & HPRT1 & 6 \\
\hline
\end{tabular}




\begin{tabular}{|c|c|c|c|}
\hline Q16531 & DNA damage-binding protein 1 & DDB1 & 6 \\
\hline P22314 & Ubiquitin-like modifier-activating enzyme 1 & UBA1 & 6 \\
\hline P00441 & Superoxide dismutase [Cu-Zn] & SOD1 & 5 \\
\hline H7BY58 & $\begin{array}{l}\text { Protein-L-isoaspartate O-methyltransferase;Protein-L-isoaspartate(D-aspartate) O- } \\
\text { methyltransferase }\end{array}$ & PCMT1 & 5 \\
\hline P10768 & S-formylglutathione hydrolase & ESD & 5 \\
\hline P09543 & 2,3-cyclic-nucleotide 3-phosphodiesterase & CNP & 5 \\
\hline P06733 & Alpha-enolase;Enolase & ENO1 & 5 \\
\hline P26038 & Moesin & MSN & 5 \\
\hline O75368 & $\mathrm{SH} 3$ domain-binding glutamic acid-rich-like protein & SH3BGRL & 5 \\
\hline K7EQ48 & Glucose-6-phosphate isomerase & GPI & 5 \\
\hline P25787 & Proteasome subunit alpha type-2 & PSMA2 & 5 \\
\hline P49721 & Proteasome subunit beta type- 2 & PSMB2 & 5 \\
\hline F5H8J2 & Protein disulfide-isomerase & $\mathrm{P} 4 \mathrm{HB}$ & 5 \\
\hline C9J9P4 & Phospholipid scramblase 1 & PLSCR1 & 5 \\
\hline P09211 & Glutathione S-transferase P & GSTP1 & 5 \\
\hline B5MDF5 & GTP-binding nuclear protein Ran & RAN & 5 \\
\hline P07900 & Heat shock protein HSP 90-alpha & HSP90AA1 & 5 \\
\hline K7EQ02 & DAZ-associated protein 1 & DAZAP1 & 5 \\
\hline Q13630 & GDP-L-fucose synthase & TSTA3 & 5 \\
\hline F5H0T1 & Stress-induced-phosphoprotein 1 & STIP1 & 5 \\
\hline P50502 & Hsc70-interacting protein;Putative protein FAM10A5;Putative protein FAM10A4 & $\begin{array}{l}\text { ST13;ST13P5 } \\
\text {;ST13P4 }\end{array}$ & 5 \\
\hline P20618 & Proteasome subunit beta type- 1 & PSMB1 & 5 \\
\hline P62805 & Histone H4 & HIST1H4A & 5 \\
\hline P51148 & Ras-related protein Rab-5C & RAB5C & 5 \\
\hline $\mathrm{H} 7 \mathrm{C} 2 \mathrm{G} 2$ & Ecto-ADP-ribosyltransferase 4 & ART4 & 5 \\
\hline J3KQ18 & D-dopachrome decarboxylase;D-dopachrome decarboxylase-like protein & DDT;DDTL & 5 \\
\hline H3BPK3 & Hydroxyacylglutathione hydrolase, mitochondrial & HAGH & 5 \\
\hline B4DIT7 & Protein-glutamine gamma-glutamyltransferase 2 & TGM2 & 5 \\
\hline O43633 & Charged multivesicular body protein $2 a$ & CHMP2A & 5 \\
\hline B4DQH4 & T-complex protein 1 subunit theta & ССТ8 & 5 \\
\hline Q9UN37 & Vacuolar protein sorting-associated protein $4 \mathrm{~A}$ & VPS4A & 5 \\
\hline I3L397 & Eukaryotic translation initiation factor $5 \mathrm{~A}-1$; Eukaryotic translation initiation factor $5 \mathrm{~A}-1$-like & $\begin{array}{l}\text { EIF5A;EIF5A } \\
\text { L1 }\end{array}$ & 5 \\
\hline Q9Y5Z4 & Heme-binding protein 2 & HEBP2 & 5 \\
\hline Q9UKV8 & Protein argonaute-2 & AGO2 & 5 \\
\hline $\mathrm{F} 5 \mathrm{H} 442$ & Tumor susceptibility gene 101 protein & TSG101 & 5 \\
\hline H3BLV0 & Complement decay-accelerating factor & CD55 & 5 \\
\hline P02008 & Hemoglobin subunit zeta & HBZ & 5 \\
\hline E7EPV7 & Alpha-synuclein & SNCA & 4 \\
\hline P63104 & 14-3-3 protein zeta/delta & YWHAZ & 4 \\
\hline P02724 & Glycophorin-A & GYPA;GPErik & 4 \\
\hline U3KQE2 & Calpain small subunit 1 & CAPNS1 & 4 \\
\hline Q9NP59 & Solute carrier family 40 member 1 & SLC40A1 & 4 \\
\hline Q5QPM9 & Proteasome inhibitor PI31 subunit & PSMF1 & 4 \\
\hline C9J8U2 & Nicotinate phosphoribosyltransferase & NAPRT & 4 \\
\hline
\end{tabular}




\begin{tabular}{|c|c|c|c|}
\hline P61981 & 14-3-3 protein gamma;14-3-3 protein gamma, $\mathrm{N}$-terminally processed & YWHAG & 4 \\
\hline Q9UQ80 & Proliferation-associated protein $2 \mathrm{G} 4$ & PA2G4 & 4 \\
\hline E5RJR5 & S-phase kinase-associated protein 1 & SKP1 & 4 \\
\hline Q9NRV9 & Heme-binding protein 1 & HEBP1 & 4 \\
\hline Q9H444 & Charged multivesicular body protein $4 \mathrm{~b}$ & CHMP4B & 4 \\
\hline P10599 & Thioredoxin & TXN & 4 \\
\hline Q5VSJ9 & Blood group Rh(CE) polypeptide;Blood group Rh(D) polypeptide & RHCE;RHD & 4 \\
\hline Q9UK41 & Vacuolar protein sorting-associated protein 28 homolog & VPS28 & 4 \\
\hline Q9Y3I1 & F-box only protein 7 & FBXO7 & 4 \\
\hline P61026 & Ras-related protein Rab-10 & RAB10 & 4 \\
\hline Q14974 & Importin subunit beta-1 & KPNB1 & 4 \\
\hline P27797 & Calreticulin & CALR & 4 \\
\hline P18669 & Phosphoglycerate mutase 1 ;Probable phosphoglycerate mutase 4 & $\begin{array}{l}\text { PGAM1;PGA } \\
\text { M4 }\end{array}$ & 4 \\
\hline P54725 & UV excision repair protein RAD23 homolog A & RAD23A & 4 \\
\hline P30613 & Pyruvate kinase PKLR & PKLR & 4 \\
\hline P63000 & $\begin{array}{l}\text { Ras-related C3 botulinum toxin substrate 1;Ras-related C3 botulinum toxin substrate 3;Ras- } \\
\text { related C3 botulinum toxin substrate } 2\end{array}$ & $\begin{array}{l}\text { RAC1; RAC3; } \\
\text { RAC2 }\end{array}$ & 4 \\
\hline P05164 & Myeloperoxidase & MPO & 4 \\
\hline F5GWY2 & $\begin{array}{l}\text { Bifunctional purine biosynthesis protein PURH;Phosphoribosylaminoimidazolecarboxamide } \\
\text { formyltransferase;IMP cyclohydrolase }\end{array}$ & ATIC & 4 \\
\hline P48637 & Glutathione synthetase & GSS & 4 \\
\hline F5H5V4 & 26S proteasome non-ATPase regulatory subunit 9 & PSMD9 & 4 \\
\hline G5E9R5 & Low molecular weight phosphotyrosine protein phosphatase & ACP1 & 3 \\
\hline P46976 & Glycogenin-1 & GYG1 & 3 \\
\hline P28072 & Proteasome subunit beta type- 6 & PSMB6 & 3 \\
\hline P26447 & Protein S100-A4 & S100A4 & 3 \\
\hline F5GXQ0 & BRO1 domain-containing protein BROX & BROX & 3 \\
\hline P08754 & Guanine nucleotide-binding protein $G(k)$ subunit alpha & GNAI3 & 3 \\
\hline Q99436 & Proteasome subunit beta type-7 & PSMB7 & 3 \\
\hline P62942 & Peptidyl-prolyl cis-trans isomerase & FKBP1A & 3 \\
\hline U3KQK0 & Histone H2B & HIST1H2B & 3 \\
\hline J3QKR3 & Proteasome subunit beta type- 3 & PSMB3 & 3 \\
\hline P01116 & $\begin{array}{c}\text { GTPase KRas;GTPase KRas, N-terminally processed;GTPase HRas;GTPase HRas, N- } \\
\text { terminally processed;GTPase NRas }\end{array}$ & $\begin{array}{l}\text { KRAS;HRAS; } \\
\text { NRAS }\end{array}$ & 3 \\
\hline P13489 & Ribonuclease inhibitor & $\mathrm{RNH} 1$ & 3 \\
\hline Q08722 & Leukocyte surface antigen CD47 & CD47 & 3 \\
\hline Q5T123 & SH3 domain-binding glutamic acid-rich-like protein 3 & SH3BGRL3 & 3 \\
\hline Q8WYQ7 & Galectin;Galectin-9 & LGALS9 & 3 \\
\hline O75695 & Protein XRP2 & RP2 & 3 \\
\hline P00167 & Cytochrome b5 & CYB5A & 3 \\
\hline Q9Y4D1 & Disheveled-associated activator of morphogenesis 1 & DAAM1 & 3 \\
\hline P11021 & $78 \mathrm{kDa}$ glucose-regulated protein & HSPA5 & 3 \\
\hline H7C1D4 & Translin & TSN & 3 \\
\hline P07737 & Profilin-1 & PFN1 & 3 \\
\hline M0R389 & Platelet-activating factor acetylhydrolase IB subunit gamma & PAFAH1B3 & 3 \\
\hline A6NJA2 & Ubiquitin carboxyl-terminal hydrolase 14 & USP14 & 3 \\
\hline P10644 & cAMP-dependent protein kinase type I-alpha regulatory subunit & PRKAR1A & 3 \\
\hline
\end{tabular}




\begin{tabular}{|c|c|c|c|}
\hline Q9BS40 & Latexin & LXN & 3 \\
\hline G5EA52 & Protein disulfide-isomerase A3 & PDIA3 & 3 \\
\hline P53004 & Biliverdin reductase $A$ & BLVRA & 3 \\
\hline Q04656 & Copper-transporting ATPase 1 & ATP7A & 3 \\
\hline H9KV70 & Neutrophil gelatinase-associated lipocalin & LCN2 & 3 \\
\hline O00299 & Chloride intracellular channel protein 1 & CLIC1 & 3 \\
\hline F8WF69 & Clathrin light chain $\mathrm{A}$ & CLTA & 3 \\
\hline G3V2F7 & Ubiquitin-conjugating enzyme E2 variant 1;Ubiquitin-conjugating enzyme E2 variant 2 & $\begin{array}{c}\text { UBE2V1;UBE } \\
2 \mathrm{~V} 2 \\
\end{array}$ & 3 \\
\hline F8WDS9 & LanC-like protein 1 & LANCL1 & 3 \\
\hline P60891 & Ribose-phosphate pyrophosphokinase 1 & PRPS1 & 3 \\
\hline K7ESE8 & Bleomycin hydrolase & BLMH & 3 \\
\hline HOYNE3 & Proteasome activator complex subunit 1 & PSME1 & 3 \\
\hline $\mathrm{P} 16930$ & Fumarylacetoacetase & FAH & 3 \\
\hline F8VSD4 & Ubiquitin-conjugating enzyme E2 N & UBE2N & 3 \\
\hline P07203 & Glutathione peroxidase 1 & GPX1 & 3 \\
\hline P62328 & Thymosin beta-4;Hematopoietic system regulatory peptide & $\begin{array}{l}\text { TMSB4X;TM } \\
\text { SB4XP4 }\end{array}$ & 3 \\
\hline E5RIW3 & Tubulin-specific chaperone A & TBCA & 3 \\
\hline MOROY2 & Alpha-soluble NSF attachment protein & NAPA & 3 \\
\hline P15374 & Ubiquitin carboxyl-terminal hydrolase isozyme L3 & UCHL3 & 3 \\
\hline P04921 & Glycophorin-C & GYPC & 2 \\
\hline HOYDI1 & Lymphocyte function-associated antigen 3 & CD58 & 2 \\
\hline B4E220 & Aquaporin-1 & AQP1 & 2 \\
\hline C9JEN3 & Protein lifeguard 3 & TMBIM1 & 2 \\
\hline F5H2R5 & Rho GDP-dissociation inhibitor 2 & ARHGDIB & 2 \\
\hline Q53TN4 & Cytochrome $\mathrm{b}$ reductase 1 & CYBRD1 & 2 \\
\hline Q9NZD4 & Alpha-hemoglobin-stabilizing protein & AHSP & 2 \\
\hline Q8NHG7 & Small VCP/p97-interacting protein & SVIP & 2 \\
\hline Q5JYX0 & Cell division control protein 42 homolog & $\mathrm{CDC} 42$ & 2 \\
\hline Q71RC9 & Small integral membrane protein 5 & SMIM5 & 2 \\
\hline E9PNW4 & CD59 glycoprotein & CD59 & 2 \\
\hline P09105 & Hemoglobin subunit theta-1 & HBQ1 & 2 \\
\hline R4GN98 & Protein S100;Protein S100-A6 & S100A6 & 2 \\
\hline O75531 & Barrier-to-autointegration factor;Barrier-to-autointegration factor, $\mathrm{N}$-terminally processed & BANF1 & 2 \\
\hline Q5T6W5 & Heterogeneous nuclear ribonucleoprotein $\mathrm{K}$ & HNRNPK & 2 \\
\hline F5H4Q5 & Vacuolar protein sorting-associated protein $37 \mathrm{C}$ & VPS37C & 2 \\
\hline J3QK90 & NSFL1 cofactor $p 47$ & NSFL1C & 2 \\
\hline H3BV85 & BolA-like protein 2 & $\begin{array}{c}\text { BOLA2B;BOL } \\
\text { A2 }\end{array}$ & 2 \\
\hline Q9NRX4 & 14 kDa phosphohistidine phosphatase & PHPT1 & 2 \\
\hline H3BS66 & Small integral membrane protein 1 & SMIM1 & 2 \\
\hline E7ESC6 & Exportin-7 & XPO7 & 2 \\
\hline P68402 & Platelet-activating factor acetylhydrolase IB subunit beta & PAFAH1B2 & 2 \\
\hline Q9BRF8 & Serine/threonine-protein phosphatase CPPED1 & CPPED1 & 2 \\
\hline P08246 & Neutrophil elastase & ELANE & 2 \\
\hline E9PN50 & $26 \mathrm{~S}$ protease regulatory subunit $6 \mathrm{~A}$ & PSMC3 & 2 \\
\hline
\end{tabular}




\begin{tabular}{|c|c|c|c|}
\hline E7EUC7 & UTP--glucose-1-phosphate uridylyltransferase & UGP2 & 2 \\
\hline B8ZZB8 & CB1 cannabinoid receptor-interacting protein 1 & CNRIP1 & 2 \\
\hline E9PCS3 & $26 \mathrm{~S}$ proteasome non-ATPase regulatory subunit 2 & PSMD2 & 2 \\
\hline P59666 & $\begin{array}{c}\text { Neutrophil defensin 3;HP 3-56;Neutrophil defensin 2;Neutrophil defensin 1;HP 1-56;Neutrophil } \\
\text { defensin } 2\end{array}$ & $\begin{array}{l}\text { DEFA3;DEFA } \\
1\end{array}$ & 2 \\
\hline 015400 & Syntaxin-7 & STX7 & 2 \\
\hline P00338 & L-lactate dehydrogenase A chain & LDHA & 2 \\
\hline P61970 & Nuclear transport factor 2 & NUTF2 & 2 \\
\hline E7EMV0 & Protein diaphanous homolog 1 & DIAPH1 & 2 \\
\hline F5GY90 & Porphobilinogen deaminase & HMBS & 2 \\
\hline P61020 & Ras-related protein Rab-5B & RAB5B & 2 \\
\hline Q99828 & Calcium and integrin-binding protein 1 & CIB1 & 2 \\
\hline B4DUA0 & Plastin-2 & LCP1 & 2 \\
\hline C9JTY3 & Protein TFG & TFG & 2 \\
\hline P27348 & 14-3-3 protein theta & YWHAQ & 2 \\
\hline HOYKZ7 & Annexin;Annexin A2;Putative annexin A2-like protein & $\begin{array}{l}\text { ANXA2;ANXA } \\
\text { 2P2 }\end{array}$ & 2 \\
\hline P08238 & Heat shock protein HSP 90-beta & HSP90AB1 & 2 \\
\hline J3KQP6 & Ras-related protein Rab-11B;Ras-related protein Rab-11A & $\begin{array}{l}\text { RAB11A;RAB } \\
\text { 11B }\end{array}$ & 2 \\
\hline A6NMU3 & Signal transducing adapter molecule 1 & STAM & 2 \\
\hline P53985 & Monocarboxylate transporter 1 & SLC16A1 & 2 \\
\hline F6USW4 & F-actin-capping protein subunit beta & CAPZB & 2 \\
\hline O14964 & Hepatocyte growth factor-regulated tyrosine kinase substrate & HGS & 2 \\
\hline P20020 & Plasma membrane calcium-transporting ATPase 1;Calcium-transporting ATPase & ATP2B1 & 2 \\
\hline P36959 & GMP reductase 1 & GMPR & 2 \\
\hline Q9Y376 & Calcium-binding protein 39 & CAB39 & 2 \\
\hline Q9Y6M5 & Zinc transporter 1 & SLC30A1 & 2 \\
\hline Q8IZ83 & Aldehyde dehydrogenase family 16 member $A 1$ & ALDH16A1 & 2 \\
\hline Q99459 & Cell division cycle 5 -like protein & CDC5L & 2 \\
\hline $\mathrm{P} 06132$ & Uroporphyrinogen decarboxylase & UROD & 2 \\
\hline J3KNT0 & Fascin & FSCN1 & 2 \\
\hline P49189 & 4-trimethylaminobutyraldehyde dehydrogenase & ALDH9A1 & 2 \\
\hline H3BNT7 & $26 \mathrm{~S}$ proteasome non-ATPase regulatory subunit 7 & PSMD7 & 2 \\
\hline P05023 & $\begin{array}{l}\text { Sodium/potassium-transporting ATPase subunit alpha-1;Sodium/potassium-transporting } \\
\text { ATPase subunit alpha-3;Sodium/potassium-transporting ATPase subunit alpha- } \\
\text { 2;Sodium/potassium-transporting ATPase subunit alpha-4;Potassium-transporting ATPase } \\
\text { alpha chain 1;Potassium-transporting ATPase alpha chain } 2 \\
\end{array}$ & $\begin{array}{l}\text { ATP1A1;ATP } \\
\text { 1A2;ATP1A3; } \\
\text { ATP1A4;ATP } \\
\text { 4A;ATP12A }\end{array}$ & 2 \\
\hline P34932 & Heat shock $70 \mathrm{kDa}$ protein 4 & HSPA4 & 2 \\
\hline K7EMV3 & Histone $\mathrm{H} 3$ & $\mathrm{H} 3 \mathrm{~F} 3 \mathrm{~B}$ & 2 \\
\hline Q8IU68 & Transmembrane channel-like protein 8 & TMC8 & 2 \\
\hline E7ENZ3 & T-complex protein 1 subunit epsilon & CCT5 & 2 \\
\hline Q5TZA2 & Rootletin & CROCC & 2 \\
\hline Q9P203 & BTB/POZ domain-containing protein 7 & BTBD7 & 2 \\
\hline Q7LBR1 & Charged multivesicular body protein $1 \mathrm{~b}$ & CHMP1B & 2 \\
\hline U3KQ56 & Glyoxylate reductase/hydroxypyruvate reductase & GRHPR & 2 \\
\hline HOYJ11 & Alpha-actinin-1;Alpha-actinin-2;Alpha-actinin-4 & $\begin{array}{c}\text { ACTN1;ACTN } \\
4 ; \text { ACTN2 }\end{array}$ & 2 \\
\hline Q9UDT6 & CAP-Gly domain-containing linker protein 2 & CLIP2 & 2 \\
\hline
\end{tabular}




\begin{tabular}{|c|c|c|c|}
\hline P09960 & Leukotriene A-4 hydrolase & LTA4H & 2 \\
\hline Q5HY54 & Filamin-A & FLNA & 2 \\
\hline E9PJL5 & Uncharacterized protein C12orf55;Putative uncharacterized protein C12orf63 & $\begin{array}{l}\text { C12orf55;C12 } \\
\text { orf63 }\end{array}$ & 2 \\
\hline G3V2U7 & Acylphosphatase;Acylphosphatase-1 & FBN3;ACYP1 & 2 \\
\hline E9PQN4 & Complement receptor type 1 & CR1 & 2 \\
\hline Q9BSL1 & Ubiquitin-associated domain-containing protein 1 & UBAC1 & 2 \\
\hline Q04917 & $14-3-3$ protein eta & YWHAH & 2 \\
\hline B7ZBP9 & Serine/threonine-protein phosphatase $2 \mathrm{~A}$ activator & $\begin{array}{c}\text { PPP2R4;DKF } \\
\text { Zp781M1716 } \\
5 \\
\end{array}$ & 2 \\
\hline Q8NDC0 & MAPK-interacting and spindle-stabilizing protein-like & MAPK1IP1L & 1 \\
\hline P68133 & $\begin{array}{l}\text { Actin, alpha skeletal muscle;Actin, alpha cardiac muscle 1;Actin, gamma-enteric smooth } \\
\text { muscle;Actin, aortic smooth muscle }\end{array}$ & $\begin{array}{c}\text { ACTA1;ACTC } \\
1 ; \mathrm{ACTG} 2 ; \mathrm{AC} \\
\text { TA2 } \\
\end{array}$ & 1 \\
\hline P69891 & Hemoglobin subunit gamma-1 & HBG1 & 1 \\
\hline S4R3Y4 & Protein AMBP;Alpha-1-microglobulin;Inter-alpha-trypsin inhibitor light chain;Trypstatin & AMBP & 1 \\
\hline I3L3E4 & Charged multivesicular body protein 6 & CHMP6 & 1 \\
\hline Q16570 & Atypical chemokine receptor 1 & ACKR1 & 1 \\
\hline Q5VY30 & $\begin{array}{l}\text { Retinol-binding protein 4;Plasma retinol-binding protein(1-182);Plasma retinol-binding } \\
\text { protein(1-181);Plasma retinol-binding protein(1-179);Plasma retinol-binding protein(1-176) }\end{array}$ & RBP4 & 1 \\
\hline E7END7 & Ras-related protein Rab-1A & RAB1A & 1 \\
\hline Q5VU59 & & TPM3 & 1 \\
\hline P17066 & Heat shock $70 \mathrm{kDa}$ protein 6;Putative heat shock $70 \mathrm{kDa}$ protein 7 & $\begin{array}{l}\text { HSPA6;HSPA } \\
7 \\
\end{array}$ & 1 \\
\hline Q04760 & Lactoylglutathione lyase & GLO1 & 1 \\
\hline D6RD66 & WD repeat-containing protein 1 & WDR1 & 1 \\
\hline K7EM02 & Katanin p60 ATPase-containing subunit A-like 2 & KATNAL2 & 1 \\
\hline P14209 & CD99 antigen & CD99 & 1 \\
\hline E9PIR7 & Thioredoxin reductase 1 , cytoplasmic & $\begin{array}{c}\text { GML;TXNRD } \\
1\end{array}$ & 1 \\
\hline K7EMQ9 & & EIF3K & 1 \\
\hline P15531 & Nucleoside diphosphate kinase A & NME1 & 1 \\
\hline H7BZT4 & $\begin{array}{c}\text { Small ubiquitin-related modifier 4;Small ubiquitin-related modifier 2;Small ubiquitin-related } \\
\text { modifier } 3\end{array}$ & $\begin{array}{l}\text { SUMO2;SUM } \\
\text { O3;SUMO4 }\end{array}$ & 1 \\
\hline 000560 & Syntenin-1 & SDCBP & 1 \\
\hline Q9BVM4 & Gamma-glutamylaminecyclotransferase & GGACT & 1 \\
\hline K7EKH5 & Fructose-bisphosphate aldolase C & ALDOC & 1 \\
\hline P49773 & Histidine triad nucleotide-binding protein 1 & HINT1 & 1 \\
\hline HOYBY6 & Disks large-associated protein 2 & DLGAP2 & 1 \\
\hline Q9Y624 & Junctional adhesion molecule $A$ & F11R & 1 \\
\hline B1AKQ8 & $\begin{array}{c}\text { Guanine nucleotide-binding protein } \mathrm{G}(\mathrm{I}) / \mathrm{G}(\mathrm{S}) / \mathrm{G}(\mathrm{T}) \text { subunit beta-1;Guanine nucleotide-binding } \\
\text { protein } \mathrm{G}(\mathrm{I}) / \mathrm{G}(\mathrm{S}) / \mathrm{G}(\mathrm{T}) \text { subunit beta-3 }\end{array}$ & GNB1;GNB3 & 1 \\
\hline K7EKN6 & Urea transporter 1 & SLC14A1 & 1 \\
\hline I3LOK2 & Thioredoxin domain-containing protein 17 & TXNDC17 & 1 \\
\hline A8MXY0 & Syntaxin-4 & STX4 & 1 \\
\hline 014773 & Tripeptidyl-peptidase 1 & TPP1 & 1 \\
\hline E9PNW0 & Nucleosome assembly protein 1-like 1;Nucleosome assembly protein 1-like 4 & $\begin{array}{l}\text { NAP1L4;NAP } \\
\text { 1L1 }\end{array}$ & 1 \\
\hline Q5TDH0 & Protein DDI1 homolog 2 & DDI2 & 1 \\
\hline Q96JM4 & Leucine-rich repeat and IQ domain-containing protein 1 & LRRIQ1 & 1 \\
\hline F5GWT9 & Phosphoribosylformylglycinamidine synthase & PFAS & 1 \\
\hline
\end{tabular}




\begin{tabular}{|c|c|c|c|}
\hline $\mathrm{F} 2 \mathrm{Z} 3 \mathrm{~J} 2$ & $26 S$ proteasome non-ATPase regulatory subunit 5 & PSMD5 & 1 \\
\hline J3QL74 & Zinc finger and BTB domain-containing protein 14 & ZBTB14 & 1 \\
\hline E9PJC7 & CD82 antigen & CD82 & 1 \\
\hline Q9H936 & Mitochondrial glutamate carrier 1 & SLC25A22 & 1 \\
\hline D6RD63 & COP9 signalosome complex subunit 4 & COPS4 & 1 \\
\hline Q6B0K9 & Hemoglobin subunit mu & HBM & 1 \\
\hline Q31611 & HLA class I histocompatibility antigen, alpha chain G & HLA-G & 1 \\
\hline H7BY04 & Laminin subunit gamma-3 & LAMC3 & 1 \\
\hline Q9UL25 & Ras-related protein Rab-21 & RAB21 & 1 \\
\hline H7C3P7 & Ras-related protein Ral-A & RALA & 1 \\
\hline P08311 & Cathepsin G & CTSG & 1 \\
\hline E9PE37 & Ras-related protein Rab-2A;Ras-related protein Rab-2B & $\begin{array}{l}\text { RAB2B;RAB2 } \\
\text { A }\end{array}$ & 1 \\
\hline G3V1N2 & & HBA2 & 1 \\
\hline P00387 & $\begin{array}{l}\text { NADH-cytochrome b5 reductase 3;NADH-cytochrome b5 reductase } 3 \text { membrane-bound } \\
\text { form;NADH-cytochrome b5 reductase } 3 \text { soluble form }\end{array}$ & CYB5R3 & 1 \\
\hline 075339 & $\begin{array}{c}\text { Cartilage intermediate layer protein } 1 ; \text { Cartilage intermediate layer protein } 1 \mathrm{C} 1 ; \text { Cartilage } \\
\text { intermediate layer protein } 1 \mathrm{C} 2\end{array}$ & CILP & 1 \\
\hline P14324 & Farnesyl pyrophosphate synthase & FDPS & 1 \\
\hline K7EKG2 & Thioredoxin-like protein 1 & TXNL1 & 1 \\
\hline
\end{tabular}

\section{B. Uniprot Complete Proteome Homo sapiens database when the heamoglobin was analyzed separately}

\begin{tabular}{|c|c|c|c|}
\hline $\begin{array}{l}\text { Protein } \\
\text { ID }\end{array}$ & Protein names & $\begin{array}{c}\text { Gene } \\
\text { names }\end{array}$ & $\begin{array}{c}\text { Razor + } \\
\text { unique } \\
\text { peptide } \\
\text { s }\end{array}$ \\
\hline P02549 & Spectrin alpha chain, erythrocytic 1 & SPTA1 & 197 \\
\hline P11277 & Spectrin beta chain, erythrocytic & SPTB & 177 \\
\hline P16157 & Ankyrin-1 & ANK1 & 94 \\
\hline P55072 & Transitional endoplasmic reticulum ATPase & VCP & 53 \\
\hline P111714 & Protein 4.1 & EPB41 & 52 \\
\hline P35579 & Myosin-9 & MYH9 & 44 \\
\hline Q8WUM4 & Programmed cell death 6-interacting protein & PDCD6IP & 43 \\
\hline P02730 & Band 3 anion transport protein & SLC4A1 & 43 \\
\hline P16452 & Erythrocyte membrane protein band 4.2 & EPB42 & 42 \\
\hline P04040 & Catalase & CAT & 40 \\
\hline $\begin{array}{c}\text { A0A087WVQ } \\
6\end{array}$ & Clathrin heavy chain;Clathrin heavy chain 1 & CLTC & 38 \\
\hline P35612 & Beta-adducin & ADD2 & 37 \\
\hline $\mathrm{P} 16157$ & Ankyrin-1 & ANK1 & 36 \\
\hline Q14254 & Flotillin-2 & FLOT2 & 33 \\
\hline P20073 & Annexin A7 & ANXA7 & 31 \\
\hline O75955 & Flotillin-1 & FLOT1 & 30 \\
\hline P53396 & ATP-citrate synthase & ACLY & 30 \\
\hline P06753 & & TPM3 & 29 \\
\hline P49368 & T-complex protein 1 subunit gamma & ССТ3 & 29 \\
\hline P236344 & Plasma membrane calcium-transporting ATPase 4 & ATP2B4 & 28 \\
\hline
\end{tabular}




\begin{tabular}{|c|c|c|c|}
\hline P11142 & Heat shock cognate $71 \mathrm{kDa}$ protein & HSPA8 & 28 \\
\hline P60709 & Actin, cytoplasmic $1 ;$ Actin, cytoplasmic $1, \mathrm{~N}$-terminally processed & ACTB & 28 \\
\hline Q5T4S7 & E3 ubiquitin-protein ligase UBR4 & UBR4 & 27 \\
\hline P78371 & T-complex protein 1 subunit beta & СCT2 & 26 \\
\hline P28289 & Tropomodulin-1 & TMOD1 & 26 \\
\hline P50395 & Rab GDP dissociation inhibitor beta & GDI2 & 25 \\
\hline P27105 & Erythrocyte band 7 integral membrane protein & STOM & 25 \\
\hline P68871 & Hemoglobin subunit beta;LVV-hemorphin-7;Spinorphin & HBB & 25 \\
\hline P02730 & Band 3 anion transport protein & SLC4A1 & 25 \\
\hline Q00013 & $55 \mathrm{kDa}$ erythrocyte membrane protein & MPP1 & 24 \\
\hline J3KPS3 & Fructose-bisphosphate aldolase;Fructose-bisphosphate aldolase A & ALDOA & 24 \\
\hline P00352 & Retinal dehydrogenase 1 & ALDH1A1 & 24 \\
\hline Q86VP6 & Cullin-associated NEDD8-dissociated protein 1 & CAND1 & 24 \\
\hline P49327 & Fatty acid synthase & FASN & 24 \\
\hline Q13228 & Selenium-binding protein 1 & SELENBP1 & 22 \\
\hline P00915 & Carbonic anhydrase 1 & CA1 & 22 \\
\hline P50991 & T-complex protein 1 subunit delta & CCT4 & 22 \\
\hline P50990 & T-complex protein 1 subunit theta & ССТ8 & 22 \\
\hline P32119 & Peroxiredoxin-2 & PRDX2 & 21 \\
\hline P50995 & Annexin A11 & ANXA11 & 21 \\
\hline P69905 & Hemoglobin subunit alpha & HBA1 & 21 \\
\hline P00558 & Phosphoglycerate kinase 1 & PGK1 & 20 \\
\hline H7BXK9 & ATP-binding cassette sub-family B member 6 , mitochondrial & ABCB6 & 20 \\
\hline P08758 & Annexin A5;Annexin & ANXA5 & 20 \\
\hline P09525 & Annexin A4;Annexin & ANXA4 & 20 \\
\hline P07900 & Heat shock protein HSP 90 -alpha & HSP90AA1 & 20 \\
\hline P48643 & T-complex protein 1 subunit epsilon & CCT5 & 20 \\
\hline P07384 & Calpain-1 catalytic subunit & CAPN1 & 20 \\
\hline P22314 & Ubiquitin-like modifier-activating enzyme 1 & UBA1 & 19 \\
\hline P04406 & Glyceraldehyde-3-phosphate dehydrogenase & GAPDH & 19 \\
\hline Q08495 & Dematin & DMTN & 19 \\
\hline Q99832 & T-complex protein 1 subunit eta & $\mathrm{CCT7}$ & 19 \\
\hline P29144 & Tripeptidyl-peptidase 2 & TPP2 & 19 \\
\hline P30041 & Peroxiredoxin-6 & PRDX6 & 18 \\
\hline E9PM69 & $26 \mathrm{~S}$ protease regulatory subunit $6 \mathrm{~A}$ & PSMC3 & 18 \\
\hline P40227 & T-complex protein 1 subunit zeta & CCT6A & 18 \\
\hline P50570 & Dynamin-2 & DNM2 & 18 \\
\hline E7EQB2 & Lactotransferrin;Lactoferricin-H;Kaliocin-1;Lactoferroxin-A;Lactoferroxin-B;Lactoferroxin-C & LTF & 18 \\
\hline P31948 & Stress-induced-phosphoprotein 1 & STIP1 & 18 \\
\hline E7ESC6 & Exportin-7 & XPO7 & 18 \\
\hline E7EV99 & Alpha-adducin & ADD1 & 17 \\
\hline P62258 & 14-3-3 protein epsilon & YWHAE & 17 \\
\hline P30613 & Pyruvate kinase PKLR & PKLR & 17 \\
\hline A0A0G2JIW1 & Heat shock $70 \mathrm{kDa}$ protein $1 \mathrm{~B} ;$ Heat shock $70 \mathrm{kDa}$ protein $1 \mathrm{~A}$ & $\begin{array}{c}\text { HSPA1B;HSP } \\
\text { A1A }\end{array}$ & 17 \\
\hline
\end{tabular}




\begin{tabular}{|c|c|c|c|}
\hline Q16531 & DNA damage-binding protein 1 & DDB1 & 17 \\
\hline P11021 & $78 \mathrm{kDa}$ glucose-regulated protein & HSPA5 & 17 \\
\hline $\mathrm{F} 5 \mathrm{H} 2 \mathrm{~F} 4$ & C-1-tetrahydrofolate synthase, cytoplasmic;Methylenetetrahydrofolate dehydrogenase & MTHFD1 & 17 \\
\hline P07195 & L-lactate dehydrogenase B chain;L-lactate dehydrogenase & LDHB & 16 \\
\hline P45974 & Ubiquitin carboxyl-terminal hydrolase 5 & USP5 & 16 \\
\hline $\mathrm{O} 43242$ & $26 S$ proteasome non-ATPase regulatory subunit 3 & PSMD3 & 16 \\
\hline C9J0K6 & Sorcin & SRI & 16 \\
\hline P08133 & Annexin A6;Annexin & ANXA6 & 16 \\
\hline Q13200 & 26S proteasome non-ATPase regulatory subunit 2 & PSMD2 & 16 \\
\hline P23276 & Kell blood group glycoprotein & KEL & 16 \\
\hline P34932 & Heat shock $70 \mathrm{kDa}$ protein 4 & HSPA4 & 16 \\
\hline AOAOAOMSIO & Peroxiredoxin-1 & PRDX1 & 16 \\
\hline Q9Y230 & RuvB-like 2 & RUVBL2 & 16 \\
\hline Q5XPI4 & E3 ubiquitin-protein ligase RNF123 & RNF123 & 16 \\
\hline P68871 & Hemoglobin subunit beta;LVV-hemorphin-7;Spinorphin & HBB & 15 \\
\hline P60174 & Triosephosphate isomerase & TPI1 & 15 \\
\hline P00491 & Purine nucleoside phosphorylase & PNP & 15 \\
\hline C9JIF9 & Acylamino-acid-releasing enzyme & APEH & 15 \\
\hline H7BYY1 & Tropomyosin alpha-1 chain & TPM1 & 15 \\
\hline P35998 & $26 S$ protease regulatory subunit 7 & PSMC2 & 15 \\
\hline P17987 & T-complex protein 1 subunit alpha & TCP1 & 15 \\
\hline P09543 & 2,3-cyclic-nucleotide 3-phosphodiesterase & CNP & 15 \\
\hline Q99460 & 26S proteasome non-ATPase regulatory subunit 1 & PSMD1 & 15 \\
\hline Q9Y4E8 & Ubiquitin carboxyl-terminal hydrolase 15 & USP15 & 15 \\
\hline Q9C0C9 & E2/E3 hybrid ubiquitin-protein ligase UBE2O & UBE2O & 15 \\
\hline P26038 & Moesin & MSN & 15 \\
\hline P04083 & Annexin A1;Annexin & ANXA1 & 14 \\
\hline P30043 & Flavin reductase (NADPH) & BLVRB & 14 \\
\hline P11166 & Solute carrier family 2 , facilitated glucose transporter member 1 & SLC2A1 & 14 \\
\hline P00918 & Carbonic anhydrase 2 & CA2 & 14 \\
\hline P06733 & Alpha-enolase & ENO1 & 14 \\
\hline Q5TDH0 & Protein DDI1 homolog 2 & DDI2 & 14 \\
\hline B0QZ18 & Copine-1 & CPNE1 & 14 \\
\hline O75326 & Semaphorin-7A & SEMA7A & 14 \\
\hline P05164 & Myeloperoxidase & MPO & 14 \\
\hline Q9Y265 & RuvB-like 1 & RUVBL1 & 14 \\
\hline P29401 & Transketolase & TKT & 14 \\
\hline I3L0N3 & Vesicle-fusing ATPase & NSF & 14 \\
\hline Q4VB86 & Protein 4.1 & EPB41 & 14 \\
\hline P11277 & Spectrin beta chain, erythrocytic & SPTB & 14 \\
\hline P13716 & Delta-aminolevulinic acid dehydratase & ALAD & 13 \\
\hline P07738 & Bisphosphoglycerate mutase & BPGM & 13 \\
\hline P48506 & Glutamate--cysteine ligase catalytic subunit & GCLC & 13 \\
\hline Q99816 & Tumor susceptibility gene 101 protein & TSG101 & 13 \\
\hline O14818 & Proteasome subunit alpha type-7 & PSMA7 & 13 \\
\hline
\end{tabular}




\begin{tabular}{|c|c|c|c|}
\hline P23526 & Adenosylhomocysteinase & $\mathrm{AHCY}$ & 13 \\
\hline P61225 & Ras-related protein Rap- $2 b$ & RAP2B & 13 \\
\hline O00231 & $26 S$ proteasome non-ATPase regulatory subunit 11 & PSMD11 & 13 \\
\hline P11413 & Glucose-6-phosphate 1-dehydrogenase & G6PD & 13 \\
\hline P00338 & L-lactate dehydrogenase A chain & LDHA & 12 \\
\hline Q99808 & Equilibrative nucleoside transporter 1 & SLC29A1 & 12 \\
\hline A6NJA2 & Ubiquitin carboxyl-terminal hydrolase;Ubiquitin carboxyl-terminal hydrolase 14 & USP14 & 12 \\
\hline Q06323 & Proteasome activator complex subunit 1 & PSME1 & 12 \\
\hline P28074 & Proteasome subunit beta type- 5 & PSMB5 & 12 \\
\hline B3KQV6 & Serine/threonine-protein phosphatase $2 \mathrm{~A} 65 \mathrm{kDa}$ regulatory subunit $\mathrm{A}$ alpha isoform & PPP2R1A & 12 \\
\hline Q14974 & Importin subunit beta-1 & KPNB1 & 12 \\
\hline P25786 & Proteasome subunit alpha type-1;Proteasome subunit alpha type & PSMA1 & 12 \\
\hline Q86X55 & Histone-arginine methyltransferase CARM1 & CARM1 & 12 \\
\hline A6NG10 & WW domain-binding protein 2 & WBP2 & 12 \\
\hline P63092 & Guanine nucleotide-binding protein $\mathrm{G}(\mathrm{s})$ subunit alpha & GNAS & 12 \\
\hline P31939 & $\begin{array}{c}\text { Bifunctional purine biosynthesis protein PURH;Phosphoribosylaminoimidazolecarboxamide } \\
\text { formyltransferase;IMP cyclohydrolase }\end{array}$ & ATIC & 12 \\
\hline P52209 & 6-phosphogluconate dehydrogenase, decarboxylating & PGD & 12 \\
\hline A0A087X0C8 & Calpain-5 & CAPN5 & 12 \\
\hline F8W9S7 & GTPase-activating protein and VPS9 domain-containing protein 1 & GAPVD1 & 12 \\
\hline P60842 & Eukaryotic initiation factor $4 \mathrm{~A}-\mathrm{I}$ & EIF4A1 & 12 \\
\hline P69905 & Hemoglobin subunit alpha & HBA1 & 11 \\
\hline Q6XQN6 & Nicotinate phosphoribosyltransferase & NAPRT & 11 \\
\hline P48637 & Glutathione synthetase & GSS & 11 \\
\hline H7BZ94 & Protein disulfide-isomerase & $\mathrm{P} 4 \mathrm{HB}$ & 11 \\
\hline P21980 & Protein-glutamine gamma-glutamyltransferase 2 & TGM2 & 11 \\
\hline P50895 & Basal cell adhesion molecule & BCAM & 11 \\
\hline $\mathrm{A} 0 \mathrm{~A} 087 \mathrm{X} 2 \mathrm{I} 1$ & $26 \mathrm{~S}$ protease regulatory subunit $10 \mathrm{~B}$ & PSMC6 & 11 \\
\hline G3V1D3 & Dipeptidyl peptidase 3 & DPP3 & 11 \\
\hline P05023 & $\begin{array}{l}\text { Sodium/potassium-transporting ATPase subunit alpha-1;Sodium/potassium-transporting } \\
\text { ATPase subunit alpha-3 }\end{array}$ & $\begin{array}{l}\text { ATP1A1;ATP } \\
\text { 1A3 }\end{array}$ & 11 \\
\hline P40925 & Malate dehydrogenase, cytoplasmic;Malate dehydrogenase & MDH1 & 11 \\
\hline Q9UKV8 & Protein argonaute- 2 & AGO2 & 11 \\
\hline P30566 & Adenylosuccinate lyase & ADSL & 11 \\
\hline P20618 & Proteasome subunit beta type- 1 & PSMB1 & 11 \\
\hline P17858 & ATP-dependent 6-phosphofructokinase, liver type & PFKL & 11 \\
\hline A0A087X253 & AP-2 complex subunit beta & AP2B1 & 11 \\
\hline O95782 & AP-2 complex subunit alpha-1 & AP2A1 & 11 \\
\hline 000232 & 26S proteasome non-ATPase regulatory subunit 12 & PSMD12 & 11 \\
\hline Q9BSL1 & Ubiquitin-associated domain-containing protein 1 & UBAC1 & 11 \\
\hline $\begin{array}{l}\text { A0A087WUL } \\
0 \\
\end{array}$ & $\begin{array}{l}\text { Bifunctional ATP-dependent dihydroxyacetone kinase/FAD-AMP lyase (cyclizing);ATP- } \\
\text { dependent dihydroxyacetone kinase;FAD-AMP lyase (cyclizing) }\end{array}$ & TKFC;DAK & 11 \\
\hline P69891 & Hemoglobin subunit gamma-1 & HBG1 & 11 \\
\hline $\begin{array}{l}\text { A0A087WZE } \\
4\end{array}$ & Spectrin alpha chain, erythrocytic 1 & SPTA1 & 11 \\
\hline P48426 & Phosphatidylinositol 5-phosphate 4-kinase type-2 alpha & PIP4K2A & 10 \\
\hline P10644 & cAMP-dependent protein kinase type I-alpha regulatory subunit & PRKAR1A & 10 \\
\hline Q9BWD1 & Acetyl-CoA acetyltransferase, cytosolic & ACAT2 & 10 \\
\hline
\end{tabular}




\begin{tabular}{|c|c|c|c|}
\hline P62191 & $26 S$ protease regulatory subunit 4 & PSMC1 & 10 \\
\hline E9PBS1 & $\begin{array}{c}\text { Multifunctional protein ADE2;Phosphoribosylaminoimidazole-succinocarboxamide } \\
\text { synthase;Phosphoribosylaminoimidazole carboxylase }\end{array}$ & PAICS & 10 \\
\hline MOROY2 & Alpha-soluble NSF attachment protein & NAPA & 10 \\
\hline P78417 & Glutathione S-transferase omega-1 & GSTO1 & 10 \\
\hline P25789 & $\begin{array}{c}\text { Proteasome subunit alpha type-4;Proteasome subunit alpha type;Proteasome subunit beta } \\
\text { type }\end{array}$ & PSMA4 & 10 \\
\hline Q9H0U4 & Ras-related protein Rab-1B;Putative Ras-related protein Rab-1C & $\begin{array}{l}\text { RAB1B;RAB1 } \\
\text { C }\end{array}$ & 10 \\
\hline Q16401 & $26 \mathrm{~S}$ proteasome non-ATPase regulatory subunit 5 & PSMD5 & 10 \\
\hline P30101 & Protein disulfide-isomerase $\mathrm{A} 3$ & PDIA3 & 10 \\
\hline D6RAX7 & COP9 signalosome complex subunit 4 & COPS4 & 10 \\
\hline O75340 & Programmed cell death protein 6 & PDCD6 & 10 \\
\hline Q96P70 & Importin-9 & IPO9 & 10 \\
\hline P38606 & V-type proton ATPase catalytic subunit A & ATP6V1A & 10 \\
\hline A0A0G2JH68 & Protein diaphanous homolog 1 & DIAPH1 & 10 \\
\hline Q5T9B7 & Adenylate kinase isoenzyme 1 & AK1 & 10 \\
\hline O14980 & Exportin-1 & XPO1 & 10 \\
\hline P43686 & $26 \mathrm{~S}$ protease regulatory subunit $6 \mathrm{~B}$ & PSMC4 & 10 \\
\hline H0YH81 & ATP synthase subunit beta;ATP synthase subunit beta, mitochondrial & ATP5B & 10 \\
\hline Q04656 & Copper-transporting ATPase 1 & ATP7A & 10 \\
\hline P16452 & Erythrocyte membrane protein band 4.2 & EPB42 & 10 \\
\hline Q9BY43 & Charged multivesicular body protein $4 a$ & CHMP4A & 9 \\
\hline P51148 & Ras-related protein Rab-5C & RAB5C & 9 \\
\hline Q9NRV9 & Heme-binding protein 1 & HEBP1 & 9 \\
\hline Q9UNZ2 & NSFL1 cofactor $p 47$ & NSFL1C & 9 \\
\hline Q16851 & UTP--glucose-1-phosphate uridylyltransferase & UGP2 & 9 \\
\hline P28066 & Proteasome subunit alpha type- 5 & PSMA5 & 9 \\
\hline $\begin{array}{l}\text { A0A0C4DGQ } \\
5 \\
\end{array}$ & Calpain small subunit 1 & CAPNS1 & 9 \\
\hline A0A087X1Z3 & Proteasome activator complex subunit 2 & PSME2 & 9 \\
\hline Q01518 & Adenylyl cyclase-associated protein 1 & CAP1 & 9 \\
\hline B1AKQ8 & Guanine nucleotide-binding protein $\mathrm{G}(\mathrm{I}) / \mathrm{G}(\mathrm{S}) / \mathrm{G}(\mathrm{T})$ subunit beta-1 & GNB1 & 9 \\
\hline O75131 & Copine-3 & CPNE3 & 9 \\
\hline P54725 & UV excision repair protein RAD23 homolog $A$ & RAD23A & 9 \\
\hline P11215 & Integrin alpha-M & ITGAM & 9 \\
\hline Q93008 & Probable ubiquitin carboxyl-terminal hydrolase FAF-X & USP9X & 9 \\
\hline Q96G03 & Phosphoglucomutase-2 & PGM2 & 9 \\
\hline P49721 & Proteasome subunit beta type-2 & PSMB2 & 9 \\
\hline Q15008 & $26 S$ proteasome non-ATPase regulatory subunit 6 & PSMD6 & 9 \\
\hline Q9UNQ0 & ATP-binding cassette sub-family $\mathrm{G}$ member 2 & ABCG2 & 9 \\
\hline P22303 & Acetylcholinesterase;Carboxylic ester hydrolase & $\mathrm{ACHE}$ & 9 \\
\hline G3V5Z7 & Proteasome subunit alpha type;Proteasome subunit alpha type- 6 & PSMA6 & 9 \\
\hline 015439 & Multidrug resistance-associated protein 4 & $\mathrm{ABCC} 4$ & 9 \\
\hline P37837 & Transaldolase & TALDO1 & 9 \\
\hline O14744 & Protein arginine $\mathrm{N}$-methyltransferase 5 & PRMT5 & 9 \\
\hline P02042 & Hemoglobin subunit delta & $\mathrm{HBD}$ & 9 \\
\hline P25788 & Proteasome subunit alpha type-3 & PSMA3 & 8 \\
\hline
\end{tabular}




\begin{tabular}{|c|c|c|c|}
\hline J3QS39 & $\begin{array}{l}\text { Ubiquitin-60S ribosomal protein L40;Ubiquitin;60S ribosomal protein L40;Ubiquitin-40S } \\
\text { ribosomal protein S27a;Ubiquitin;40S ribosomal protein S27a;Polyubiquitin- } \\
\text { B;Ubiquitin;Polyubiquitin-C;Ubiquitin }\end{array}$ & $\begin{array}{l}\text { UBB;RPS27A } \\
\text {;UBC;UBA52; } \\
\text { UBBP4 }\end{array}$ & 8 \\
\hline 094919 & Endonuclease domain-containing 1 protein & ENDOD1 & 8 \\
\hline P31946 & 14-3-3 protein beta/alpha & YWHAB & 8 \\
\hline P60891 & $\begin{array}{c}\text { Ribose-phosphate pyrophosphokinase 1;Ribose-phosphate pyrophosphokinase 2; Ribose- } \\
\text { phosphate pyrophosphokinase } 3\end{array}$ & $\begin{array}{l}\text { PRPS1;PRPS } \\
2 ; \text { PRPS1L1 }\end{array}$ & 8 \\
\hline P62195 & $26 S$ protease regulatory subunit 8 & PSMC5 & 8 \\
\hline A0A024RA52 & Proteasome subunit alpha type;Proteasome subunit alpha type-2 & PSMA2 & 8 \\
\hline P04899 & Guanine nucleotide-binding protein $\mathrm{G}$ (i) subunit alpha-2 & GNAI2 & 8 \\
\hline Q13561 & Dynactin subunit 2 & DCTN2 & 8 \\
\hline P53004 & Biliverdin reductase $A$ & BLVRA & 8 \\
\hline P00387 & NADH-cytochrome b5 reductase 3 & CYB5R3 & 8 \\
\hline P16152 & Carbonyl reductase [NADPH] 1 & CBR1 & 8 \\
\hline P06744 & Glucose-6-phosphate isomerase & GPI & 8 \\
\hline Q99733 & Nucleosome assembly protein 1-like 4 & NAP1L4 & 8 \\
\hline P04792 & Heat shock protein beta-1 & HSPB1 & 8 \\
\hline P17612 & $\begin{array}{l}\text { cAMP-dependent protein kinase catalytic subunit alpha;cAMP-dependent protein kinase } \\
\text { catalytic subunit beta }\end{array}$ & $\begin{array}{l}\text { PRKACA;KIN } \\
27 ; \text { PRKACB }\end{array}$ & 8 \\
\hline P20340 & Ras-related protein Rab-6A & RAB6A & 8 \\
\hline P13796 & Plastin-2 & LCP1 & 8 \\
\hline P52907 & F-actin-capping protein subunit alpha-1 & CAPZA1 & 8 \\
\hline Q14697 & Neutral alpha-glucosidase $A B$ & GANAB & 8 \\
\hline P08514 & $\begin{array}{l}\text { Integrin alpha-Ilb;Integrin alpha-Ilb heavy chain;Integrin alpha-Ilb light chain, form 1; Integrin } \\
\text { alpha-Ilb light chain, form } 2\end{array}$ & ITGA2B & 8 \\
\hline P26641 & Elongation factor 1-gamma & EEF1G & 8 \\
\hline Q9UQ80 & Proliferation-associated protein $2 \mathrm{G} 4$ & PA2G4 & 8 \\
\hline Q9Y4D1 & Disheveled-associated activator of morphogenesis 1 & DAAM1 & 8 \\
\hline P11166 & Solute carrier family 2 , facilitated glucose transporter member 1 & SLC2A1 & 8 \\
\hline P63261 & $\begin{array}{l}\text { Actin, cytoplasmic } 2 \text {;Actin, cytoplasmic } 2, \mathrm{~N} \text {-terminally processed;Actin, cytoplasmic } 1 \text {;Actin, } \\
\text { cytoplasmic } 1, \mathrm{~N} \text {-terminally processed;Actin, gamma-enteric smooth muscle;Actin, alpha } \\
\text { skeletal muscle;Actin, alpha cardiac muscle } 1 \text {;Actin, aortic smooth muscle }\end{array}$ & $\begin{array}{l}\text { ACTG1;ACTB } \\
\text {;ACTG2;ACT } \\
\text { A1;ACTC1;A } \\
\text { CTA2 }\end{array}$ & 8 \\
\hline P02008 & Hemoglobin subunit zeta & HBZ & 8 \\
\hline P20073 & Annexin A7 & ANXA7 & 8 \\
\hline P35613 & Basigin & BSG & 7 \\
\hline P49720 & Proteasome subunit beta type- 3 & PSMB3 & 7 \\
\hline P17931 & Galectin-3;Galectin & LGALS3 & 7 \\
\hline P63104 & 14-3-3 protein zeta/delta & YWHAZ & 7 \\
\hline Q9H444 & Charged multivesicular body protein $4 \mathrm{~b}$ & CHMP4B & 7 \\
\hline 043396 & Thioredoxin-like protein 1 & TXNL1 & 7 \\
\hline P50502 & Hsc70-interacting protein;Putative protein FAM10A4;Putative protein FAM10A5 & $\begin{array}{l}\text { ST13;ST13P4 } \\
\text {;ST13P5 }\end{array}$ & 7 \\
\hline E7EQ12 & Calpastatin & CAST & 7 \\
\hline P49189 & 4-trimethylaminobutyraldehyde dehydrogenase & ALDH9A1 & 7 \\
\hline Q9Y3I1 & F-box only protein 7 & FBXO7 & 7 \\
\hline P07954 & Fumarate hydratase, mitochondrial & $\mathrm{FH}$ & 7 \\
\hline F6S8N6 & $\begin{array}{l}\text { Protein-L-isoaspartate O-methyltransferase;Protein-L-isoaspartate(D-aspartate) O- } \\
\text { methyltransferase }\end{array}$ & PCMT1 & 7 \\
\hline P49247 & Ribose-5-phosphate isomerase & RPIA & 7 \\
\hline P62834 & Ras-related protein Rap-1A & RAP1A & 7 \\
\hline
\end{tabular}




\begin{tabular}{|c|c|c|c|}
\hline $\begin{array}{l}\text { A0A087WUQ } \\
6\end{array}$ & Glutathione peroxidase;Glutathione peroxidase 1 & GPX1 & 7 \\
\hline O60256 & Phosphoribosyl pyrophosphate synthase-associated protein 2 & PRPSAP2 & 7 \\
\hline Q00796 & Sorbitol dehydrogenase & SORD & 7 \\
\hline O00299 & Chloride intracellular channel protein 1 & CLIC1 & 7 \\
\hline Q99497 & Protein deglycase DJ-1 & PARK7 & 7 \\
\hline P17174 & Aspartate aminotransferase, cytoplasmic & GOT1 & 7 \\
\hline H7BXD5 & Grancalcin & GCA & 7 \\
\hline E9PGT1 & Translin & TSN & 7 \\
\hline C9J7K9 & Phospholipid scramblase 1 & PLSCR1 & 7 \\
\hline Q13618 & Cullin-3 & CUL3 & 7 \\
\hline O75695 & Protein XRP2 & RP2 & 7 \\
\hline P09960 & Leukotriene A-4 hydrolase & LTA4H & 7 \\
\hline E9PLK3 & Puromycin-sensitive aminopeptidase & NPEPPS & 7 \\
\hline P00492 & Hypoxanthine-guanine phosphoribosyltransferase & HPRT1 & 7 \\
\hline F5H4B6 & Aldehyde dehydrogenase family 16 member $A 1$ & ALDH16A1 & 7 \\
\hline D6RA82 & Annexin;Annexin A3 & ANXA3 & 7 \\
\hline P61106 & Ras-related protein Rab-14 & RAB14 & 7 \\
\hline Q16775 & Hydroxyacylglutathione hydrolase, mitochondrial & $\mathrm{HAGH}$ & 7 \\
\hline P07355 & Annexin A2;Annexin;Putative annexin A2-like protein & $\begin{array}{l}\text { ANXA2;ANXA } \\
\text { 2P2 }\end{array}$ & 7 \\
\hline $\begin{array}{l}\text { A0A087WX0 } \\
8 \\
\end{array}$ & Gamma-adducin & ADD3 & 7 \\
\hline P08238 & Heat shock protein HSP 90-beta & HSP90AB1 & 7 \\
\hline Q8IZY2 & ATP-binding cassette sub-family A member 7 & ABCA7 & 7 \\
\hline P14780 & Matrix metalloproteinase- 9 & MMP9 & 7 \\
\hline P12955 & Xaa-Pro dipeptidase & PEPD & 7 \\
\hline P68371 & Tubulin beta-4B chain;Tubulin beta-4A chain;Tubulin beta chain & $\begin{array}{l}\text { TUBB4B;TUB } \\
\text { B4A;TUBB }\end{array}$ & 7 \\
\hline O15067 & Phosphoribosylformylglycinamidine synthase & PFAS & 7 \\
\hline P35241 & Radixin & RDX & 7 \\
\hline O60488 & Long-chain-fatty-acid--CoA ligase 4 & ACSL4 & 7 \\
\hline $\begin{array}{l}\text { A0A0C4DGX } \\
4 \\
\end{array}$ & Cullin-1 & CUL1 & 7 \\
\hline P50148 & Guanine nucleotide-binding protein $\mathrm{G}(\mathrm{q})$ subunit alpha & GNAQ & 7 \\
\hline Q15907 & Ras-related protein Rab-11B;Ras-related protein Rab-11A & $\begin{array}{l}\text { RAB11B;RAB } \\
\text { 11A }\end{array}$ & 7 \\
\hline P30086 & $\begin{array}{l}\text { Phosphatidylethanolamine-binding protein } 1 ; \text { Hippocampal cholinergic neurostimulating } \\
\text { peptide }\end{array}$ & PEBP1 & 6 \\
\hline P55036 & $26 S$ proteasome non-ATPase regulatory subunit 4 & PSMD4 & 6 \\
\hline P28070 & Proteasome subunit beta type- 4 & PSMB4 & 6 \\
\hline Q9UNS2 & COP9 signalosome complex subunit 3 & COPS3 & 6 \\
\hline P08754 & Guanine nucleotide-binding protein $\mathrm{G}(\mathrm{k})$ subunit alpha & GNAI3 & 6 \\
\hline P61006 & Ras-related protein Rab-8A & RAB8A & 6 \\
\hline P61019 & Ras-related protein Rab-2A & RAB2A & 6 \\
\hline H0Y8C6 & Importin-5 & IPO5 & 6 \\
\hline Q00577 & Transcriptional activator protein Pur-alpha & PURA & 6 \\
\hline P52565 & Rho GDP-dissociation inhibitor 1 & ARHGDIA & 6 \\
\hline Q9Y5Z4 & Heme-binding protein 2 & HEBP2 & 6 \\
\hline J3KNF4 & Copper chaperone for superoxide dismutase;Superoxide dismutase [Cu-Zn] & CCS & 6 \\
\hline
\end{tabular}




\begin{tabular}{|c|c|c|c|}
\hline $\begin{array}{l}\text { A0A087WXS } \\
7\end{array}$ & ATPase ASNA1 & ASNA1 & 6 \\
\hline P05089 & Arginase-1 & ARG1 & 6 \\
\hline 095336 & 6-phosphogluconolactonase & PGLS & 6 \\
\hline Q92508 & Piezo-type mechanosensitive ion channel component 1 & PIEZO1 & 6 \\
\hline P84077 & ADP-ribosylation factor 1;ADP-ribosylation factor 3 & ARF1;ARF3 & 6 \\
\hline P21281 & $\begin{array}{c}\text { V-type proton ATPase subunit B, brain isoform; } \mathrm{V} \text {-type proton ATPase subunit B, kidney } \\
\text { isoform }\end{array}$ & $\begin{array}{l}\text { ATP6V1B2;A } \\
\text { TP6V1B1 }\end{array}$ & 6 \\
\hline P04259 & Keratin, type II cytoskeletal 6B & KRT6B & 6 \\
\hline Q92905 & COP9 signalosome complex subunit 5 & COPS5 & 6 \\
\hline P61163 & Alpha-centractin & ACTR1A & 6 \\
\hline 095373 & Importin-7 & IPO7 & 6 \\
\hline C9JD73 & Protein phosphatase 1 regulatory subunit 7 & PPP1R7 & 6 \\
\hline Q99536 & Synaptic vesicle membrane protein VAT-1 homolog & VAT1 & 6 \\
\hline Q86UX7 & Fermitin family homolog 3 & FERMT3 & 6 \\
\hline C9JFE4 & COP9 signalosome complex subunit 1 & GPS1 & 6 \\
\hline P36959 & GMP reductase 1 & GMPR & 6 \\
\hline B5MDF5 & GTP-binding nuclear protein Ran & RAN & 6 \\
\hline F5GY90 & Porphobilinogen deaminase & HMBS & 6 \\
\hline E7EX90 & Dynactin subunit 1 & DCTN1 & 6 \\
\hline H0Y512 & Adipocyte plasma membrane-associated protein & APMAP & 6 \\
\hline Q32Q12 & $\begin{array}{l}\text { Nucleoside diphosphate kinase; Nucleoside diphosphate kinase B;Putative nucleoside } \\
\text { diphosphate kinase }\end{array}$ & $\begin{array}{c}\text { NME1- } \\
\text { NME2;NME2; } \\
\text { NME1;NME2 } \\
\text { P1 }\end{array}$ & 6 \\
\hline P13807 & Glycogen [starch] synthase, muscle & GYS1 & 6 \\
\hline K7ES02 & Bleomycin hydrolase & BLMH & 6 \\
\hline P17213 & Bactericidal permeability-increasing protein & $\mathrm{BPI}$ & 6 \\
\hline Q9UNM6 & $26 \mathrm{~S}$ proteasome non-ATPase regulatory subunit 13 & PSMD13 & 6 \\
\hline J3KQ32 & Obg-like ATPase 1 & OLA1 & 6 \\
\hline Q9Y490 & Talin-1 & TLN1 & 6 \\
\hline H0YD13 & CD44 antigen & CD44 & 6 \\
\hline P18669 & $\begin{array}{l}\text { Phosphoglycerate mutase 1;Phosphoglycerate mutase 2;Probable phosphoglycerate mutase } \\
4\end{array}$ & $\begin{array}{l}\text { PGAM1;PGA } \\
\text { M2;PGAM4 }\end{array}$ & 6 \\
\hline P23528 & Cofilin-1 & CFL1 & 6 \\
\hline Q5SR44 & Complement receptor type 1 & CR1 & 6 \\
\hline Q99436 & Proteasome subunit beta type-7 & PSMB7 & 6 \\
\hline P47756 & F-actin-capping protein subunit beta & CAPZB & 6 \\
\hline P30740 & Leukocyte elastase inhibitor & SERPINB1 & 6 \\
\hline A0A024R571 & EH domain-containing protein 1 & EHD1 & 6 \\
\hline P30043 & Flavin reductase (NADPH) & BLVRB & 6 \\
\hline P32119 & Peroxiredoxin-2 & PRDX2 & 6 \\
\hline C9J0K6 & Sorcin & SRI & 6 \\
\hline P27105 & Erythrocyte band 7 integral membrane protein & STOM & 6 \\
\hline P84077 & $\begin{array}{l}\text { ADP-ribosylation factor 1;ADP-ribosylation factor 3;ADP-ribosylation factor 5;ADP-ribosylation } \\
\text { factor } 4\end{array}$ & $\begin{array}{l}\text { ARF1;ARF3;A } \\
\text { RF5;ARF4 }\end{array}$ & 6 \\
\hline P61981 & 14-3-3 protein gamma;14-3-3 protein gamma, $\mathrm{N}$-terminally processed & YWHAG & 5 \\
\hline P09211 & Glutathione S-transferase $\mathrm{P}$ & GSTP1 & 5 \\
\hline P13489 & Ribonuclease inhibitor & $\mathrm{RNH} 1$ & 5 \\
\hline
\end{tabular}




\begin{tabular}{|c|c|c|c|}
\hline Q96PU5 & E3 ubiquitin-protein ligase NEDD4-like & NEDD4L & 5 \\
\hline Q5SRN7 & $\begin{array}{c}\text { HLA class I histocompatibility antigen, A; HLA class I histocompatibility antigen, B;HLA class I } \\
\text { histocompatibility antigen, Cw }\end{array}$ & $\begin{array}{l}\text { HLA-A;HLA- } \\
\text { C;HLA-B }\end{array}$ & 5 \\
\hline P02042 & Hemoglobin subunit delta & HBD & 5 \\
\hline $\begin{array}{l}\text { A0A087WU2 } \\
9\end{array}$ & Glycophorin-A & GYPA & 5 \\
\hline P00390 & Glutathione reductase, mitochondrial & GSR & 5 \\
\hline Q9UBV8 & Peflin & PEF1 & 5 \\
\hline Q8WVM8 & Sec1 family domain-containing protein 1 & SCFD1 & 5 \\
\hline F6TLX2 & Glyoxalase domain-containing protein 4 & GLOD4 & 5 \\
\hline H3BQF1 & Adenine phosphoribosyltransferase & APRT & 5 \\
\hline Q07960 & Rho GTPase-activating protein 1 & ARHGAP1 & 5 \\
\hline F6XSS0 & Blood group $\mathrm{Rh}(\mathrm{CE})$ polypeptide;Blood group $\mathrm{Rh}(\mathrm{D})$ polypeptide & RHCE;RHD & 5 \\
\hline $\begin{array}{l}\text { A0A087WY5 } \\
5\end{array}$ & Vacuolar protein sorting-associated protein VTA1 homolog & VTA1 & 5 \\
\hline G5E9W8 & Glycogenin-1 & GYG1 & 5 \\
\hline P07451 & Carbonic anhydrase 3 & CA3 & 5 \\
\hline Q08722 & Leukocyte surface antigen CD47 & CD47 & 5 \\
\hline X6RA14 & S-formylglutathione hydrolase & ESD & 5 \\
\hline Q8IUI8 & Cytokine receptor-like factor 3 & CRLF3 & 5 \\
\hline Q5VW32 & BRO1 domain-containing protein BROX & BROX & 5 \\
\hline P61026 & Ras-related protein Rab-10 & RAB10 & 5 \\
\hline $\begin{array}{l}\text { A0A087WWY } \\
3\end{array}$ & Filamin-A & FLNA & 5 \\
\hline HOYGX7 & Rho GDP-dissociation inhibitor 2 & ARHGDIB & 5 \\
\hline Q92783 & Signal transducing adapter molecule 1 & STAM & 5 \\
\hline Q7Z6Z7 & E3 ubiquitin-protein ligase HUWE1 & HUWE1 & 5 \\
\hline HOYHC3 & Nucleosome assembly protein 1 -like 1 & NAP1L1 & 5 \\
\hline Q5QPM7 & Proteasome inhibitor PI31 subunit & PSMF1 & 5 \\
\hline P09104 & Gamma-enolase;Enolase & ENO2 & 5 \\
\hline Q5T2B5 & Cullin-2 & CUL2 & 5 \\
\hline Q8WW22 & DnaJ homolog subfamily A member 4 & DNAJA4 & 5 \\
\hline P61201 & COP9 signalosome complex subunit 2 & COPS2 & 5 \\
\hline $\mathrm{X} 6 \mathrm{R} 433$ & Protein-tyrosine-phosphatase; Receptor-type tyrosine-protein phosphatase C & PTPRC & 5 \\
\hline P63000 & Ras-related $\mathrm{C} 3$ botulinum toxin substrate 1 & RAC1 & 5 \\
\hline F5GXM3 & IST1 homolog & IST1 & 5 \\
\hline H3BLU7 & Aflatoxin B1 aldehyde reductase member 2 & AKR7A2 & 5 \\
\hline P25325 & 3-mercaptopyruvate sulfurtransferase;Sulfurtransferase & MPST & 5 \\
\hline A0A087X0K1 & Calcium-binding protein 39 & CAB39 & 5 \\
\hline P23381 & Tryptophan--tRNA ligase, cytoplasmic;T1-TrpRS;T2-TrpRS & WARS & 5 \\
\hline P01116 & GTPase KRas;GTPase KRas, N-terminally processed & KRAS & 5 \\
\hline P30040 & Endoplasmic reticulum resident protein 29 & ERP29 & 5 \\
\hline P05198 & Eukaryotic translation initiation factor 2 subunit 1 & EIF2S1 & 5 \\
\hline Q6UX06 & Olfactomedin-4 & OLFM4 & 5 \\
\hline Q96KP4 & Cytosolic non-specific dipeptidase & CNDP2 & 5 \\
\hline Q04760 & Lactoylglutathione lyase & GLO1 & 5 \\
\hline J3QS39 & $\begin{array}{l}\text { Ubiquitin-60S ribosomal protein L40;Ubiquitin;60S ribosomal protein L40;Ubiquitin-40S } \\
\text { ribosomal protein S27a;Ubiquitin;40S ribosomal protein S27a;Polyubiquitin- } \\
\text { B;Ubiquitin;Polyubiquitin-C;Ubiquitin }\end{array}$ & $\begin{array}{l}\text { UBB;RPS27A } \\
\text {;UBC;UBA52; } \\
\text { UBBP4 }\end{array}$ & 5 \\
\hline
\end{tabular}




\begin{tabular}{|c|c|c|c|}
\hline P06702 & Protein S100-A9 & S100A9 & 5 \\
\hline P15531 & $\begin{array}{l}\text { Nucleoside diphosphate kinase A;Nucleoside diphosphate kinase;Nucleoside diphosphate } \\
\text { kinase B }\end{array}$ & $\begin{array}{l}\text { NME1;NME2; } \\
\text { NME1-NME2 }\end{array}$ & 5 \\
\hline E7EV99 & Alpha-adducin & ADD1 & 5 \\
\hline P51149 & Ras-related protein Rab-7a & RAB7A & 4 \\
\hline K7N7A8 & Aquaporin-1 & AQP1 & 4 \\
\hline P61020 & Ras-related protein Rab-5B & RAB5B & 4 \\
\hline X6R4N5 & Erythroid membrane-associated protein & ERMAP & 4 \\
\hline E5RJR5 & S-phase kinase-associated protein 1 & SKP1 & 4 \\
\hline Q9Y315 & Deoxyribose-phosphate aldolase & DERA & 4 \\
\hline X6R8F3 & Neutrophil gelatinase-associated lipocalin & LCN2 & 4 \\
\hline 075396 & Vesicle-trafficking protein SEC22b & SEC22B & 4 \\
\hline Q15102 & Platelet-activating factor acetylhydrolase IB subunit gamma & PAFAH1B3 & 4 \\
\hline P51665 & $26 \mathrm{~S}$ proteasome non-ATPase regulatory subunit 7 & PSMD7 & 4 \\
\hline Q96FZ7 & Charged multivesicular body protein 6 & CHMP6 & 4 \\
\hline Q9NRQ2 & Phospholipid scramblase 4 & PLSCR4 & 4 \\
\hline F8VWS0 & $60 S$ acidic ribosomal protein $\mathrm{P} 0 ; 60 \mathrm{~S}$ acidic ribosomal protein $\mathrm{P} 0$-like & $\begin{array}{l}\text { RPLP0;RPLP } \\
\text { OP6 } \\
\end{array}$ & 4 \\
\hline O14964 & Hepatocyte growth factor-regulated tyrosine kinase substrate & HGS & 4 \\
\hline A0A0A0MTJ9 & Neutral cholesterol ester hydrolase 1 & NCEH1 & 4 \\
\hline $\begin{array}{l}\text { A0A087WY8 } \\
2 \\
\end{array}$ & Junctional adhesion molecule A & F11R & 4 \\
\hline J3QSB7 & Purine nucleoside phosphorylase;S-methyl-5-thioadenosine phosphorylase & MTAP & 4 \\
\hline Q5VVQ6 & Ubiquitin thioesterase OTU1 & YOD1 & 4 \\
\hline P36543 & V-type proton ATPase subunit E 1 & ATP6V1E1 & 4 \\
\hline Q9BS40 & Latexin & LXN & 4 \\
\hline P47755 & F-actin-capping protein subunit alpha-2 & CAPZA2 & 4 \\
\hline Q9GZT8 & NIF3-like protein 1 & NIF3L1 & 4 \\
\hline H6UYS7 & Alpha-synuclein & SNCA & 4 \\
\hline P60953 & Cell division control protein 42 homolog & CDC42 & 4 \\
\hline Q14773 & Intercellular adhesion molecule 4 & ICAM4 & 4 \\
\hline H0Y6T7 & Nicastrin & NCSTN & 4 \\
\hline P69891 & Hemoglobin subunit gamma-1 & HBG1 & 4 \\
\hline P14625 & Endoplasmin & HSP90B1 & 4 \\
\hline Q96GD0 & Pyridoxal phosphate phosphatase & PDXP & 4 \\
\hline P08311 & Cathepsin G & CTSG & 4 \\
\hline Q9H9Q2 & COP9 signalosome complex subunit 7b & COPS7B & 4 \\
\hline P09417 & Dihydropteridine reductase & QDPR & 4 \\
\hline F8WE6 & Peptidyl-prolyl cis-trans isomerase;Peptidyl-prolyl cis-trans isomerase A & PPIA & 4 \\
\hline O15173 & Membrane-associated progesterone receptor component 2 & PGRMC2 & 4 \\
\hline P28072 & Proteasome subunit beta type-6;Proteasome subunit beta type & PSMB6 & 4 \\
\hline H3BSW0 & Leucine-rich repeat-containing protein 57 & LRRC57 & 4 \\
\hline Q9UBW8 & COP9 signalosome complex subunit $7 a$ & COPS7A & 4 \\
\hline 000560 & Syntenin-1 & SDCBP & 4 \\
\hline F5H157 & Ras-related protein Rab-35 & RAB35 & 4 \\
\hline Q9H479 & Fructosamine-3-kinase & FN3K & 4 \\
\hline Q04917 & $14-3-3$ protein eta & YWHAH & 4 \\
\hline
\end{tabular}




\begin{tabular}{|c|c|c|c|}
\hline C9JJ47 & AP-2 complex subunit mu & AP2M1 & 4 \\
\hline C9JIG9 & Serine/threonine-protein kinase OSR1 & OXSR1 & 4 \\
\hline Q13336 & Urea transporter 1 & SLC14A1 & 4 \\
\hline P46926 & $\begin{array}{c}\text { Glucosamine-6-phosphate isomerase 1;Glucosamine-6-phosphate isomerase;Glucosamine- } \\
6 \text {-phosphate isomerase } 2\end{array}$ & $\begin{array}{l}\text { GNPDA1;GN } \\
\text { PDA2 }\end{array}$ & 4 \\
\hline 043633 & Charged multivesicular body protein $2 a$ & CHMP2A & 4 \\
\hline F8VVB9 & $\begin{array}{l}\text { Tubulin alpha-1A chain;Tubulin alpha-1C chain;Tubulin alpha-1B chain;Tubulin alpha-3C/D } \\
\text { chain;Tubulin alpha-3E chain }\end{array}$ & $\begin{array}{c}\text { TUBA1B;TUB } \\
\text { A1C;TUBA1A } \\
\text {;TUBA3C;TU } \\
\text { BA3E }\end{array}$ & 4 \\
\hline A6PVN5 & Serine/threonine-protein phosphatase $2 \mathrm{~A}$ activator & PPP2R4 & 4 \\
\hline B8ZZB8 & CB1 cannabinoid receptor-interacting protein 1 & CNRIP1 & 4 \\
\hline Q9P2R3 & Rabankyrin-5 & ANKFY1 & 4 \\
\hline Q86YS7 & C2 domain-containing protein 5 & C2CD5 & 4 \\
\hline R4GMR5 & $26 S$ proteasome non-ATPase regulatory subunit 8 & PSMD8 & 4 \\
\hline E7EM64 & COP9 signalosome complex subunit 6 & COPS6 & 4 \\
\hline J3KNI6 & Integrin beta;Integrin beta-2 & ITGB2 & 4 \\
\hline H0Y5R6 & Uroporphyrinogen decarboxylase & UROD & 4 \\
\hline M0R165 & Epidermal growth factor receptor substrate 15-like 1 & EPS15L1 & 4 \\
\hline 000487 & 26S proteasome non-ATPase regulatory subunit 14 & PSMD14 & 4 \\
\hline Q13630 & GDP-L-fucose synthase & TSTA3 & 4 \\
\hline P55060 & Exportin-2 & CSE1L & 4 \\
\hline P20020 & Plasma membrane calcium-transporting ATPase 1;Calcium-transporting ATPase & ATP2B1 & 4 \\
\hline Q9NYU2 & UDP-glucose:glycoprotein glucosyltransferase 1 & UGGT1 & 4 \\
\hline H3BND8 & Ubiquitin carboxyl-terminal hydrolase;Ubiquitin carboxyl-terminal hydrolase 7 & USP7 & 4 \\
\hline Q9GZP4 & PITH domain-containing protein 1 & PITHD1 & 4 \\
\hline D6RD66 & WD repeat-containing protein 1 & WDR1 & 4 \\
\hline P48729 & Casein kinase I isoform alpha & CSNK1A1 & 4 \\
\hline P25685 & DnaJ homolog subfamily B member 1 & DNAJB1 & 4 \\
\hline P14550 & Alcohol dehydrogenase [NADP $(+)]$ & AKR1A1 & 4 \\
\hline Q6PCE3 & Glucose 1,6-bisphosphate synthase & PGM2L1 & 4 \\
\hline Q9UPN7 & Serine/threonine-protein phosphatase 6 regulatory subunit 1 & PPP6R1 & 4 \\
\hline P62805 & Histone $\mathrm{H} 4$ & HIST1H4A & 4 \\
\hline P62937 & Peptidyl-prolyl cis-trans isomerase A & PPIA & 4 \\
\hline P30046 & D-dopachrome decarboxylase;D-dopachrome decarboxylase-like protein & DDT;DDTL & 4 \\
\hline Q08495 & Dematin & DMTN & 4 \\
\hline K7EIJ0 & WW domain-binding protein 2 & WBP2 & 4 \\
\hline E5RHP7 & Carbonic anhydrase 1 & CA1 & 4 \\
\hline P09105 & Hemoglobin subunit theta-1 & HBQ1 & 4 \\
\hline E7ESC6 & Exportin-7 & XPO7 & 4 \\
\hline P61225 & Ras-related protein Rap- $2 \mathrm{~b}$;Ras-related protein Rap-2c;Ras-related protein Rap-2a & $\begin{array}{l}\text { RAP2B;RAP2 } \\
\text { A;RAP2C }\end{array}$ & 4 \\
\hline 015400 & Syntaxin-7 & STX7 & 3 \\
\hline Q5VZR0 & Golgi-associated plant pathogenesis-related protein 1 & GLIPR2 & 3 \\
\hline P40199 & Carcinoembryonic antigen-related cell adhesion molecule 6 & CEACAM6 & 3 \\
\hline P27348 & 14-3-3 protein theta & YWHAQ & 3 \\
\hline P62820 & Ras-related protein Rab-1A & RAB1A & 3 \\
\hline C9JEN3 & Protein lifeguard 3 & TMBIM1 & 3 \\
\hline
\end{tabular}




\begin{tabular}{|c|c|c|c|}
\hline Q9UDX3 & SEC14-like protein 4 & SEC14L4 & 3 \\
\hline Q9Y570 & Protein phosphatase methylesterase 1 & PPME1 & 3 \\
\hline Q96GG9 & DCN1-like protein 1;DCN1-like protein & DCUN1D1 & 3 \\
\hline BOYJC4 & Vimentin & VIM & 3 \\
\hline Q86VN1 & Vacuolar protein-sorting-associated protein 36 & VPS36 & 3 \\
\hline F8WFB9 & Endophilin-B2 & SH3GLB2 & 3 \\
\hline $\begin{array}{c}\mathrm{A} 0 \mathrm{~A} 087 \mathrm{WVQ} \\
9 \\
\end{array}$ & Elongation factor 1 -alpha 1;Putative elongation factor 1 -alpha-like 3 & $\begin{array}{c}\text { EEF1A1;EEF } \\
\text { 1A1P5 }\end{array}$ & 3 \\
\hline Q53TN4 & Cytochrome b reductase 1 & CYBRD1 & 3 \\
\hline P10809 & $60 \mathrm{kDa}$ heat shock protein, mitochondrial & HSPD1 & 3 \\
\hline $\mathrm{F} 5 \mathrm{H} 7 \mathrm{X} 1$ & $26 S$ proteasome non-ATPase regulatory subunit 9 & PSMD9 & 3 \\
\hline E9PNW4 & CD59 glycoprotein & CD59 & 3 \\
\hline E9PS74 & Solute carrier family 43 member 3 & SLC43A3 & 3 \\
\hline P53985 & Monocarboxylate transporter 1 & SLC16A1 & 3 \\
\hline Q8WWI5 & Choline transporter-like protein 1 & SLC44A1 & 3 \\
\hline E9PIR7 & Thioredoxin reductase 1 , cytoplasmic & TXNRD1 & 3 \\
\hline Q5TD07 & Ribosyldihydronicotinamide dehydrogenase [quinone] & NQO2 & 3 \\
\hline Q9UL25 & Ras-related protein Rab-21 & RAB21 & 3 \\
\hline P27824 & Calnexin & CANX & 3 \\
\hline U3KPS2 & Myeloblastin & PRTN3 & 3 \\
\hline Q9UKU0 & Long-chain-fatty-acid--CoA ligase 6 & ACSL6 & 3 \\
\hline P24666 & Low molecular weight phosphotyrosine protein phosphatase & ACP1 & 3 \\
\hline $\mathrm{H} 7 \mathrm{C} 2 \mathrm{G} 2$ & $\mathrm{NAD}(\mathrm{P})(+)$--arginine ADP-ribosyltransferase;Ecto-ADP-ribosyltransferase 4 & ART4 & 3 \\
\hline I3L1K6 & Myosin light chain 4 & MYL4 & 3 \\
\hline Q9UK41 & Vacuolar protein sorting-associated protein 28 homolog & VPS28 & 3 \\
\hline Q9NUQ9 & Protein FAM49B & FAM49B & 3 \\
\hline Q9UBQ7 & Glyoxylate reductase/hydroxypyruvate reductase & GRHPR & 3 \\
\hline B8ZZG1 & MAGUK p55 subfamily member 6 & MPP6 & 3 \\
\hline Q10567 & AP-1 complex subunit beta-1 & AP1B1 & 3 \\
\hline O75387 & Large neutral amino acids transporter small subunit 3 & SLC43A1 & 3 \\
\hline Q9BTU6 & Phosphatidylinositol 4-kinase type 2-alpha & $\mathrm{PI} 4 \mathrm{~K} 2 \mathrm{~A}$ & 3 \\
\hline J3KS22 & L-xylulose reductase & DCXR & 3 \\
\hline O15498 & Synaptobrevin homolog YKT6 & YKT6 & 3 \\
\hline Q08211 & ATP-dependent RNA helicase A & $\mathrm{DHX9}$ & 3 \\
\hline P50416 & Carnitine O-palmitoyltransferase 1 , liver isoform & CPT1A & 3 \\
\hline P08237 & ATP-dependent 6-phosphofructokinase, muscle type & PFKM & 3 \\
\hline P14735 & Insulin-degrading enzyme & IDE & 3 \\
\hline Q9H0R3 & Transmembrane protein 222 & TMEM222 & 3 \\
\hline Q14166 & Tubulin--tyrosine ligase-like protein 12 & TTLL12 & 3 \\
\hline Q14558 & Phosphoribosyl pyrophosphate synthase-associated protein 1 & PRPSAP1 & 3 \\
\hline $\begin{array}{c}\text { A0A087WTB } \\
8 \\
\end{array}$ & Ubiquitin carboxyl-terminal hydrolase;Ubiquitin carboxyl-terminal hydrolase isozyme L3 & UCHL3 & 3 \\
\hline Q9NPQ8 & Synembryn-A & RIC8A & 3 \\
\hline F6WQW2 & Ran-specific GTPase-activating protein & RANBP1 & 3 \\
\hline Q15691 & Microtubule-associated protein RP/EB family member 1 & MAPRE1 & 3 \\
\hline $\begin{array}{c}\text { A0A0A0MR5 } \\
0\end{array}$ & Cullin-4A & CUL4A & 3 \\
\hline
\end{tabular}




\begin{tabular}{|c|c|c|c|}
\hline Q96IU4 & Alpha/beta hydrolase domain-containing protein 14B & ABHD14B & 3 \\
\hline Q9P0L0 & Vesicle-associated membrane protein-associated protein A & VAPA & 3 \\
\hline E9PRY8 & Elongation factor 1-delta & EEF1D & 3 \\
\hline Q16543 & Hsp90 co-chaperone Cdc37 & $\mathrm{CDC} 37$ & 3 \\
\hline P06702 & Protein S100-A9 & S100A9 & 3 \\
\hline P13639 & Elongation factor 2 & EEF2 & 3 \\
\hline E9PJC7 & Tetraspanin;CD82 antigen & CD82 & 3 \\
\hline Q01432 & AMP deaminase 3 & AMPD3 & 3 \\
\hline B1AUU8 & Epidermal growth factor receptor substrate 15 & EPS15 & 3 \\
\hline P54709 & Sodium/potassium-transporting ATPase subunit beta- 3 & ATP1B3 & 3 \\
\hline P54727 & UV excision repair protein RAD23 homolog B & RAD23B & 3 \\
\hline P36507 & Dual specificity mitogen-activated protein kinase kinase 2 & MAP2K2 & 3 \\
\hline Q9Y2V2 & Calcium-regulated heat stable protein 1 & CARHSP1 & 3 \\
\hline P31146 & Coronin-1A;Coronin & CORO1A & 3 \\
\hline Q8IY17 & Neuropathy target esterase & PNPLA6 & 3 \\
\hline E7EQR4 & Ezrin & EZR & 3 \\
\hline F8WDS9 & LanC-like protein 1 & LANCL1 & 3 \\
\hline X6RJP6 & Transgelin-2 & TAGLN2 & 3 \\
\hline $\begin{array}{l}\text { A0A0J9YXM } \\
6 \\
\end{array}$ & WD repeat-containing protein 81 & WDR81 & 3 \\
\hline P62140 & $\begin{array}{c}\text { Serine/threonine-protein phosphatase PP1-beta catalytic subunit;Serine/threonine-protein } \\
\text { phosphatase }\end{array}$ & PPP1CB & 3 \\
\hline HOYLJ3 & Mortality factor 4-like protein 1 & MORF4L1 & 3 \\
\hline E7EPV7 & Alpha-synuclein & SNCA & 3 \\
\hline K7EK07 & Histone H3 & H3F3B & 3 \\
\hline P05109 & Protein S100-A8;Protein S100-A8, N-terminally processed & S100A8 & 3 \\
\hline I3LOAO & Ubiquitin-conjugating enzyme E2 variant 1;Ubiquitin-conjugating enzyme E2 variant 2 & $\begin{array}{l}\text { TMEM189- } \\
\text { UBE2V1;UBE } \\
\text { 2V1;UBE2V2 }\end{array}$ & 3 \\
\hline Q6B0K9 & Hemoglobin subunit mu & HBM & 3 \\
\hline O75368 & SH3 domain-binding glutamic acid-rich-like protein & SH3BGRL & 3 \\
\hline A0A0J9YXB3 & $\begin{array}{c}\text { Ras-related protein Rap-1b;Ras-related protein Rap-1A;Ras-related protein Rap-1b-like } \\
\text { protein }\end{array}$ & $\begin{array}{l}\text { RAP1B;RAP1 } \\
\text { A }\end{array}$ & 3 \\
\hline P60953 & Cell division control protein 42 homolog & CDC42 & 3 \\
\hline A0A087WTI1 & Ras-related protein Rab-1B;Ras-related protein Rab-1A & $\begin{array}{l}\text { RAB1B;RAB1 } \\
\text { A }\end{array}$ & 3 \\
\hline B5MDF5 & GTP-binding nuclear protein Ran & RAN & 3 \\
\hline P61088 & Ubiquitin-conjugating enzyme E2 N & UBE2N & 3 \\
\hline Q00013 & $55 \mathrm{kDa}$ erythrocyte membrane protein & MPP1 & 3 \\
\hline B1AKQ8 & $\begin{array}{l}\text { Guanine nucleotide-binding protein } \mathrm{G}(\mathrm{I}) / \mathrm{G}(\mathrm{S}) / \mathrm{G}(\mathrm{T}) \text { subunit beta-1;Guanine nucleotide-binding } \\
\text { protein } \mathrm{G}(\mathrm{I}) / \mathrm{G}(\mathrm{S}) / \mathrm{G}(\mathrm{T}) \text { subunit beta-3;Guanine nucleotide-binding protein } \mathrm{G}(\mathrm{I}) / \mathrm{G}(\mathrm{S}) / \mathrm{G}(\mathrm{T}) \\
\text { subunit beta-2 }\end{array}$ & $\begin{array}{l}\text { GNB1;GNB2; } \\
\quad \text { GNB3 }\end{array}$ & 3 \\
\hline P04406 & Glyceraldehyde-3-phosphate dehydrogenase & GAPDH & 3 \\
\hline Q9UJC5 & SH3 domain-binding glutamic acid-rich-like protein 2 & SH3BGRL2 & 3 \\
\hline P04921 & Glycophorin-C & GYPC & 2 \\
\hline Q9NP59 & Solute carrier family 40 member 1 & SLC40A1 & 2 \\
\hline K7EKH5 & Fructose-bisphosphate aldolase;Fructose-bisphosphate aldolase C & ALDOC & 2 \\
\hline P11233 & Ras-related protein Ral-A & RALA & 2 \\
\hline F8WBR5 & Calmodulin & $\begin{array}{l}\text { CALM2;CAL } \\
\text { M3;CALM1 }\end{array}$ & 2 \\
\hline
\end{tabular}




\begin{tabular}{|c|c|c|c|}
\hline P00441 & Superoxide dismutase [Cu-Zn] & SOD1 & 2 \\
\hline HOYDI1 & Lymphocyte function-associated antigen 3 & CD58 & 2 \\
\hline HOYNE9 & Ras-related protein Rab-8B & RAB8B & 2 \\
\hline J3KN67 & & TPM3 & 2 \\
\hline P20160 & Azurocidin & AZU1 & 2 \\
\hline $\begin{array}{l}\mathrm{A} 0 \mathrm{~A} 087 \mathrm{WZZ} \\
4\end{array}$ & Ammonium transporter Rh type A & RHAG & 2 \\
\hline F5GXS0 & Complement C4-A;Complement C4-B & $\mathrm{C} 4 \mathrm{~B} ; \mathrm{C} 4 \mathrm{~A}$ & 2 \\
\hline Q8ND76 & Cyclin-Y & CCNY & 2 \\
\hline Q14739 & Lamin-B receptor & LBR & 2 \\
\hline Q15181 & Inorganic pyrophosphatase & PPA1 & 2 \\
\hline J3QS92 & Galectin-9 & LGALS9 & 2 \\
\hline I3L471 & Phosphatidylinositol transfer protein alpha isoform & PITPNA & 2 \\
\hline P01111 & GTPase NRas & NRAS;KRAS & 2 \\
\hline F5H4Q5 & Vacuolar protein sorting-associated protein $37 \mathrm{C}$ & VPS37C & 2 \\
\hline $\begin{array}{l}\text { AOAOAOMSW } \\
4\end{array}$ & Phosphatidylinositol transfer protein beta isoform & PITPNB & 2 \\
\hline P67775 & $\begin{array}{c}\begin{array}{c}\text { Serine/threonine-protein phosphatase } 2 \mathrm{~A} \text { catalytic subunit alpha isoform;Serine/threonine- } \\
\text { protein phosphatase }\end{array} \\
\end{array}$ & $\begin{array}{l}\text { PPP2CA;PPP } \\
\text { 2CB }\end{array}$ & 2 \\
\hline P41091 & $\begin{array}{l}\text { Eukaryotic translation initiation factor } 2 \text { subunit 3;Putative eukaryotic translation initiation } \\
\text { factor } 2 \text { subunit 3-like protein }\end{array}$ & $\begin{array}{l}\text { EIF2S3;EIF2 } \\
\text { S3L }\end{array}$ & 2 \\
\hline $\begin{array}{l}\text { A0A087WWS } \\
7\end{array}$ & Syntaxin-binding protein 2 & STXBP2 & 2 \\
\hline F8VQX6 & Methyltransferase-like protein $7 \mathrm{~A}$ & METTL7A & 2 \\
\hline B3КT28 & FAS-associated factor 1 & FAF1 & 2 \\
\hline K7EIJ8 & Katanin p60 ATPase-containing subunit A-like 2 & KATNAL2 & 2 \\
\hline P20339 & Ras-related protein Rab-5A & RAB5A & 2 \\
\hline 095456 & Proteasome assembly chaperone 1 & PSMG1 & 2 \\
\hline K7EK45 & Polypyrimidine tract-binding protein 1 & PTBP1 & 2 \\
\hline Q15365 & Poly(rC)-binding protein 1;Poly(rC)-binding protein 3 & $\begin{array}{l}\text { PCBP1;PCBP } \\
3\end{array}$ & 2 \\
\hline Q9BSJ8 & Extended synaptotagmin-1 & ESYT1 & 2 \\
\hline H3BP35 & Diphosphomevalonate decarboxylase & MVD & 2 \\
\hline H0Y8C4 & Serine/threonine-protein phosphatase $2 \mathrm{~A} 56 \mathrm{kDa}$ regulatory subunit delta isoform & PPP2R5D & 2 \\
\hline K7EP09 & $\begin{array}{l}\text { Bifunctional coenzyme A synthase;Phosphopantetheine adenylyltransferase;Dephospho-CoA } \\
\text { kinase }\end{array}$ & COASY & 2 \\
\hline F8VNT9 & Tetraspanin;CD63 antigen & CD63 & 2 \\
\hline Q8NEV1 & Casein kinase II subunit alpha 3;Casein kinase II subunit alpha & $\begin{array}{l}\text { CSNK2A3;CS } \\
\text { NK2A1 }\end{array}$ & 2 \\
\hline F8VTQ5 & Heterogeneous nuclear ribonucleoprotein A1 & HNRNPA1 & 2 \\
\hline A0A087X2E2 & $\begin{array}{l}\text { Carcinoembryonic antigen-related cell adhesion molecule 8; Carcinoembryonic antigen-related } \\
\text { cell adhesion molecule 1;Carcinoembryonic antigen-related cell adhesion molecule } 5\end{array}$ & $\begin{array}{c}\text { CEACAM8;C } \\
\text { EACAM5;CE } \\
\text { ACAM1 }\end{array}$ & 2 \\
\hline HOYAS8 & Clusterin;Clusterin beta chain;Clusterin alpha chain;Clusterin & CLU & 2 \\
\hline E9PP54 & Tubulin-specific chaperone cofactor E-like protein & TBCEL & 2 \\
\hline P43034 & Platelet-activating factor acetylhydrolase IB subunit alpha & PAFAH1B1 & 2 \\
\hline Q9NT62 & Ubiquitin-like-conjugating enzyme ATG3 & ATG3 & 2 \\
\hline K7ERZ3 & Perilipin-3 & PLIN3 & 2 \\
\hline Q6DD88 & Atlastin-3 & ATL3 & 2 \\
\hline Q15084-3 & Protein disulfide-isomerase $\mathrm{A} 6$ & PDIA6 & 2 \\
\hline K7EQH4 & ATP synthase subunit alpha, mitochondrial & ATP5A1 & 2 \\
\hline
\end{tabular}




\begin{tabular}{|c|c|c|c|}
\hline G3V1U5 & Vesicle transport protein GOT1B & GOLT1B & 2 \\
\hline O00186 & Syntaxin-binding protein 3 & STXBP3 & 2 \\
\hline Q5T6W2 & Heterogeneous nuclear ribonucleoprotein $\mathrm{K}$ & HNRNPK & 2 \\
\hline HOYEY4 & ADP-sugar pyrophosphatase & NUDT5 & 2 \\
\hline P35580 & Myosin-10 & MYH10 & 2 \\
\hline $\mathrm{F} 5 \mathrm{H} 081$ & Solute carrier family 2 , facilitated glucose transporter member 4 & SLC2A4 & 2 \\
\hline Q9H1C7 & Cysteine-rich and transmembrane domain-containing protein 1 & CYSTM1 & 2 \\
\hline K7EJ83 & Cyclin-dependent kinase 2; Cyclin-dependent kinase 3 & CDK3;CDK2 & 2 \\
\hline C9J352 & Importin subunit alpha-5;Importin subunit alpha-5, N-terminally processed & KPNA1 & 2 \\
\hline H9KV75 & Alpha-actinin-1;Alpha-actinin-4;Alpha-actinin-2;Alpha-actinin-3 & $\begin{array}{c}\text { ACTN1;ACTN } \\
\text { 4;ACTN3;AC } \\
\text { TN2 }\end{array}$ & 2 \\
\hline $\begin{array}{l}\text { AOAOAOMQS } \\
1\end{array}$ & Pyrroline-5-carboxylate reductase;Pyrroline-5-carboxylate reductase 3 & PYCRL & 2 \\
\hline D6RBY0 & Rieske domain-containing protein & RFESD & 2 \\
\hline C9JC71 & Low affinity immunoglobulin gamma Fc region receptor III-A & FCGR3A & 2 \\
\hline P51811 & Membrane transport protein XK & XK & 2 \\
\hline C9J1G2 & DnaJ homolog subfamily B member 2 & DNAJB2 & 2 \\
\hline Q9UN37 & $\begin{array}{l}\text { Vacuolar protein sorting-associated protein 4A;Vacuolar protein sorting-associated protein } \\
4 \mathrm{~B} ; \text { Fidgetin-like protein } 1\end{array}$ & $\begin{array}{l}\text { VPS4A;VPS4 } \\
\text { B;FIGNL1 }\end{array}$ & 2 \\
\hline P61160 & Actin-related protein 2 & ACTR2 & 2 \\
\hline P16930 & Fumarylacetoacetase & $\mathrm{FAH}$ & 2 \\
\hline A0A087X0K4 & CUB and sushi domain-containing protein 2 & CSMD2 & 2 \\
\hline P10746 & Uroporphyrinogen-III synthase & UROS & 2 \\
\hline K7EQ02 & DAZ-associated protein 1 & DAZAP1 & 2 \\
\hline F5GYN4 & Ubiquitin thioesterase OTUB1 & OTUB1 & 2 \\
\hline P10599 & Thioredoxin & TXN & 2 \\
\hline 095197 & Reticulon-3 & RTN3 & 2 \\
\hline E7ETB3 & Aspartyl aminopeptidase & DNPEP & 2 \\
\hline P14868 & Aspartate--tRNA ligase, cytoplasmic & DARS & 2 \\
\hline Q08AM6 & Protein VAC14 homolog & VAC14 & 2 \\
\hline Q93034 & Cullin-5 & CUL5 & 2 \\
\hline Q9BQA1 & Methylosome protein 50 & WDR77 & 2 \\
\hline A0A0B4J2G9 & Ubiquitin-conjugating enzyme E2 L3 & UBE2L3 & 2 \\
\hline Q04446 & 1,4-alpha-glucan-branching enzyme & GBE1 & 2 \\
\hline Q96NA2 & Rab-interacting lysosomal protein & RILP & 2 \\
\hline Q92539 & Phosphatidate phosphatase LPIN2 & LPIN2 & 2 \\
\hline P28482 & Mitogen-activated protein kinase 1 & MAPK1 & 2 \\
\hline Q7Z406 & Myosin-14;Myosin-11 & $\begin{array}{l}\text { MYH14;MYH } \\
11\end{array}$ & 2 \\
\hline Q8IU68 & Transmembrane channel-like protein 8 & TMC8 & 2 \\
\hline Q96BJ3 & Axin interactor, dorsalization-associated protein & AIDA & 2 \\
\hline P20042 & Eukaryotic translation initiation factor 2 subunit 2 & EIF2S2 & 2 \\
\hline $\begin{array}{l}\text { AOAOAOMQR } \\
0\end{array}$ & $\begin{array}{l}\text { Docosahexaenoic acid omega-hydroxylase CYP4F3;Phylloquinone omega-hydroxylase } \\
\text { CYP4F2;Cytochrome P450 4F12;Phylloquinone omega-hydroxylase CYP4F11 }\end{array}$ & $\begin{array}{c}\text { CYP4F2;CYP } \\
\text { 4F3;CYP4F11 } \\
\text {;CYP4F12 }\end{array}$ & 2 \\
\hline Q9BS26 & Endoplasmic reticulum resident protein 44 & ERP44 & 2 \\
\hline 000178 & GTP-binding protein 1 & GTPBP1 & 2 \\
\hline P27797 & Calreticulin & CALR & 2 \\
\hline
\end{tabular}




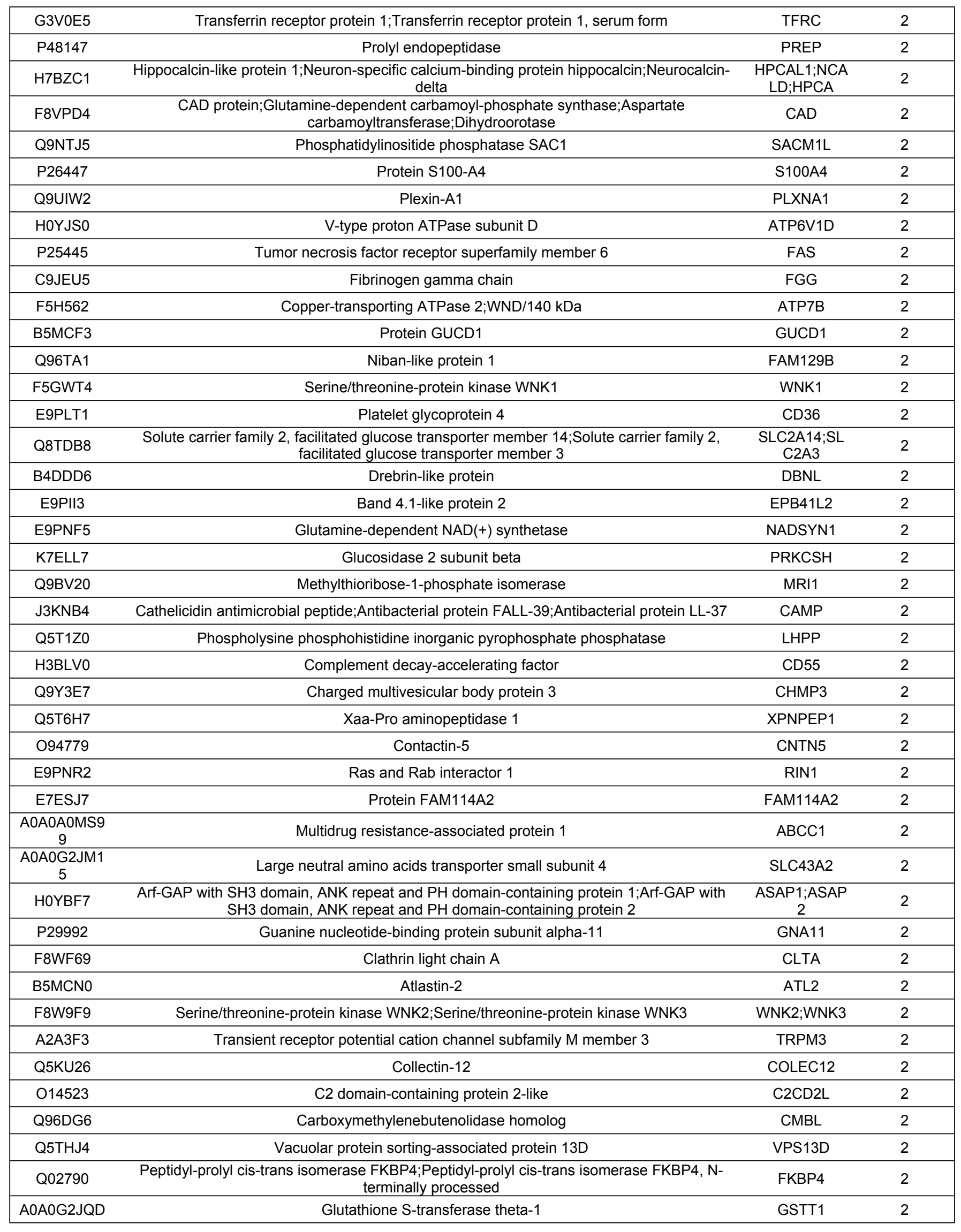




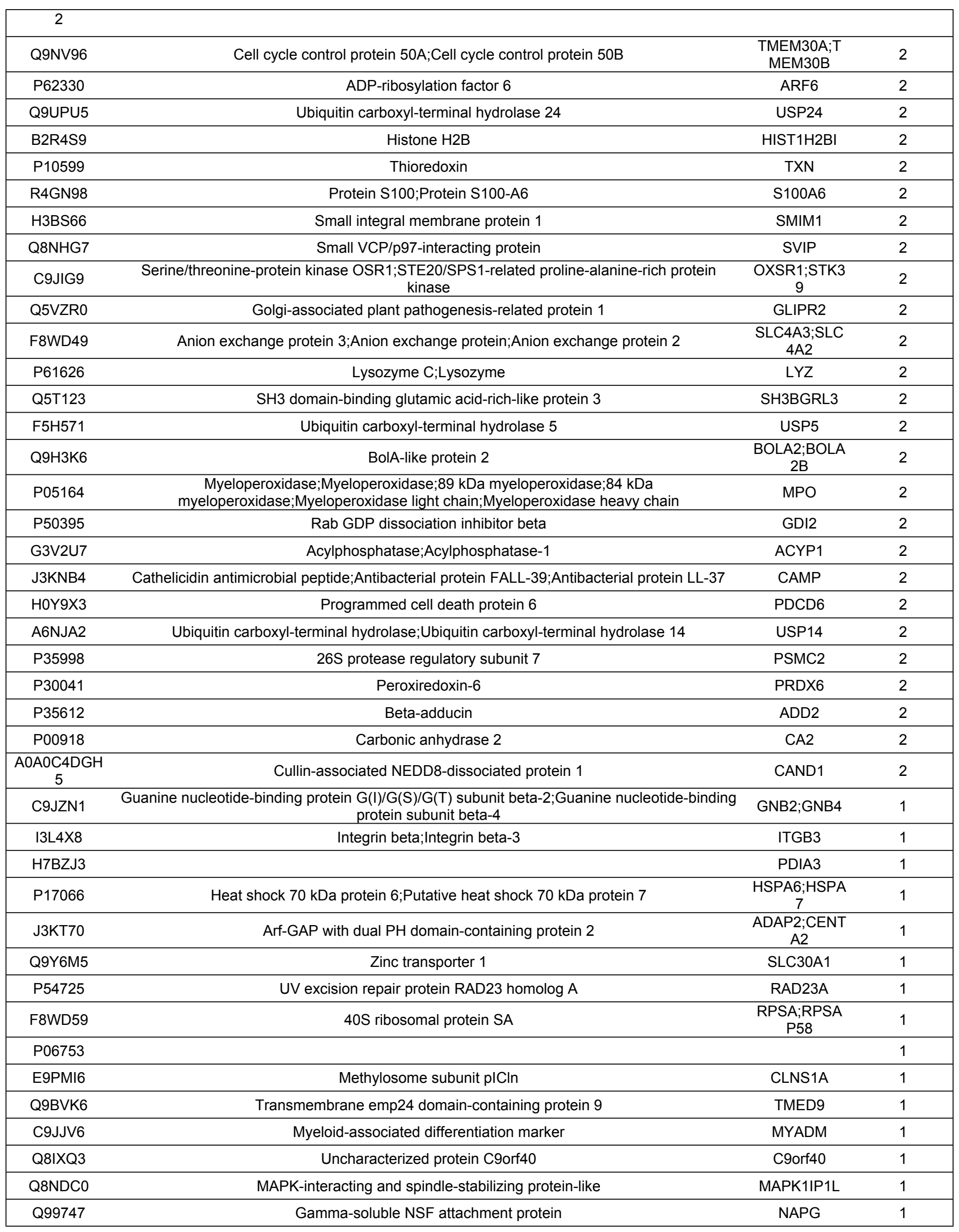




\begin{tabular}{|c|c|c|c|}
\hline E7EWE1 & Ubiquitin-like modifier-activating enzyme 5 & UBA5 & 1 \\
\hline J3KNE3 & Platelet-activating factor acetylhydrolase IB subunit beta & PAFAH1B2 & 1 \\
\hline Q8IUI8 & Cytokine receptor-like factor 3 & CRLF3 & 1 \\
\hline Q9BTX7 & Alpha-tocopherol transfer protein-like & TTPAL & 1 \\
\hline P63261 & Actin, cytoplasmic 2;Actin, cytoplasmic $2, \mathrm{~N}$-terminally processed & ACTG1 & 1 \\
\hline P31153 & S-adenosylmethionine synthase isoform type-2 & MAT2A & 1 \\
\hline 000560 & Syntenin-1 & SDCBP & 1 \\
\hline Q4VB86 & Protein 4.1 & EPB41 & 1 \\
\hline Q8WUD1 & Ras-related protein Rab-2B & $\begin{array}{l}\text { RAB2B;DKFZ } \\
\text { p313C1541 }\end{array}$ & 1 \\
\hline Q9NWV4 & UPF0587 protein C1orf123 & C1orf123 & 1 \\
\hline Q9Y2Z0 & Suppressor of G2 allele of SKP1 homolog & SUGT1 & 1 \\
\hline H0YK48 & Tropomyosin alpha-1 chain & TPM1 & 1 \\
\hline H3BS66 & Small integral membrane protein 1 & SMIM1 & 1 \\
\hline Q5VTS0 & Neurensin-1 & NRSN1 & 1 \\
\hline H0Y904 & Multidrug resistance-associated protein 7 & $\mathrm{ABCC} 10$ & 1 \\
\hline P08F94 & Fibrocystin & PKHD1 & 1 \\
\hline G3V5X4 & Nesprin-2 & SYNE2 & 1 \\
\hline P48507 & Glutamate--cysteine ligase regulatory subunit & GCLM & 1 \\
\hline H3BUF4 & Cyclin-D1-binding protein 1 & CCNDBP1 & 1 \\
\hline F8WB30 & Target of Myb protein 1 & TOM1 & 1 \\
\hline E5RJI8 & & CA1 & 1 \\
\hline S4R3E5 & Importin subunit alpha-7 & KPNA6 & 1 \\
\hline E7EVS6 & & ACTB & 1 \\
\hline P04206 & $\begin{array}{c}\text { Ig kappa chain V-III region GOL;Ig kappa chain V-III region WOL;Ig kappa chain V-III region } \\
\text { Ti; Ig kappa chain V-III region SIE }\end{array}$ & 1 & \\
\hline Q5SSV3 & $\mathrm{N}(\mathrm{G}), \mathrm{N}(\mathrm{G})$-dimethylarginine dimethylaminohydrolase 2 & DDAH2 & 1 \\
\hline H0YG54 & Oligoribonuclease, mitochondrial & REXO2 & 1 \\
\hline P08246 & Neutrophil elastase & ELANE & 1 \\
\hline P40926 & Malate dehydrogenase, mitochondrial & $\mathrm{MDH} 2$ & 1 \\
\hline P98172 & Ephrin-B1 & EFNB1 & 1 \\
\hline Q96DD7 & Protein shisa-4 & SHISA4 & 1 \\
\hline Q71RC9 & Small integral membrane protein 5 & SMIM5 & 1 \\
\hline P68133 & $\begin{array}{l}\text { Actin, alpha skeletal muscle;Actin, alpha cardiac muscle 1;Actin, gamma-enteric smooth } \\
\text { muscle;Actin, aortic smooth muscle }\end{array}$ & $\begin{array}{l}\text { ACTA1;ACTC } \\
1 ; \text { ACTG2;AC } \\
\text { TA2 }\end{array}$ & 1 \\
\hline H0Y9Q6 & Clathrin light chain B & CLTB & 1 \\
\hline G3V5P0 & & KTN1 & 1 \\
\hline Q9NWX6 & Probable tRNA(His) guanylyltransferase & THG1L & 1 \\
\hline Q15404 & Ras suppressor protein 1 & RSU1 & 1 \\
\hline B2R4S9 & Histone H2B & HIST1H2B & 1 \\
\hline K7EK06 & Phenylalanine--tRNA ligase alpha subunit & FARSA & 1 \\
\hline H7C3S9 & COP9 signalosome complex subunit 8 & COPS8 & 1 \\
\hline J3KRV4 & Dual specificity mitogen-activated protein kinase kinase 3 & MAP2K3 & 1 \\
\hline Q15042 & Rab3 GTPase-activating protein catalytic subunit & RAB3GAP1 & 1 \\
\hline P01893 & $\begin{array}{l}\text { Putative HLA class I histocompatibility antigen, alpha chain H;HLA class I histocompatibility } \\
\text { antigen, Cw-6 alpha chain;HLA class I histocompatibility antigen, B-38 alpha chain;HLA class } \\
\text { I histocompatibility antigen, B-67 alpha chain;HLA class I histocompatibility antigen, B-82 } \\
\text { alpha chain;HLA class I histocompatibility antigen, B-39 alpha chain;HLA class I }\end{array}$ & $\begin{array}{l}\text { HLA-H;HLA- } \\
\text { C;HLA-B }\end{array}$ & 1 \\
\hline
\end{tabular}




\begin{tabular}{|c|c|c|c|}
\hline & $\begin{array}{l}\text { histocompatibility antigen, Cw-18 alpha chain;HLA class I histocompatibility antigen, Cw-7 } \\
\text { alpha chain;HLA class I histocompatibility antigen, B-42 alpha chain;HLA class I } \\
\text { histocompatibility antigen, B-14 alpha chain;HLA class I histocompatibility antigen, B-8 alpha } \\
\text { chain;HLA class I histocompatibility antigen, B-7 alpha chain }\end{array}$ & & \\
\hline Q9UNW1 & Multiple inositol polyphosphate phosphatase 1 & MINPP1 & 1 \\
\hline Q6B0K9 & Hemoglobin subunit mu & HBM & 1 \\
\hline O75915 & PRA1 family protein 3 & ARL6IP5 & 1 \\
\hline 095376 & E3 ubiquitin-protein ligase ARIH2 & ARIH2 & 1 \\
\hline E9PBW4 & Hemoglobin subunit gamma-2 & HBG2 & 1 \\
\hline C9J1X0 & WD repeat-containing protein 91 & WDR91 & 1 \\
\hline Q8NCV1 & & & 1 \\
\hline Q9Y4P8 & WD repeat domain phosphoinositide-interacting protein 2 & WIPI2 & 1 \\
\hline $\begin{array}{c}\text { A0A087WUX } \\
6\end{array}$ & Proteasomal ubiquitin receptor ADRM1 & ADRM1 & 1 \\
\hline Q9NQS7 & Inner centromere protein & INCENP & 1 \\
\hline P62805 & Histone H4 & HIST1H4A & 1 \\
\hline Q8TDY2 & RB1-inducible coiled-coil protein 1 & RB1CC1 & 1 \\
\hline C9JFM5 & Syntaxin-4 & STX4 & 1 \\
\hline B0QZ43 & Erlin-2;Erlin-1 & $\begin{array}{c}\text { ERLIN1;ERLI } \\
\text { N2 }\end{array}$ & 1 \\
\hline C9J8T0 & Selenocysteine-specific elongation factor & EEFSEC & 1 \\
\hline P61224 & Ras-related protein Rap-1b;Ras-related protein Rap-1b-like protein & RAP1B & 1 \\
\hline Q99828 & Calcium and integrin-binding protein 1 & CIB1 & 1 \\
\hline Q53GQ0 & Very-long-chain 3-oxoacyl-CoA reductase & HSD17B12 & 1 \\
\hline H0Y9Q9 & ADP-ribosyl cyclase/cyclic ADP-ribose hydrolase 2 & BST1 & 1 \\
\hline R4GN98 & Protein S100;Protein S100-A6 & S100A6 & 1 \\
\hline Q8TB73 & Protein NDNF & NDNF & 1 \\
\hline Q6P1A2 & Lysophospholipid acyltransferase 5 & LPCAT3 & 1 \\
\hline $\mathrm{F} 2 \mathrm{Z} 2 \mathrm{Y} 4$ & Pyridoxal kinase & PDXK & 1 \\
\hline Q9HA65 & TBC1 domain family member 17 & TBC1D17 & 1 \\
\hline G3V126 & V-type proton ATPase subunit $\mathrm{H}$ & ATP6V1H & 1 \\
\hline D6RGE2 & Isochorismatase domain-containing protein 1 & ISOC1 & 1 \\
\hline A0A0B4J222 & ADP-ribosylation factor-like protein 15 & ARL15 & 1 \\
\hline F8W7W4 & Androglobin & ADGB & 1 \\
\hline Q9GZR7 & & & 1 \\
\hline $\begin{array}{c}\text { A0A087WVC } \\
4\end{array}$ & cAMP-dependent protein kinase catalytic subunit beta & PRKACB & 1 \\
\hline A8MU39 & Serine/threonine-protein phosphatase;Serine/threonine-protein phosphatase 5 & PPP5C & 1 \\
\hline G3V1N2 & & HBA2 & 1 \\
\hline P69892 & Hemoglobin subunit gamma-2 & HBG2 & 1 \\
\hline F8WEZ0 & 1-phosphatidylinositol 3-phosphate 5-kinase & PIKFYVE & 1 \\
\hline $\begin{array}{c}\text { A0A087WZZ } \\
4\end{array}$ & Ammonium transporter $\mathrm{Rh}$ type $\mathrm{A}$ & RHAG & 1 \\
\hline Q1JUQ3 & Peptidyl-prolyl cis-trans isomerase;Peptidyl-prolyl cis-trans isomerase FKBP1A & $\begin{array}{c}\text { FKBP12- } \\
\text { Exin;FKBP1A }\end{array}$ & 1 \\
\hline F8VWZ5 & H2.0-like homeobox protein & HLX & 1 \\
\hline P62877 & E3 ubiquitin-protein ligase RBX1;E3 ubiquitin-protein ligase RBX1, N-terminally processed & RBX1 & 1 \\
\hline Q7Z5P9 & Mucin-19 & MUC19 & 1 \\
\hline F8VPB3 & & TPK1 & 1 \\
\hline F8WBF4 & Transmembrane protein 50B & TMEM50B & 1 \\
\hline
\end{tabular}




\begin{tabular}{|c|c|c|c|}
\hline C9JL85 & Myotrophin & MTPN & 1 \\
\hline Q53EQ6 & Tigger transposable element-derived protein 5 & TIGD5 & 1 \\
\hline E3W974 & & DNPEP & 1 \\
\hline H7BYV1 & $\begin{array}{l}\text { Interferon-induced transmembrane protein } 1 \text {; Interferon-induced transmembrane protein } \\
2 \text {; Interferon-induced transmembrane protein } 3\end{array}$ & $\begin{array}{l}\text { IFITM2;IFITM } \\
\text { 3;IFITM1 }\end{array}$ & 1 \\
\hline D6RC06 & Histidine triad nucleotide-binding protein 1 & HINT1 & 1 \\
\hline E9PNW4 & CD59 glycoprotein & CD59 & 1 \\
\hline $\mathrm{H} 7 \mathrm{C} 2 \mathrm{Z6}$ & Grancalcin & GCA & 1 \\
\hline Q9H1C7 & Cysteine-rich and transmembrane domain-containing protein 1 & CYSTM1 & 1 \\
\hline H0YK07 & ATP-dependent Clp protease ATP-binding subunit clpX-like, mitochondrial & CLPX & 1 \\
\hline E9PG15 & 14-3-3 protein theta & YWHAQ & 1 \\
\hline K7ENK9 & Vesicle-associated membrane protein 3;Vesicle-associated membrane protein 2 & $\begin{array}{l}\text { VAMP2;VAM } \\
\text { P3 }\end{array}$ & 1 \\
\hline F8WDD6 & Cation channel sperm-associated protein subunit gamma & CATSPERG & 1 \\
\hline P35754 & Glutaredoxin-1 & GLRX & 1 \\
\hline Q5THJ4 & Vacuolar protein sorting-associated protein 13D & VPS13D & 1 \\
\hline B4E3H6 & Transforming acidic coiled-coil-containing protein 1 & TACC1 & 1 \\
\hline BOYJC4 & Vimentin & VIM & 1 \\
\hline H7C5R6 & AT-rich interactive domain-containing protein $4 \mathrm{~B}$ & ARID4B & 1 \\
\hline P49755 & Transmembrane emp24 domain-containing protein 10 & TMED10 & 1 \\
\hline E9PMJ3 & Ribonuclease inhibitor & $\mathrm{RNH} 1$ & 1 \\
\hline B1AHA9 & DNA replication licensing factor MCM5 & MCM5 & 1 \\
\hline P23634 & Plasma membrane calcium-transporting ATPase 4 & ATP2B4 & 1 \\
\hline Q14152 & Eukaryotic translation initiation factor 3 subunit $A$ & EIF3A & 1 \\
\hline C9IY70 & $60 S$ ribosomal export protein NMD3 & NMD3 & 1 \\
\hline $\begin{array}{l}\text { A0A087WUS } \\
7\end{array}$ & Ig delta chain $\mathrm{C}$ region & IGHD & 1 \\
\hline P07384 & Calpain-1 catalytic subunit & CAPN1 & 1 \\
\hline G3V2C9 & $\begin{array}{l}\text { Guanine nucleotide-binding protein subunit gamma;Guanine nucleotide-binding protein } \\
\qquad \mathrm{G}(\mathrm{I} / \mathrm{G}(\mathrm{S}) / \mathrm{G}(\mathrm{O}) \text { subunit gamma-2 }\end{array}$ & GNG2 & 1 \\
\hline Q9Y2Y8 & Proteoglycan 3 & PRG3 & 1 \\
\hline V9GY70 & & DNAJB12 & 1 \\
\hline U5GXS0 & MAM and LDL-receptor class A domain-containing protein 1 & MALRD1 & 1 \\
\hline Q92625 & Ankyrin repeat and SAM domain-containing protein $1 \mathrm{~A}$ & ANKS1A & 1 \\
\hline
\end{tabular}

Table S3. Complete list of proteins identified in the EEV proteome. Lists of the protein groups identified by LC-MS/MS analysis using Andromeda/MaxQuant search engine in the Uniprot Complete Proteome Homo sapiens database for the non-depleted sample (356 proteins) (A) or when hemoglobin was analyzed separately (818 proteins) (B). The lists were filtered at 1\% False Discovery Rate using a target/decoy database search. 